\title{
The Role of Akt in Platelet Activation
}

\author{
BY \\ KELLY A. O'BRIEN \\ B.S., DePaul University, 2005
}

\begin{abstract}
THESIS
Submitted as partial fulfillment of the requirements

for the degree of Doctor of Philosophy in Pharmacology

in the Graduate College of the

University of Illinois at Chicago, 2012
\end{abstract}

Chicago, Illinois

Defense Committee:

Xiaoping Du, Chair and Advisor

Jaehyung Cho

Masuko Ushio-Fukai

Randal Skidgel

Nissim Hay, Biochemistry and Molecular Genetics 


\section{ACKNOWLEDGEMENTS}

I would like to sincerely thank my advisor, Dr. Xiaoping Du for all of his support and guidance during my $\mathrm{PhD}$ training.

I would like to thank my research and thesis committee members for all of their helpful suggestions and guidance: Dr. Stephen Lam, Dr. Jaehyung Cho, Dr. Nissim Hay, Dr. Randal Skidgel, and Dr. Masuko Ushio-Fukai.

I would like to thank members of the Du lab for all of their assistance and support: Aleksandra Stojanovic-Terpo, M. Keegan Delaney, Bo Shen, Brian Estevez, Dr. Xiaojuan Zhou, Dr. Zhenyu Li, Dr. Guoying Zhang, Dr. Junling Liu, Dr. Hong Yin, and Dr. Panagiotis Flevaris.

I would like to thank Dr. Nissim Hay and Dr. T. Kent Gartner for their collaboration and providing us with Akt and P2Y12 knockout mice.

I would like to thank Dr. Athar Chishti for recommending me to the graduate program.

I would like to thank all of my fellow students, staff, and faculty in the Department of Pharmacology.

I would like to thank my family and friends for all of their support and encouragement. 


\section{TABLE OF CONTENTS}

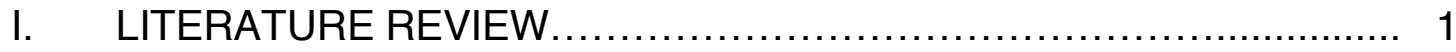

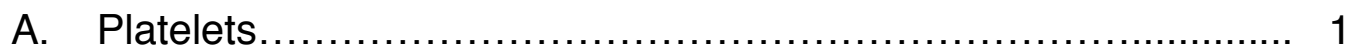

1. Platelet morphology ....................................... 1

2. Physiological functions ...................................... 3

B. Signaling during platelet activation and adhesion................. 6

1. G-Protein coupled receptor pathways........................ 6

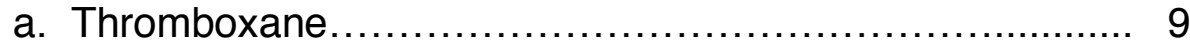

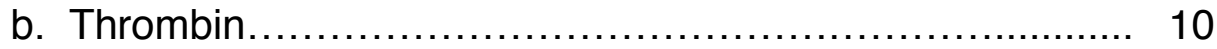

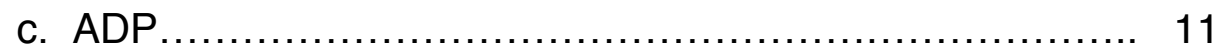

2. Adhesion receptor pathways ................................. 13

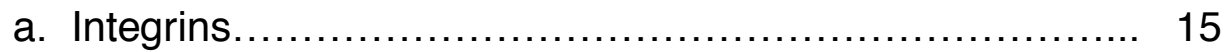

i. Inside-out............................................ 15

ii. Outside-in .......................................... 16

b. Glycoprotein Ib-IX-V ...................................... 19

c. Collagen/GPVI....................................... 20

C. Signaling during platelet granule secretion........................ 22

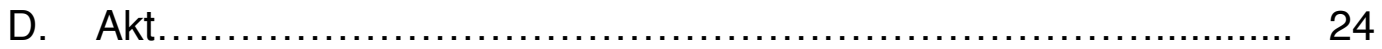

1. Structure and function.......................................... 24

2. Regulatory mechanisms..................................... 25

3. Akt isoform specificity ....................................... 28

4. Akt signaling in disease ....................................... 29

5. Akt and platelet activation.................................. 31

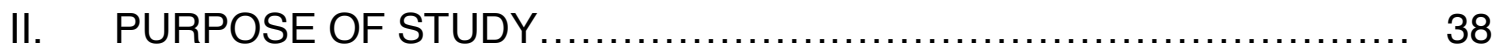

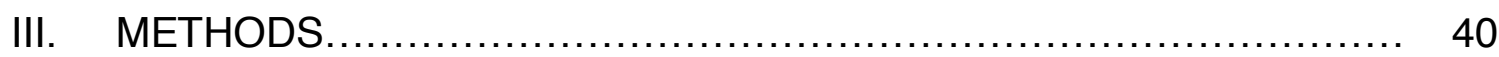

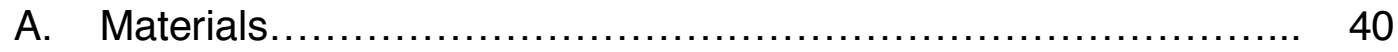

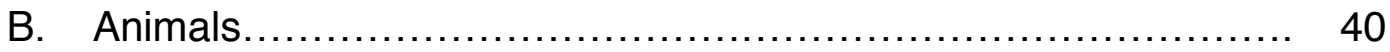

C. Preparation of platelets........................................ 40

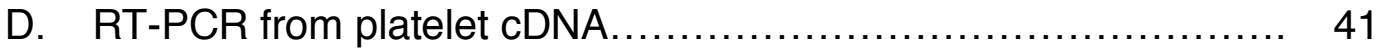

E. Immunoabsorption................................................ 42

F. Immunoblot detection......................................... 42

G. Platelet aggregation and secretion............................... 43

$\mathrm{H}$. Platelet adhesion under shear stress............................ 44

I. In vivo thrombosis................................................. 45

J. Platelet spreading on immobilized fibrinogen...................... 45

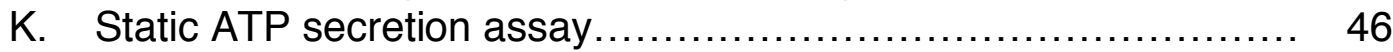

IV. RESULTS AND DISCUSSION .................................... 47

A. An important role for Akt3 in platelet activation and thrombosis.... 47 


\section{TABLE OF CONTENTS (continued)}

CHAPTER PAGE

a. Results...................................................... 47

1. Akt3 is a significant Akt isoform expressed in platelets.

47

2. The role of Akt3 in platelet secretion and aggregation........ 53

3. The role of Akt3 in mediating GSK-3 $\beta$ phosphorylation........ 60

4. The role of Akt3 in platelet adhesion and thrombus formation under flow conditions in vitro........................ 67

5. Akt3 promotes in vivo thrombosis.......................... 67

b. Discussion....................................................... 70

B. ADP-stimulated activation of Akt during integrin

outside-in signaling promotes platelet spreading................... 76

a. Results...................................................... 76

1. The role of Akt isoforms as downstream effectors of PI3K in mediating platelet spreading..................... 76

2. Akt-dependent phosphorylation of GSK-3 $\beta$ is a downstream mechanism of integrin outside-in signaling

3. Src and ADP receptor-dependent activation of the PI3K-Akt signaling pathway during integrin signaling ...................................................... 85

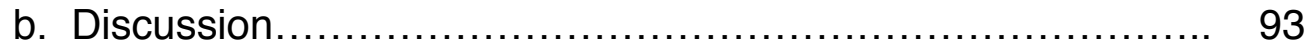

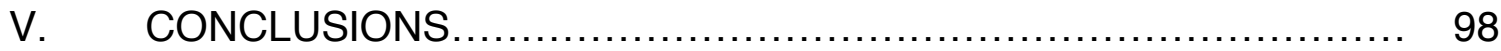

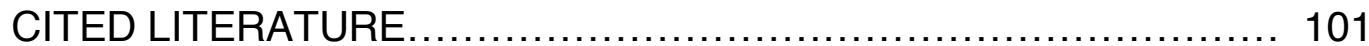

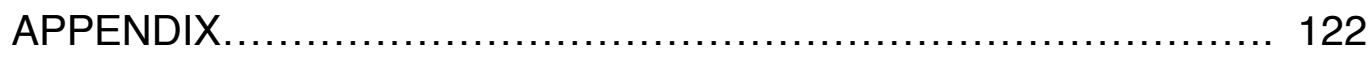

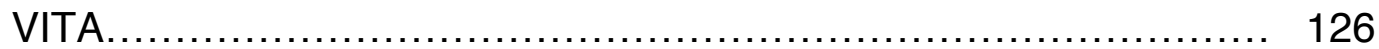




\section{LIST OF TABLES}

TABLE

PAGE

I. UNIQUE AND OVERLAPPING ROLES OF AKT ISOFORMS

IN PLATELET ACTIVATION................................... 73 


\section{LIST OF FIGURES}

FIGURE $\quad$ PAGE

1. G-protein coupled receptor platelet activation signaling......... 8

2. Signaling pathways of major platelet adhesion receptors....... 14

3. Regulatory mechanisms of Akt activation.................... 27

4. The role of Akt isoforms in platelet activation................... 37

5. Expression of Akt3 mRNA in platelets........................ 48

6. Expression of Akt3 protein in platelets........................ 49

7. Total and phosphorylated Akt in WT and Akt3 ${ }^{-1-}$ platelets....... 52

8. Stimulatory role of Akt3 in platelet aggregation and secretion in response to thrombin and PAR4 agonist peptide... 56

9. Responses of $\mathrm{Akt}^{-/}$platelets to other platelet agonists......... 57

10. Effect of aspirin treatment on WT and Akt3 ${ }^{-/-}$platelets......... 58

11. Comparison of knockouts of different Akt isoforms in platelet aggregation......................................... 59

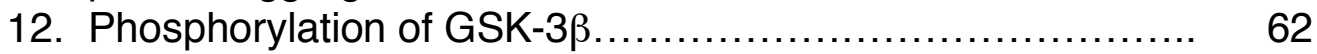

13. Phosphorylation of GSK-3 $\beta$ in response to PAR agonist peptide, collagen, and ADP

14. Reversal of the inhibitory effect of Akt3 knockout on platelet aggregation by GSK-3 $\beta$ inhibitor SB216763 ......... 66

15. Akt $^{-/-}$delays formation of stable thrombi...................... 69

16. Effect of an Akt inhibitor on platelet spreading................. 78

17. Effects of Akt3 knockout on integrin outside-in signaling and the role of GSK-3 $\beta$.

81

18. Spreading of Akt isoform knockout mouse platelets........... 82

19. Reversal of the inhibitory effect of PI3K/Akt inhibitors on platelet spreading by GSK-3 $\beta$....

84

20. Upstream molecules important in Akt activation................. 87

21. Effect of P2Y12 knockout and ADP receptor antagonists on integrin-dependent Akt activation.

89

22. Effect of P2Y12 knockout and ADP receptor antagonists on platelet spreading

23. Integrin $\alpha$ llb $\beta 3$-mediated activation of the PI3K-Akt-GSK-3 $\beta$ pathway important in outside-in signaling.

24. Summary of the role of Akt isoforms in platelet activation. 


\section{LIST OF ABBREVIATIONS}

\begin{tabular}{|c|c|}
\hline 2-MeSAMP & $\begin{array}{l}\text { 2-methylthioadenosine 5'-monophosphate } \\
\text { triethylammonium salt }\end{array}$ \\
\hline А3Р5P & adenosine-3'-phosphate-5'phosphate \\
\hline ACD & acid citrate dextrose \\
\hline ADP & adenosine diphosphate \\
\hline ATP & adenosine triphosphate \\
\hline CaIDAG-GEFI & $\begin{array}{l}\text { calcium and diacylglycerol-regulated guanine } \\
\text { nucleotide exchange factor I }\end{array}$ \\
\hline CAMP & cyclic adenosine monophosphate \\
\hline cGMP & cyclic guanosine monophosphate \\
\hline DAG & diacylglycerol \\
\hline DMSO & dimethyl sulfoxide \\
\hline EDTA & ethylenediaminetetraacetic acid \\
\hline eNOS & endothelial nitric oxide synthase \\
\hline ERK & extracellular signal-regulated kinase \\
\hline $\mathrm{FcR} \gamma$ & Fc receptor gamma \\
\hline Fc $\gamma R \| A$ & Fc gamma receptor IIA \\
\hline $\mathrm{FeCl} 3$ & ferric chloride \\
\hline GDP & guanosine diphosphate \\
\hline GEF & guanine nucleotide exchange factor \\
\hline GPCRs & G protein-coupled receptors \\
\hline GPIb & glycoprotein lb \\
\hline GPS & gray platelet syndrome \\
\hline GPVI & glycoprotein VI \\
\hline GSK-3 $\beta$ & glycogen synthase kinase- 3 beta \\
\hline GTP & guanosine triphosphate \\
\hline HPS & Hermansky-Pudlak Syndrome \\
\hline IL-1 $\beta$ & interleukin- 1 beta \\
\hline IP3 & inositol triphosphate \\
\hline ITAM & immunoreceptor tyrosine-based activation motif \\
\hline MAPK & mitogen-activated protein kinase \\
\hline MLC & myosin light chain \\
\hline mTOR & mammalian target of rapamycin \\
\hline NO & nitric oxide \\
\hline OCS & open canalicular system \\
\hline PAF & platelet activating factor \\
\hline PAGE & polyacrylamide gel electrophoresis \\
\hline PAR & protease activated receptor \\
\hline PBS & phosphate buffered saline \\
\hline PCR & polymerase chain reaction \\
\hline PDGF & platelet derived growth factor \\
\hline
\end{tabular}




\section{LIST OF ABBREVIATIONS (continued)}

\begin{tabular}{|c|c|}
\hline $\begin{array}{l}\text { PDK1 } \\
\text { PECAM-1 }\end{array}$ & $\begin{array}{l}\text { phosphoinositide dependent kinase } \\
\text { platelet endothelial cell adhesion molecule-1 }\end{array}$ \\
\hline PF4 & platelet factor 4 \\
\hline PI3K & phosphoinositide-3 kinase \\
\hline PKB & protein kinase B \\
\hline PKC & protein kinase $\mathrm{C}$ \\
\hline PKG & cGMP-dependent protein kinase \\
\hline PSGL-1 & P-selectin glycoprotein ligand-1 \\
\hline PLC $\beta$ & phospholipase $\mathrm{C}$ beta \\
\hline PLC $\gamma 2$ & phospholipase $\mathrm{C}$ gamma 2 \\
\hline ptdlns & phosphatidylinositol \\
\hline RGS & regulators of G-protein signaling \\
\hline RIAM & rap1-GTP-interacting adaptor molecule I \\
\hline ROCK & Rho-dependent kinase \\
\hline RT-PCR & reverse transcriptase polymerase chain reaction \\
\hline S1P & sphingosine-1 phosphate \\
\hline Ser & serine \\
\hline SDS & sodium dodecyl sulfate \\
\hline SFK & src family kinase \\
\hline SNARE & $\begin{array}{l}\text { soluble } \mathrm{N} \text {-ethylmaleimide-sensitive factor } \\
\text { attachment proteins }\end{array}$ \\
\hline SPD & storage pool deficiencies \\
\hline $\mathrm{TXA}_{2}$ & thromboxane $\mathrm{A}_{2}$ \\
\hline Thr & threonine \\
\hline TP & thromboxane prostanoid \\
\hline VAMP & vesicle associated membrane proteins \\
\hline vWF & von Willebrand factor \\
\hline
\end{tabular}




\section{SUMMARY}

Platelet activation is critical for the maintenance of hemostasis. Under pathological conditions, platelets also play a critical role in thrombosis, a leading cause of heart attack and stroke. Platelets are activated by adhesive proteins and soluble agonists. This initiates a signal transduction cascade leading to platelet adhesion, spreading, secretion, and aggregation, which are important for the formation of a platelet plug. Therefore, understanding the mechanisms of platelet activation may aid in the development of novel anti-thrombotic agents.

PI3 Kinases (PI3Ks) have been shown to be a common and key signal mediator in platelet activation. The most well known effector of PI3Ks is Akt. Akt is a family of serine threonine kinases with 3 isoforms: Akt1, Akt2, and Akt3. Previous studies from our lab and others have shown that Akt1 and Akt2 have important roles in stimulating platelet activation. In particular, Akt1 and Akt2 have been shown to be important in stimulating the second wave of secretion dependent platelet activation induced by thrombin, thromboxane $\left(\mathrm{TXA}_{2}\right)$, and von willebrand factor (VWF), and a major downstream mechanism for the role of Akt1 and Akt2 is mediated by the NO-cGMP-PKG signaling pathway. Although Akt3 was not previously identified in platelets in some previous studies, we present data in Chapter IV A that Akt3 is expressed in substantial amounts in human and mouse platelets. Using platelets isolated from Akt3 knockout mice, to assess the role of Akt3 in platelet function, we show that Akt3 is important in stimulating 


\section{SUMMARY (continued)}

platelet aggregation and secretion in response to low concentrations of thrombin receptor agonists and thromboxane $A_{2}\left(T X A_{2}\right)$, but not collagen or VWF. This is in contrast to Akt1 and Akt2, which are important is stimulating platelet activation induced by thrombin, $\mathrm{TXA}_{2}$, and vWF, while Akt1 is also important in stimulating platelet aggregation in response to collagen. Thus, our study revealed that there are differences among Akt isoforms in specific platelet signaling pathways. Importantly, we have found that Akt3 also promotes the formation of occlusive arterial thrombi in an in vivo $\mathrm{FeCl}_{3}$-induced carotid artery thrombosis model. Thus, we show that Akt3 plays an important and distinct role in platelet activation and in thrombosis.

In identifying a mechanism responsible for the role of Akt3 in platelet activation, we demonstrated that Akt3 is important in thrombin-induced phosphorylation of glycogen synthase kinase-3 $\beta$ (GSK-3 $\beta$ ) at Ser $^{9}$, which is known to inhibit GSK-3 $\beta$ function. Inhibition of GSK-3 $\beta$ reversed the inhibitory effect of Akt3 knockout on platelet aggregation and secretion in response to low dose thrombin. Thus, Akt3-mediated phosphorylation and inhibition of GSK-3 $\beta$ may be a mechanism by which Akt3 stimulates platelet activation.

Integrins mediate platelet adhesion and transmit "outside in" signals, leading to platelet spreading. PI3Ks play a critical role in outside-in signaling and platelet spreading; however, the mechanisms of PI3K activation and function in outside-in signaling are unclear. We hypothesized that downstream from PI3K, 


\section{SUMMARY (continued)}

Akt plays a stimulatory role in integrin outside-in signaling and platelet spreading. In testing this hypothesis in Chapter III B, we demonstrate that Akt is important in integrin outside-in signaling and platelet spreading on fibrinogen using platelets treated with an inhibitor of Akt and platelets from Akt3 knockout mice. Our studies revealed that Akt isoforms are also important in integrin-dependent

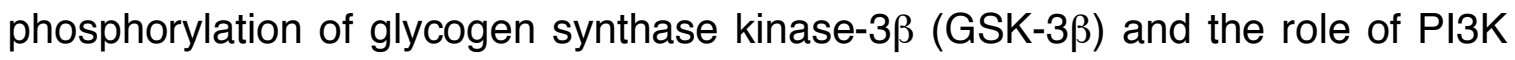
and Akt on platelet spreading is at least partially mediated by inhibition of GSK$3 \beta$. We have determined that integrin-dependent activation of the PI3K-Akt pathway requires Src Family Kinase (SFK). In addition, integrin-dependent activation of the PI3K-Akt pathway is also promoted by ADP secretion signaling through P2Y1 and P2Y12 ADP receptors during spreading. Thus, we have characterized an integrin outside-in signaling pathway involving SFK-dependent and P2Y12/P2Y1-facilitated activation of the PI3K-Akt pathway, which inhibits GSK-3 $\beta$ and promotes platelet spreading. 


\section{LITERATURE REVIEW}

\section{A. Platelets}

\section{Platelet morphology}

Platelets are small, anucleate cells that circulate in the blood. They are derived from precursor megakaryocytes in a process called thrombopoiesis. Platelets range in size from 2.0 to $5.0 \mu \mathrm{m}$ in diameter. Platelets typically circulate in the blood for 7-10 days. The exterior surface of the platelet or glycocalyx serves as the first site of contact and is covered with receptors that sense changes in the platelet environment and facilitate adhesion. The platelet surface membrane is a lipid bilayer, similar to that of other cell types (White and Conard, 1973). The platelet cytoskeleton is important for regulating the platelet shape, and serves as a scaffold to bind and activate signaling molecules. The cytoskeleton consists of a spectrin-based skeleton, which is adherent to the cytoplasmic side of the membrane, a microtubule coil, and cross-linked actin filaments with myosin heads (Fox, 2001). The cytoplasmic side of the membrane is coated with a hexagonal meshwork of spectrin tetramers, which interconnect the ends of actin filaments (Hartwig et al., 1999). Actin filaments are also linked to membrane glycoproteins. Importantly, actin filaments are connected to glycoprotein lb (GPIb) through the actin crosslinking and scaffolding protein, filamin. In addition, actin interaction with myosin promotes contractile forces (Fox, 2001). The platelet microtubule coil is formed from a single microtubule that is 
wound 8 to 12 times into a coil, which supports the shape of the platelet (Haydon and Taylor, 1965). Microtubules are rigid, hollow polymers that are assembled from $\alpha$ and $\beta$ tubulin heterodimers (Kenney and Linck, 1985). Platelets have an open canalicular system (OCS), which consists of invaginations of the surface membrane that form channels that tunnel into the cytoplasm (Escolar and White, 1991). The channels of the OCS serve as a source for increased surface area for spreading platelets and provide a means for small molecules to enter the deepest recesses of the cell (Escolar and White, 1991). In addition to the cellular organelles such as mitochondria and Golgi apparatus that are common to other cell types, platelets contain three major types of granules in the cytoplasm: $\alpha$ granules, dense granules, and lysosomes, which may be released during platelet activation (more on platelet granule secretion will be discussed in Chapter IC). Platelet granules serve as reservoirs of growth factors, adhesive proteins, and soluble agonists that further amplify platelet activation and recruit circulating platelets. Platelets have a dense tubular system, which represents the residual endoplasmic reticulum of the megakaryocyte, and is the major calcium sequestering organelle (Ebbeling et al., 1992). The dense tubular system rapidly releases this calcium upon platelet agonist stimulation to increase intracellular calcium levels. This is initiated by binding of the Phospholipase $C$ (PLC) product, inositol triphosphate (IP3), to receptors on the dense tubular system membrane (Sage and Rink, 1987). 


\section{Physiological function}

Platelets play a key role in hemostasis, which is the cessation of bleeding. Platelets are also important for thrombosis, which is the pathological formation of occlusive thrombi in the vessels. Under normal conditions, platelets circulate in a "resting" state. Upon damage to the endothelial cell surface or disruption of endothelial monolayers, platelets are exposed to the underlying subendothelial matrix and also extracellular matrix of tissues, which consists of adhesive proteins such as collagen. Platelets adhere to extracellular matrix proteins such as collagen and collagen-bound VWF, via the interaction of these adhesive proteins with their respective receptors on platelet membranes. Damage to tissues and cells also cause the release or formation of soluble agonists such as $\mathrm{TXA}_{2}$, adenosine diphosphate (ADP), or thrombin. These soluble agonists activate platelets through their respective receptors and lead to the recruitment of additional circulating platelets. Activated platelets release their granule contents, which include platelet soluble agonists and adhesive proteins that greatly amplify platelet activation and help recruit circulating platelets to the site of vascular injury. At the molecular level, the consequence of platelet activation is the transformation of the major platelet adhesion receptor integrin $\alpha_{\| 1 b} \beta_{3}$, from its resting to activated state, which allows platelets to bind integrin ligands such as fibrinogen, VWF and fibronectin, and mediate platelet aggregation and stable adhesion. Platelet aggregation is the clustering together of platelets, resulting in a thrombus. 
Activated platelets can release microparticles, which are small membrane vesicles. Platelet microparticles are highly procoagulant, because they contain the exposed, anionic phospholipid, phosphatidylserine, which facilitates the assembly of components of the coagulation cascade (Owens and Mackman, 2011). The coagulation cascade is required for thrombin generation and conversion of fibrinogen to fibrin, which in turn strengthens the platelet thrombus.

In addition to the central role of platelets in hemostasis and thrombosis, platelets play a dynamic role in a number of physiological processes. Platelets are important in maintaining vascular integrity. Platelets can interact with activated or damaged endothelium mainly through ligation of platelet-endothelial cell adhesion molecule-1 (PECAM-1) (Newman, 1994), and endothelial Pselectin with platelet GPIb and PSGL-1 (Frenette et al., 2000; Frenette et al., 1995; Romo et al., 1999). Platelets can also bind VWF, a ligand for GPIb and integrins, which is secreted from Weibel Palade bodies of activated endothelial cells (Wagner et al., 1982). Through platelet-endothelial cell interactions, platelets can help maintain the endothelial barrier to prevent excessive leakage of fluids and proteins into tissues (Ho-Tin-Noe et al., 2011). Platelets also have an important role in inflammation. Leukocytes can roll and tether on activated platelets through interaction of platelet P-selectin and leukocyte PSGL-1, which promotes leukocyte activation (Mayadas et al., 1993; Norman et al., 1995). Activated platelets can promote leukocyte recruitment in inflamed tissues through 
secretion of a number of inflammatory and immune modulating factors from their granules (Ho-Tin-Noe et al., 2011). These include histamine, platelet activating factor (PAF), sphingosine-1 phosphate (S1P), platelet factor 4 (PF4), and interleukin-1 $\beta$ (IL-1 $\beta)$. Several studies have suggested that secretion of growth factors from platelet granules promotes angiogenesis (Feng et al., 2011; Kisucka et al., 2006; Rhee et al., 2004), tumorigenesis, and cancer progression (Jain et al., 2010). Taken together, platelets play a critical role not only in hemostasis and thrombosis, but also in several important physiological and pathophysiological processes. Understanding the mechanisms of platelet activation will therefore aid in the prevention and treatment of a number of diseases.

The advancement of research on platelet activation has led to the development and clinical use of a number of anti-platelet drugs for the prevention and treatment of thrombosis. These established anti-platelet drugs target cyclooxygenase (aspirin), integrin $\alpha_{\| l b} \beta_{3}$ (abciximab, tirofiban, eptifibatide), and the ADP receptor P2Y12 (ticlopidine, clopidogrel). There are however, problems and side effects associated with the use of these drugs. A significant amount of patients using these anti-platelet agents still experience thrombotic events (Yousuf and Bhatt, 2011; Yusuf et al., 2001). Potential explanations for this occurence is drug resistance attributable to genetic polymorphisms, and competition in metabolism (Michelson, 2010). In addition, the use of anti-platelet agents has resulted in bleeding side effects and thrombocytopenia in some patients (Michelson, 2010). Therefore, novel anti-platelet agents are needed that 
inhibit thrombosis, yet maintain hemostasis. Detailed understanding of the mechanisms regulating signaling during platelet activation and adhesion are essential for the discovery of novel targets for anti-thrombotic therapy.

\section{B. Signaling during platelet activation and adhesion}

Soluble agonists and adhesive proteins bind to their respective platelet receptors and induce an intracellular signal transduction cascade. Signaling downstream of ligand-occupied platelet receptors converge on several common signaling pathways that lead to platelet activation. These signaling pathways are responsible for inducing fundamental platelet functions such as shape change, granule secretion, and integrin-dependent adhesion and aggregation. These platelet signaling events result in several feedback loops and cross-talk between signaling pathways that significantly amplify and stabilize platelet thrombus

formation (For review please see (Li et al., 2010a)). Significant progress has been made in recent years to unravel the complex signaling pathways regulating platelet activation. The main platelet signaling pathways can be divided into two major categories: G-protein coupled receptor signaling pathways and adhesion receptor signaling pathways.

\section{G-Protein Coupled Receptor Pathways}


Numerous soluble platelet agonists are generated at sites of vascular injury or released from damaged or stimulated endothelial cells, inflammatory cells, or from granules of activated platelets at sites of vascular injury. Soluble platelet agonists include thrombin, ADP, $\mathrm{TXA}_{2}$, serotonin, platelet activating factor, and lysophosphatidic acid. The majority of these soluble platelet agonists bind to seven transmembrane spanning receptors, known as G protein-coupled receptors (GPCRs), because they are coupled to heterotrimeric G-proteins. Heterotrimeric G-proteins consist of an $\alpha, \beta$, and $\gamma$ subunit. Agonist binding induces conformational changes in the seven transmembrane receptors that allow the receptor to act as a guanine nucleotide exchange factor (GEF) and cause the $\alpha$ subunit to be converted from a guanosine diphosphate (GDP)-bound form to the active guanosine triphosphate (GTP)-bound form. The GTP-bound $\alpha$ subunit dissociates from the receptor and the $\beta / \gamma$ complex, and interacts with specific downstream effectors. The $\beta / \gamma$ complex can also dissociate and interact with intracellular signaling targets such as PI3K (Stephens et al., 1997). Regulators of G-protein signaling (RGS) proteins regulate $\mathrm{G} \alpha$ signaling by accelerating the hydrolysis of the GTP of Go subunits (Signarvic et al., 2010). Platelets express Gq, G12/13, Gi/z, and Gs subfamilies of G-proteins. The major soluble platelet agonists that bind to $G$ protein-coupled receptors include $\mathrm{TXA}_{2}$, thrombin, and ADP, which will be discussed as follows (Figure 1). 


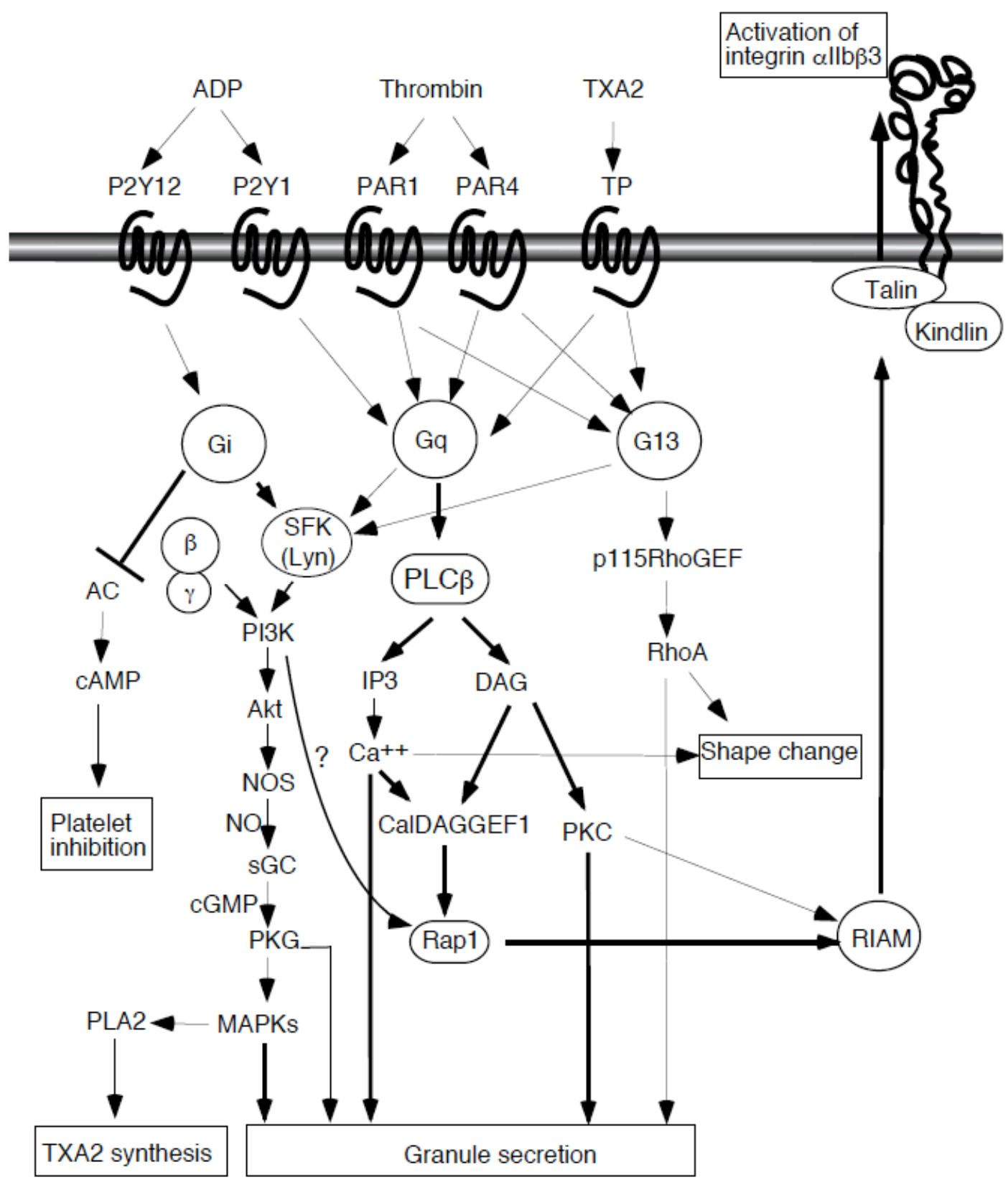

Figure 1. G-protein coupled receptor platelet activation signaling

This figure has been modified from its original form published in ATVB (Li et al., 2010a). 


\section{a. Thromboxane $\mathrm{A}_{\underline{2}}$}

Thromboxane $A_{2}\left(T X A_{2}\right)$ is a short-lived lipid mediator that is the product of thromboxane synthase. The enzyme cyclooxygenase catalyzes the formation of intermediate prostaglandin endoperoxide $\mathrm{PGH}_{2}$ from arachidonic acid. Thromboxane synthase then forms $\mathrm{TXA}_{2}$ from PGH2. Aspirin is widely and successfully used as an antithrombotic drug, because it inhibits cyclooxygenase, and thus $\mathrm{TXA}_{2}$ production. $T X \mathrm{~A}_{2}$ can diffuse through the platelet membrane to activate neighboring platelets, and thus serves as an important amplification mechanism for platelet activation. TXA 2 is quickly converted to non-functional thromboxane $B_{2}$. Because thromboxane is short lived, the synthetic stable analog, U46619 is used for platelet experiments in vitro. TXA signals through binding to thromboxane prostanoid (TP) receptor. Deletion of TP in mice results in defects in platelet aggregation and hemostasis (Thomas et al., 1998). TP receptor is coupled to G12/G13, and Gq pathways (Djellas et al., 1999; Knezevic et al., 1993). Gq activation leads to stimulation of Phospholipase C $\beta$ (PLC $\beta$ ), which catalyzes the generation of inositol triphosphate (IP3) and diacylglycerol (DAG). IP3 stimulates calcium mobilization, and DAG activates Protein Kinase C(PKC) dependent pathways, which promote platelet granule secretion (Offermanns et al., 1997). G12/13 activation results in stimulation of the RhoA pathway. Guanosine triphosphate (GTP) loaded Ga13 interacts with p115RhoGEF, which converts RhoA into the active GTP-bound form (Kozasa et 
al., 1998). The RhoA pathway is important for platelet shape change and granule secretion (Klages et al., 1999; Moers et al., 2003).

\section{b. Thrombin}

Thrombin is a serine protease that is converted from the inactive prothrombin when the coagulation cascade is activated either through the exposure of tissue factor during cell injury (extrinsic pathway) or through activation of FXII-dependent pathway (intrinsic pathway) (Coughlin, 2005). The protease activated receptors (PAR) are the major thrombin receptors. Activation of PARs is induced when thrombin cleaves the $\mathrm{N}$-terminus of the receptor, resulting in a new $\mathrm{N}$-terminus that serves as a tethered ligand (Vu et al., 1991). Thus, peptides based on the tethered ligand sequences can activate these receptors and are used as platelet agonists to mimick the effect of thrombin in inducing PAR signaling and platelet activation. Human platelets express PAR-1 and PAR-4, while mouse platelets express PAR-3 and PAR-4. PAR-1 is coupled to $\mathrm{G} \alpha 12 / 13$, Gaq, and Gai/z families of heterotrimeric G proteins. PAR-4 is coupled to $\mathrm{G} \alpha \mathrm{q}$ and $\mathrm{G} \alpha 12 / 13$. Ga13 appears to be the major G-protein stimulated downstream from PAR-1 (Huang et al., 2007). Receptor activation of PAR-1 and PAR-4 leads to stimulation of numerous signaling pathways including PLC, PI3K, and the small GTPases Rho, Rac, and Rap1, and also causes calcium mobilization and inhibition of cAMP formation (Coughlin, 2005). In mouse platelets, a lack of PAR-4 causes defects in shape change, calcium mobilization, 
and ADP secretion and aggregation in response to thrombin (Sambrano et al., 2001). Knockout of PAR-3 in mouse revealed that PAR-3 is necessary for platelet aggregation and secretion induced by low, but not high concentrations of thrombin (Kahn et al., 1998). The results of another study supported the notion that PAR-3 serves as a cofactor to localize thrombin to the platelet surface to promote cleavage and activation by PAR-4 (Nakanishi-Matsui et al., 2000). It has also been shown that thrombin binds to GPIb $\alpha$ (Okumura et al., 1978); however the physiological relevance of GPIb-thrombin interaction is still uncertain (Ruggeri et al., 2010).

\section{c. $\underline{\text { ADP }}$}

$\mathrm{ADP}$ is an important platelet activator and is secreted from platelet dense granules. ADP may also be released from damaged red blood cells at sites of vascular injury. Platelets contain two receptors for ADP that are members of the purinergic class of GPCRs: P2Y1 and P2Y12. P2Y1 receptor is coupled to Gaq, while P2Y12 receptor is coupled to Gai. Platelets also contain a P2X1 receptor, which is an ionotropic adenosine triphosphate (ATP) receptor that induces calcium influx (Kunapuli et al., 2003). The P2Y1 receptor, by coupling to Gaq, leads to activation of PLC, generation of IP3, and subsequently mobilization of calcium. P2Y1 receptor signaling also leads to activation of the small G-protein RhoA that mediates platelet shape change. Mice deficient in P2Y1 exhibit defective platelet aggregation, shape change, and increased resistance to 
thrombosis in vivo (Leon et al., 1999). The P2Y12 receptor, by coupling to Gai, inhibits adenylyl cyclase and cyclic adenosine monophosphate (cAMP) production. Knockout of $\mathrm{P} 2 \mathrm{Y} 12$ in mouse platelets results in prolonged bleeding time, reduced aggregation, but normal shape change and calcium flux in response to ADP (Foster et al., 2001). P2Y1 null mice and P2Y12 null mice both exhibit reduced responses to other platelet agonists such as thrombin and collagen, supporting the importance of ADP secretion in stabilization of platelet aggregation (Foster et al., 2001; Leon et al., 1999). It has also been shown that ADP secretion can promote platelet spreading on immobilized fibrinogen and scavengers of ADP such as apyrase can inhibit platelet spreading (Haimovich et al., 1993; Jirouskova et al., 2007). Furthermore, it has been reported that platelets from a patient deficient in ADP receptor $\mathrm{P} 2 \mathrm{Y} 12$ have defective spreading on fibrinogen (Shiraga et al., 2005). This suggests a role for ADP in promoting integrin dependent platelet spreading. In addition, the activation of ADP receptor P2Y12 has been shown to be a major mechanism for the stimulation of the PI3K pathway, as G $\beta \gamma$ has been shown to directly bind PI3K and induce its activation (Jackson et al., 2004). Because of the importance of ADP receptor signaling in the secondary amplification mechanism of platelet activation, several pharmacological agents specifically targeting ADP receptors have been developed as anti-thrombotic agents. Clopidogrel and ticlopidine are two widely prescribed anti-platelet agents that are irreversible antagonists of the P2Y12 receptor (Kunapuli et al., 2003). 


\section{Adhesion Receptor Pathways}

Platelet adhesion receptors are key initiators of platelet activation at sites of vascular injury. These receptors are responsible for capturing and tethering platelets circulating in the bloodstream to exposed extracellular matrix proteins. Ligation of platelet adhesion receptors induces intracellular signaling that is critical for platelet plug formation. The major platelet adhesion receptors include integrin $\alpha$ llb $\beta 3$, GPIb-IX-V, and GPVI (Figure 2). 


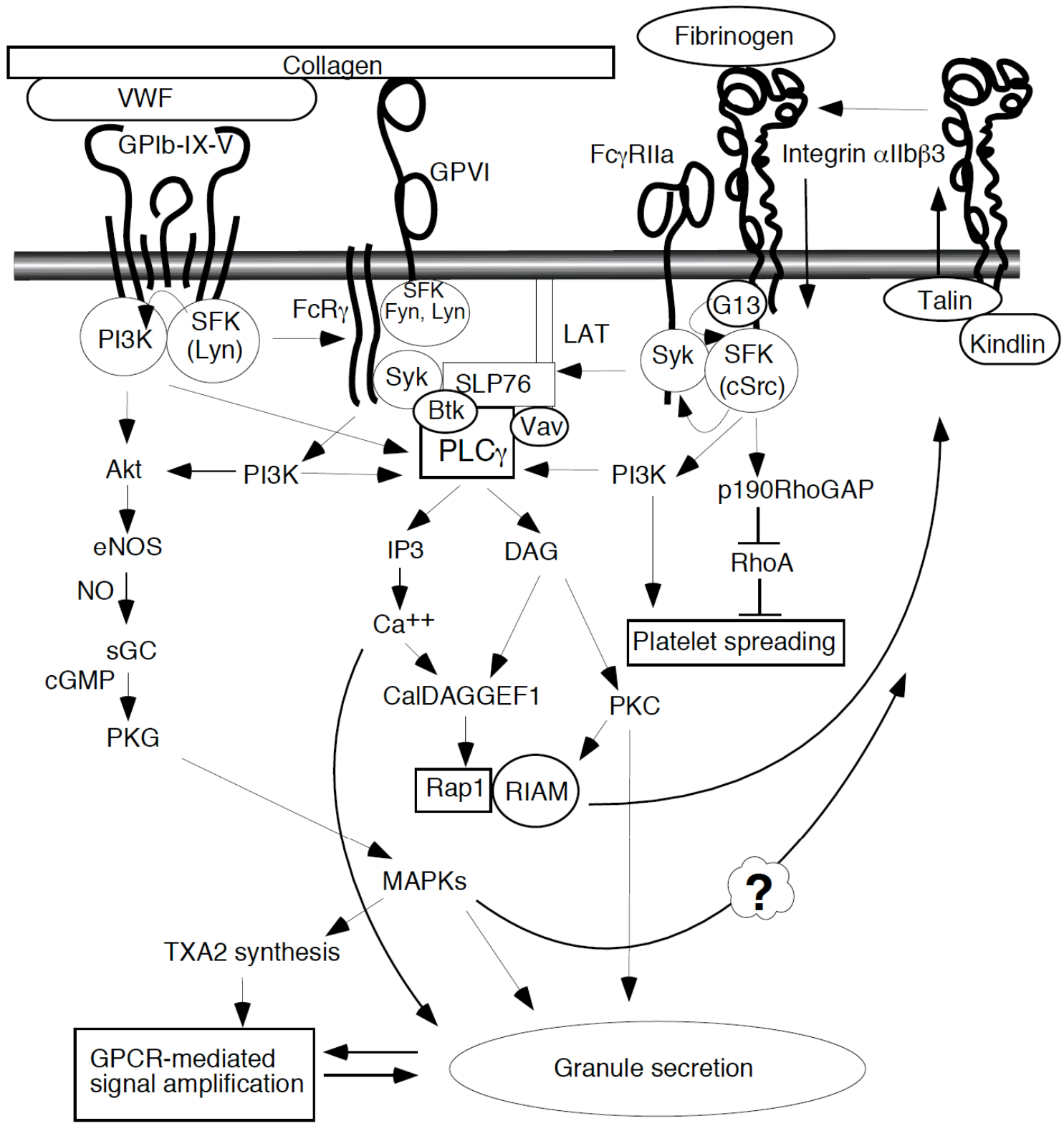

Figure 2. Signaling pathways of major platelet adhesion receptors

This figure has been modified from its original form published in ATVB (Li et al., 2010a). 


\section{a. Integrin $\alpha \operatorname{llb} \beta 3$}

Integrins are a family of cell adhesion receptors that regulate numerous cellular processes such as adhesion, migration, and proliferation. Integrins are heterodimeric transmembrane proteins consisting of an $\alpha$ and $\beta$ subunit. Platelets express $\alpha_{\| 1 b} \beta_{3}$ (fibrinogen receptor), $\alpha_{2} \beta_{1}$ (collagen receptor), $\alpha_{v} \beta_{3}$ (vitronectin receptor), $\alpha_{5} \beta_{1}$ (fibronectin receptor), and $\alpha_{6} \beta_{1}$ (laminin recptor), but integrin $\alpha_{\| l b} \beta_{3}$ is the major integrin subtype expressed in blood platelets. Under normal conditions, platelet integrin $\alpha_{\| 1 b} \beta_{3}$ has low affinity for its ligands. Upon agonist stimulation at sites of blood vessel injury, integrins become activated and can bind ligands, and mediate platelet aggregation and adhesion. Integrin signaling is bidirectional in that intracellular signaling mechanisms induce changes in the extracellular ligand binding domain of integrins to an activated state (inside-out signaling), and ligand binding to the activated integrins conversely transmits "outside-in" signals (Ginsberg et al., 2005; Li et al., 2010a; Ma et al., 2007), which are critically important in stable platelet adhesion, spreading, and clot retraction (Shattil and Newman, 2004). The regulation of integrin $\alpha_{\| l b} \beta_{3}$ is therefore critically important for hemostasis, as well as thrombosis.

\section{i. Inside-out signaling}

Integrins are also activated from signals within cells, known as inside-out signaling. Stimulation of $G$ protein-coupled receptors or adhesion 
receptors induces intracellular signals that lead to conformational changes in the extracellular domain of integrins that allows integrins to bind their ligands. Activated integrins mediate adhesion and platelet aggregation. Two major integrin binding proteins that are required for integrin inside out signaling are talin and kindlin. Talin is a large $(280-\mathrm{kDa})$, cytoplasmic protein that is recruited to the plasma membrane by intracellular signals of Rap1 and RIAM, where it binds $\beta$ integrin cytoplasmic tails (Lee et al., 2009). Deletion of talin1 in mice results in severe bleeding and dramatically impaired platelet aggregation (Petrich et al., 2007). Though talin binds $\beta$ integrin cytoplasmic tails at multiple sites and this binding is required for changes in the extracellular domain and subsequent ligand binding, precisely how talin- $\beta$ integrin interaction can trigger integrin activation is still under intense investigation. Recently, the kindlin family of proteins was also identified to be an important regulator of integrin activation (Malinin et al., 2009; Moser et al., 2008; Ye and Petrich, 2011). Kindlin 3 is the major isoform expressed in platelets and its deletion results in increased bleeding, defective platelet aggregation and integrin activation (Malinin et al., 2009; Moser et al., 2008). Kindlin also binds to the $\beta$ integrin cytoplasmic tail, but at a site distinct from talin (Harburger et al., 2009; Ma et al., 2008; Moser et al., 2008). It is unclear at this time whether kindlin functions as a coactivator of $\beta$ integrin, a scaffold, or both; thus, future studies are warranted to pinpoint the precise requirement of kindlin and talin in integrin inside-out signaling.

\section{ii. Outside-In Signaling}


Signaling originating from extracellular ligand binding to integrin to induce intracellular signaling and cellular responses is known as outside-in signaling. Cell spreading is an early consequence of integrin outside-in signaling and represents the outward movement of the cell membrane, characterized by formation of lamellipodia and filipodia. Understanding the mechanisms and signaling proteins involved in "outside-in" signal transduction may facilitate the development of pharmacological inhibitors for regulation of these processes. Numerous proteins have been shown to interact with integrin $\beta 3$ cytoplasmic domain (Shattil and Newman, 2004); however we have recently shown that the most proximal event following integrin ligation is the binding of the $G$ protein subunit $\mathrm{G} \alpha 13$ to the cytoplasmic domain of $\beta 3$ integrin (Gong et al., 2010). This interaction then leads to activation of Src Family Kinases (SFKs), particularly cSrc, which is associated with $\beta_{3}$ (Arias-Salgado et al., 2003; Obergfell et al., 2002). A downstream pathway of the Ga13-c-Src-mediated signal is the Srcdependent phosphorylation of p190 RhoGAP, which leads to inactivation of RhoA and subsequent inhibition of the RhoA contractile pathway, thus promoting cell spreading (Arthur and Burridge, 2001; Flevaris et al., 2007). c-Src is also important for the phosphorylation of the $\beta_{3}$ cytoplasmic domain and for the activation of the immunoreceptor tyrosine-based activation motif (ITAM) and Syk signaling pathway (Boylan et al., 2008; Obergfell et al., 2002). The ITAM and Syk signaling pathway is important for activation of PLC $\gamma 2$ (Wonerow et al., 2003). PLC $\gamma 2$ generates the lipid products IP3 and DAG. IP3 and DAG are important for 
calcium mobilization and subsequent activation of calcium and diacylglycerolregulated guanine nucleotide exchange factor I (CaIDAG-GEFI). DAG is required for activation of PKC. PKC $\theta$ and PKC $\beta$ were reported to be important for integrin outside-in signaling, however further studies are required to identify its substrates and specific role in the process (Buensuceso et al., 2005; Soriani et al., 2006). CalDAG-GEFI is also important for integrin signaling and is required for activation of Rap1 (Bergmeier et al., 2007; Crittenden et al., 2004; Eto et al., 2002; Stefanini et al., 2009). Rap1b is important for integrin outside-in signaling and spreading (Zhang et al., 2011b). Activation of Rap1b results in its association with Rap1-GTP-interacting adaptor molecule (RIAM), which is important to promote talin-dependent integrin activation (Lee et al., 2009; Watanabe et al., 2008). Numerous groups have also reported that PI3Ks play important roles in integrin outside-in signaling (Banfic et al., 1998; Canobbio et al., 2009; Heraud et al., 1998; Jackson et al., 2004; Zhang et al., 1998).

Another platelet response that requires integrin signaling is clot retraction. Cell retraction is mediated through the RhoA and Rac1-dependent retractile signaling pathways (Flevaris et al., 2009; Flevaris et al., 2007; Jaffe and Hall, 2005). Association of $c-S r c$ with $\beta 3$ is required for inhibition of the RhoA retractile pathway, which promotes cell spreading (Arthur and Burridge, 2001; Flevaris et al., 2007). During integrin outside-in signaling and platelet spreading, calpain, which is a calcium-regulated cysteine protease, becomes activated in response to increased intracellular calcium levels. Calpain cleaves the 
cytoplasmic domain of $\beta_{3}$ integrin mainly at $Y^{759}$ (Du et al., 1995; Xi et al., 2003). Increased $\beta_{3}$ cleavage occurs after dephosphorylation of $Y^{759}$ (Xi et al., 2006). The calpain cleavage of $\beta_{3}$ relieves the inhibitory effects of Src on the RhoA retractile pathway, thus allowing for platelet retraction (Flevaris et al., 2007). RhoA activates Rho dependent kinase (ROCK) that phosphorylates and inactivates myosin light chain (MLC) phosphatase, thereby leading to an increase in MLC phosphorylation (Kimura et al., 1996). However, inhibition of calpain cleavage only partially rescued integrin mediated clot retraction (Flevaris et al., 2007). We have recently shown that a second pathway is present, which depends on the small GTPase, Rac1 (Flevaris et al., 2009). Rac 1 dependent integrin outside-in signaling leads to activation of mitogen-activated protein kinase (MAPK), which induces phosphorylation of MLC (Flevaris et al., 2009). MLC phosphorylation is essential for cell retraction and the actomyosin complex.

\section{b. Glycoprotein Ib-IX-V}

Under high shear rates conditions, the platelet receptor for Von Willebrand factor (VWF), the glycoprotein Ib-IX-V complex (GPIb-IX), is required to mediate initial platelet adhesion to subendothelial-bound VWF at sites of vascular injury and transduce signals (Du, 2007). GPIb-IX signaling leads to platelet activation, stable platelet adhesion, and thrombus formation (Du, 2007; Ruggeri, 1994; Ware, 1998). GPIb-IX consists of GPIb $\alpha$, GPIb $\beta$, GPIX and loosely associated GPV (Lopez, 1994). The extracellular domain of GPIb $\alpha$ 
contains the binding site for VWF. In addition to its interaction with VWF, GPIb-IX also binds thrombin (Okumura et al., 1978), and interacts with leukocyte integrin $\alpha_{m} \beta_{2}$ (Simon et al., 2000), P-selectin (Romo et al., 1999), and coagulation factors XI and XII (Baglia et al., 2004; Bradford et al., 2000), high molecular weight kininogen (Bradford et al., 1997), and thrombospondin-1 (Jurk et al., 2003). Thus, GPIb-IX is also important for platelet adhesion to endothelial cells, leukocyte recruitment to sites of vascular injury, and in thrombin-induced platelet activation and coagulation. The cytoplasmic domain of GPIb-IX interacts with several molecules, including 14-3-3 protein (Du et al., 1996; Du et al., 1994), filamin (Andrews and Fox, 1991; Fox, 1985), PI3K (Mu et al., 2010), calmodulin (Andrews et al., 2001), and Src family kinases (Wu et al., 2003). Recent studies from our lab and others have shown that GPIb-IX signaling requires sequential activation of Src family kinases (Kasirer-Friede et al., 2004), particularly Lyn (Liu et al., 2005; Yin et al., 2008a), Rac1 (Du lab unpublished data), PI3K/Akt (Kasirer-Friede et al., 2004; Yin et al., 2008b), cGMP-dependent protein kinase (Li et al., 2003a), and the MAPKs (Li et al., 2001). GPIb-IX signaling results in calcium elevation, integrin activation, and $\mathrm{TXA}_{2}$-dependent granule secretion of ADP (Du, 2007; Liu et al., 2005). The signaling that results in $\mathrm{TXA}_{2}$ production was shown to be initiated by SFK, and propagated through Syk, Btk, SLP-76, PI3K, PLC $\gamma 2$, and PKC (Kroll et al., 1991; Liu et al., 2006; Liu et al., 2005; Yin et al., 2008b).

\section{c. Collagen/GPVI}


Blood vessel injury results in exposure of platelets to subendothelial protein collagen. Platelets express collagen receptors GPVI and $\alpha_{2} \beta_{1}$ that mediate platelet tethering, adhesion, and aggregation. GPVI is the major platelet collagen receptor and is a member of the immunoglobulin superfamily (Clemetson et al., 1999). GPVI consists of 2 Ig domains, a mucin like stalk, a transmembrane region and a short cytoplasmic tail consisting of 51 amino acids. GPVI is coupled to a Fc receptor (FcR) $\gamma$ chain that is essential for its expression and function in platelets (Kato et al., 2003; Poole et al., 1997). Each FcR $\gamma$ chain contains an ITAM. ITAM undergoes phosphorylation on two tyrosine residues, by SFKs Lyn and Fyn, upon GPVI-collagen crosslinking (Quek et al., 2000). This leads to binding and activation of the tyrosine kinase Syk by SFKs (Yanaga et al., 1995). Activated Syk induces intracellular signaling through adapter proteins LAT, SLP76, Gads, and the Tec family kinase Btk, as well as PI3Ks (Pasquet et al., 1999a) (Barry and Gibbins, 2002; Gross et al., 1999a; Gross et al., 1999b; Pasquet et al., 1999b; Quek et al., 1998; Ragab et al., 2007). This protein complex is responsible for the activation of PLC $\gamma 2$. Filamin A was also shown to interact with Syk and contribute to PLC $\gamma 2$ activation (Falet et al., 2010). PLC $\gamma 2$ is necessary for calcium mobilization, activation of protein kinase $\mathrm{C}$, and platelet granule secretion (Blake et al., 1994; Wang et al., 2000). Downstream from PI3K, Akt1 is also required to promote platelet granule secretion induced by collagen and signals mainly by activating the NO-cGMP-PKG-MAPK pathway (Chen et al., 2004; Stojanovic et al., 2006). PKC- and calcium- regulated pathways also 
contribute to GPVI stimulated platelet activation (Quinton et al., 2002). Platelet endothelial cell adhesion molecule-1 (PECAM-1) is known to negatively regulate collagen signaling through activation of SHP-1/2 phosphatases (Newman et al., 2001).

Integrin $\alpha_{2} \beta_{1}$ is also a platelet collagen receptor. Studies using $\beta_{1}$ Cre-loxP conditional knockout showed a relatively mild collagen induced aggregation defect and a mild adhesion defect on collagen compared to mice lacking GPVI, which could not activate integrins, adhere to and aggregate on soluble or fibrillar collagen (Nieswandt et al., 2001). Studies using $\alpha 2$ deficient mouse platelets revealed defects in adhesion to Type1 collagen under static or shear conditions (Chen et al., 2002). Therefore, the role of integrin $\alpha_{2} \beta_{1}$ in collagen induced platelet activation is somewhat controversial and may in part be due to the type of collagen used (Nieswandt and Watson, 2003).

\section{Platelet Granule Secretion}

Activated platelets secrete a number of soluble agonists and adhesive proteins from their granules. Secreted granule contents aid in the recruitment and activation of circulating platelets and amplify thrombus formation at sites of blood vessel injury. The importance of platelet secretion in hemostasis is evidenced by the identification of bleeding disorders in patients with defective exocytosis such as in Storage Pool Deficiencies (SPD), Hermansky-Pudlak Syndrome (HPS), and Gray Platelet Syndrome (GPS) (Nurden and Nurden, 2011; Ren et al., 2008). 
Platelets carry a large amount of biologically active molecules in their granules that may also implicate platelets in other physiological processes including inflammation, wound healing, angiogenesis, and atherosclerosis. Platelets contain three types of granules: dense granules, $\alpha$-granules, and lysosomes. Dense granules contain small molecules such as ADP, serotonin, and calcium. $\alpha-$ Granules contain proteins such as PF4, VWF, platelet derived growth factor (PDGF), fibrinogen, and fibronectin. P-selectin is a type I integral membrane protein that resides in $\alpha$-granules of unstimulated platelets. P-selectin is exposed on the surface of activated platelets upon platelet $\alpha$-granule release, and thus serves as a marker for platelet activation (Furie et al., 2001). Because P-selectin can interact with P-selectin glycoprotein ligand-1 (PSGL-1) on the surface of leukocytes, $\alpha$-granule release and P-selectin exposure on activated platelets is an important mechanism for platelet-leukocyte interaction (Furie et al., 2001). Lysosomal granules contain ezymes such as cathepsins and hexosaminidase (Ren et al., 2008). Interestingly, it has recently been proposed that there is heterogeneity among $\alpha$-granules in that distinct subpopulations of $\alpha$-granules contain different cargo and may undergo differential release upon platelet activation (Italiano and Battinelli, 2009).

Platelet secretion occurs when granules fuse with the target membrane and exocytose their cargo. Soluble $\mathrm{N}$-ethylmaleimide-sensitive factor attachment proteins (SNARE) are critical in this process. tSNAREs are membrane proteins associated with target membranes. Platelets express tSNAREs: syntaxin 2, 4, 7, 
11, SNAP-23, and SNAP-29 (Ren et al., 2008). vSNAREs are membrane proteins located on vesicles. Human and mouse platelets express vesicle associated membrane proteins (VAMP): VAMP-2, VAMP-3, VAMP-7, and VAMP8 (Ren et al., 2008). During exocytosis, vSNAREs and tSNARES interact with each other and this interaction is controlled by SNARE regulators, Munc 18 and Munc 13 (Ren et al., 2010; Schraw et al., 2003). Members of the Ras subfamily of GTPases, Rab 27a and Rab27b have also been shown to be important for dense granule secretion (Tolmachova et al., 2007). A number of common signaling pathways have been shown to promote platelet secretion. Among these, PKC isoforms have been shown to play a major role in regulating platelet secretion and the mechanism may involve phosphorylation of SNARE protein family members (Chung et al., 2000; Harper and Poole, 2010; Polgar et al., 2003).

D. $\underline{\text { Akt }}$

\section{Structure and Function}

Akt, also known as Protein Kinase $B$, is a $57 \mathrm{kDa}$ serine/threonine kinase. Akt isoforms share kinase domain homology to Protein Kinases A, G, and $\mathrm{C}$, and therefore, are members of the AGC superfamily. Akt was first identified from the viral oncogene v-akt (Staal, 1987). There are three isoforms of Akt in mammalian cells: Akt1 $(\mathrm{PKB} \alpha)$, Akt2 $(\mathrm{PKB} \beta)$ and Akt3 (PKB $\gamma)$, encoded by 3 
separate genes. Akt consists of a $\mathrm{N}$-terminal $\mathrm{PH}$ domain, a central catalytic domain, and a C-terminal regulatory domain. The $\mathrm{PH}$ domain interacts with the membrane lipid products of PI3K, phosphatidylinositol $(3,4,5)$ trisphosphate (PIP3). The PH domain and catalytic domain are linked by a short-glycine rich region. The kinase catalytic domain shares a high degree of homology with other AGC kinases. The catalytic domain also contains a conserved threonine residue (Thr 308), which is phosphorylated to partially activate Akt. The regulatory domain contains a hydrophobic motif that is characteristic of the AGC family of kinases. Phosphorylation of Serine 473 in this region is required for full activation of Akt. Although the positions of Thr308 and Ser473 vary slightly among the Akt isoforms, the sequences surrounding these sites are conserved. Akt isoforms are approximately $80 \%$ homologous in their amino acid sequences. Interestingly, Akt isoforms cannot be distinguished by their substrate specificity in vitro (Walker et al., 1998).

\section{Regulatory mechanisms of Akt}

Akt is the downstream effector of PI3K (Figure 3). PI3K is a family of lipid kinases that are activated downstream from $G$ protein-coupled receptors, receptor tyrosine kinases and adhesion receptors (Hawkins et al., 2006). Activated PI3K generates lipid second messengers by phosphorylating the 3' position of phosphoinositides, resulting in $\operatorname{Ptdlns}(3,4) \mathrm{P}_{2}$ and $\operatorname{Ptdlns}(3,4,5) \mathrm{P}_{3}$. Ptdlns $(3,4) \mathrm{P}_{2}$ and Ptdlns $(3,4,5) \mathrm{P}_{3}$ interact with Akt and phosphatidylinositol 
Dependent Kinase-1 (PDK1) via their PH domains (For reviews please see (Bhaskar and Hay, 2007; Kandel and Hay, 1999; Manning and Cantley, 2007; Song et al., 2005). Both Akt and PDK1 are thus recruited to the same site on the membrane where Thr308 of Akt is phosphorylated by PDK1 (Alessi et al., 1997). Ser473 of Akt is phosphorylated by mTORC2, mammalian target of rapamycin 2 complex (Sarbassov et al., 2004). mTORC2 consists of mTOR, mLST8, Rictor, and SIN1 proteins (Jacinto et al., 2004). Akt may also be indirectly regulated by the lipid phosphatase PTEN that dephosphorylates and depletes Ptdlns $(3,4,5) \mathrm{P}_{3}$ (Stambolic et al., 1998), or by PHLPP, a PH domain leucine-rich repeat phosphatase, that dephosphorylates Ser473 of Akt (Gao et al., 2005). It was reported that the Rab5 effector Appl1 can regulate Akt activity and substrate specificity (Schenck et al., 2008). Once fully activated by phosphorylation at Thr308 and Ser473, Akt catalyzes phosphorylation on serine and threonine residues of a variety of substrates. The recognition motif of Akt substrates consists of R-X-R-X-X-S/T-B, where $\mathrm{X}$ stands for any amino acid and $\mathrm{B}$ represents bulky hydrophobic residues (Manning and Cantley, 2007). However, not all verified Akt substrates contain such a motif (example: eNOS); therefore, it is possible that there are unknown sequence contexts or molecular interactions that allow for Akt substrate preference. More than 100 substrates have been identified in the literature and perhaps many more remain undiscovered (Manning and Cantley, 2007) 


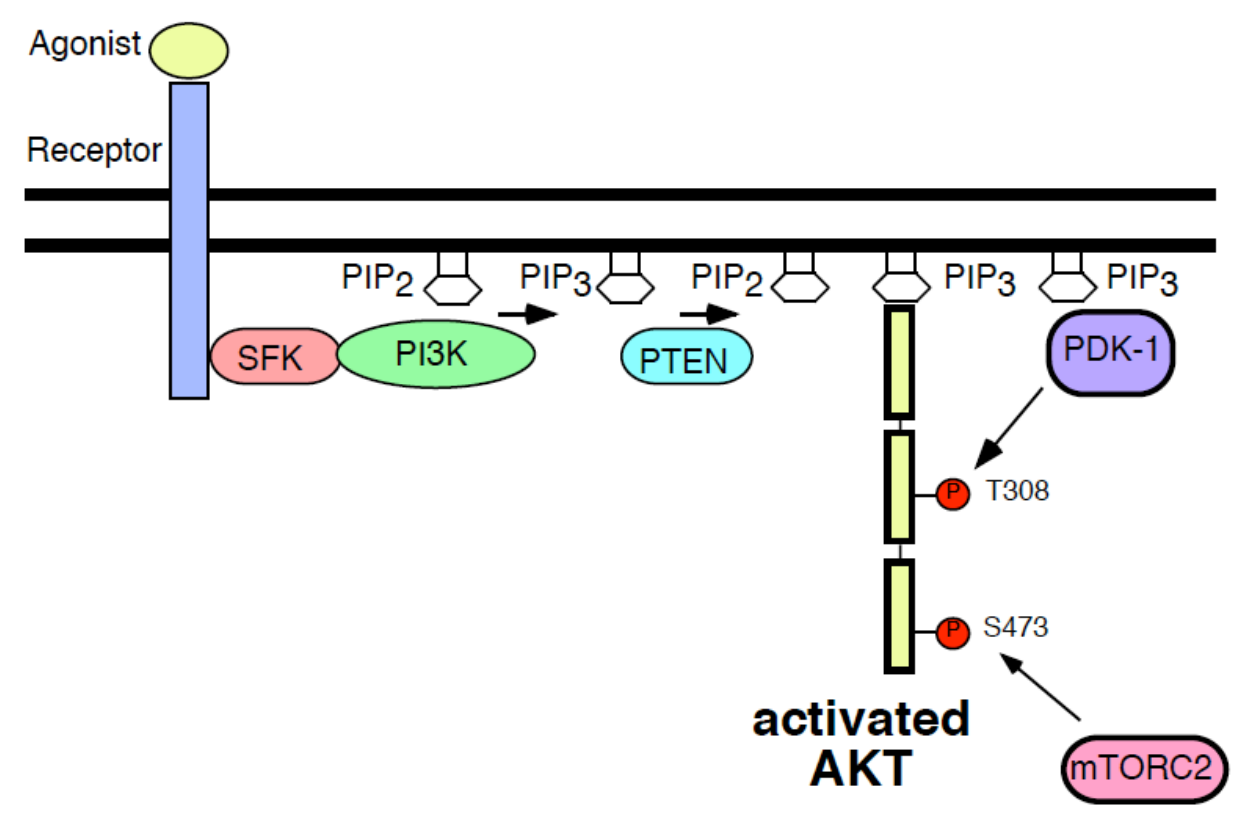

Figure 3. Regulatory mechanisms of Akt activation 


\section{Akt isoforms and specificity}

A large extent of knowledge regarding individual Akt isoforms has been gained by the study of knockout mouse models and the expression profiles of the various isoforms. The expression of Akt isoforms differs among tissues. Akt1 is ubiquitously expressed and the predominant isoform in most tissues (Konishi et al., 1995). Akt2 is predominantly expressed in insulin-responsive tissues (Altomare et al., 1998). Akt3 is predominant in the brain and testes (Masure et al., 1999). The phenotypes of individual Akt isoform knockout mouse models are also distinct. Akt1 deficient mice experience growth retardation and increased apoptosis in thymus and testes (Chen et al., 2001). Akt2 deficient mice suffer from severe diabetes, emphasizing the importance for Akt2 in glucose metabolism (Garofalo et al., 2003). Akt3 knockout mice show a $20 \%$ decrease in brain size (Easton et al., 2005). Akt1 and Akt2 double knockout mice die immediately after birth (Peng et al., 2003). Akt2 and Akt3 double knockout are viable and exhibit combined phenotypes of individual knockouts (Dummler et al., 2006). Akt1 and Akt3 double knockout is embryonic lethal (Tschopp et al., 2005). Surprisingly, mice containing a single allele of only Akt1 $\left(\mathrm{Akt}^{+/-} \mathrm{Akt2}^{-/-} \mathrm{Akt} 3^{-/-}\right.$ knockout) are viable, although their body size is approximately $50 \%$ smaller than wild type and Akt triple knockout is lethal (Dummler et al., 2006). The fact that different Akt isoforms have differential tissue expression implies Akt isoforms possess some unique functions. The distinct phenotypes of Akt knockout mouse models also imply that Akt isoforms possess some non-redundant functions. 
Growing evidence regarding contrasting roles of Akt isoforms is accumulating. For example, it has been reported that Akt1 and Akt2 play opposing roles in the regulation of cell migration in breast epithelial cells, and that Akt1 and Akt2 have distinct functions in the regulation of GLUT4 translocation and 2-deoxyglucose uptake in 3T3-L1 adipocytes and Chinese hamster ovary cells (Irie et al., 2005; Katome et al., 2003). It was recently reported that Akt2 plays a predominant role in regulating neutrophil functions such as migration, granule enzyme release, and superoxide production (Chen et al.). Interestingly as previously noted, Akt isoforms are approximately $80 \%$ homologous in amino acid sequence and no differences in substrate specificity are distinguishable in vitro, thus the mechanism by which Akt isoforms exert their substrate specificity remains unknown at this time. Detailed studies comparing Akt isoforms and the utilization of Akt isoform specific knockout mice will hopefully aid future understanding of the specificity and unique signaling mechanisms of Akt1, Akt2, and Akt3.

\section{Akt signaling in disease}

Akt has been implicated in a number of critical cellular processes including growth, survival, proliferation, and metabolism. Dysregulation of Akt signaling has been associated with a number of human diseases including cancer, diabetes, cardiovascular, and neurological diseases. The Akt signaling pathway is constitutively activated in many types of cancer. Mechanisms that cause enhanced Akt activation in cancer include dysregulation of the Akt 
suppressor PTEN, amplification or overexpression of $\mathrm{PI} 3 \mathrm{~K}$ or Akt, and constitutive activation of receptors activating Akt signaling (Bhaskar and Hay, 2007; LoPiccolo et al., 2008). As a result, several inhibitors targeting the Akt pathway are being investigated for use in cancer treatment (LoPiccolo et al., 2008). It was reported that diabetes in one human family is due to a loss of function mutation in Akt2 (George et al., 2004). Akt is associated with glucose homeostasis because it stimulates translocation of GLUT4 glucose transporter (Kohn et al., 1996), and is a mediator of insulin signaling (Jiang et al., 2003). Akt is implicated in vascular disease because Akt regulates endothelial cells, smooth muscle cells, and cardiac myocytes (Shiojima and Walsh, 2002; Shiojima and Walsh, 2006). In endothelial cells, Akt stimulates NO release and vasodilation (Dimmeler et al., 1999), and Akt promotes angiogenesis (Chen et al., 2005). Akt is implicated in neurological diseases, because Akt is a suppressor of neuronal cell death (Datta et al., 1997; Dudek et al., 1997). Interestingly, the mechanism of action of lithium, a widely prescribed drug for treatment of Alzheimer's, schizophrenia, and depression, is to inhibit the activity of Akt substrate GSK-3 $\beta$ (Eldar-Finkelman, 2002). In conclusion, Akt is an attractive therapeutic target for the treatment of a number of diseases because of its importance in many pathways. On the other hand, widespread inhibition of Akt may cause toxicity. Research demonstrating isoform-specific roles of Akt may facilitate the development of isoform- specific inhibitors with less toxic side effects. 
5. Akt and platelet activation

PI3K is activated downstream of nearly all platelet GPCRs and adhesion receptors and therefore, is a common mediator of signaling during platelet activation. PI3K is required for Akt activation, and platelets have been shown to express members of class la PI3Ks (PI3K $\alpha$ and PI3K $\beta)$, class Ib $(\mathrm{PI} 3 \mathrm{~K} \gamma)$ and class II (PI3KC2 $\alpha$ ) (Rittenhouse, 1996). Studies using PI3K isoform-selective inhibitors as well as genetically modified mice have shed light on the involvement of PI3K isoforms in platelet signaling pathways and Akt activation. Mice deficient in $\mathrm{PI} 3 \mathrm{~K} \gamma$ have defective aggregation and Akt phosphorylation in response to ADP and low concentrations of TXA 2 analogue U46619, (Hirsch et al., 2001; Li et al., 2003b). Studies utilizing PI3K $\beta$ selective inhibitors or PI3K $\beta$ kinase dead mutant mouse platelets, suggested that $\mathrm{PI} 3 \mathrm{~K} \beta$ is important in Akt phosphorylation induced by collagen, and several GPCR agonists (Canobbio et al., 2009; Gratacap et al., 2011; Jackson et al., 2005; Kim et al., 2009). PI3K $\beta$ kinase dead mutant mouse platelets also had defective platelet aggregation in response to nearly all platelet agonists, as well as defective adhesion and spreading on fibrinogen (Canobbio et al., 2009). Treatment of platelets with PI3K $\alpha$ inhibitors or in platelets from $\mathrm{p} 85 \alpha^{-1-}$, resulted in defective collagen induced Akt phosphorylation, aggregation, secretion and thrombus formation (Gilio et al., 2009). The role of class II PI3KC2 $\alpha$ has not been thoroughly investigated in platelets. Studies from our lab have indicated PI3Ks play an important role in 
stimulating platelet granule secretion (Li et al., 2003b; Stojanovic et al., 2006; Yin et al., 2008b). Many questions remain about the precise mechanism by which PI3Ks become activated upon platelet stimulation. It has been shown that PI3Ks is directly associated with GPIb (Munday et al., 2000). In the case of ADP/Gi stimulation, PI3K is activated by G $\beta \gamma$ subunits (Stephens et al., 1997). Several studies have also implicated SFKs, particularly Lyn, in stimulating PI3K dependent activation of Akt in platelets stimulated with thrombin, collagen, and VWF (Cho et al., 2002; Li et al., 2010b; Liu et al., 2005; Yin et al., 2008a). One potential mechanism for the role of SFK in PI3K activation has been proposed in lymphocytes where the SH3 domain of SFKs binds the p85 subunit of PI3Ks and increases PI3K activation (Pleiman et al., 1994). Thus, SFK-PI3K interaction is likely a general mechanism for PI3K-Akt activation in platelets.

Because of the importance of PI3K in platelet activation and signaling, it has prompted many groups to assess the role of Akt in platelets (For review, please see (Woulfe, 2010)). There are three isoforms of Akt, but only Akt1 and Akt2 have been detected in platelets. It has been demonstrated by RT-PCR and Western blot analysis that Akt1 and Akt2 mRNA transcripts and proteins are present in human platelets, however Akt3 has not been detected (Kroner et al., 2000). Akt1 and Akt2 proteins have also been shown to be expressed in mouse platelets (Chen et al., 2004; Woulfe et al., 2004). Important roles for Akt in stimulating platelet activation has been shown through the use of gene deletion studies of Akt1 and Akt2 in mice, and also pan Akt inhibitors in human platelets. 
It has been shown that Akt1 and Akt2 are functionally important in stimulating platelet activation. Akt $1^{-/-}$mouse platelets revealed impaired platelet aggregation to thrombin, collagen, and TXA 2 analog, U46619 (Chen et al., 2004; Stojanovic et al., 2006). In addition, Akt ${ }^{-1-}$ platelets showed decreased ATP secretion in response to similar agonists (Chen et al., 2004; Stojanovic et al., 2006). Genetic deletion of Akt1 also resulted in significantly longer tail bleeding times than wild type mice, suggesting an important role for Akt1 in platelet function (Chen et al., 2004). Platelet rich plasma from $\mathrm{Akt2}^{-/}$mice also showed significant defects in platelet aggregation in response to PAR4 agonist and U46619 (Woulfe et al., 2004). It is also notable that $A k t 2^{-/-}$mice demonstrated defective in vivo thrombus formation using the ferric chloride injury model (Woulfe et al., 2004). Akt1 and Akt2 are also both required for VWF mediated platelet aggregation, stable adhesion under flow, and platelet spreading on VWF (Yin et al., 2008b). Because of the partial defect in platelet functions in $\mathrm{Akt}^{1--}$ or $\mathrm{Akt}^{-{ }^{--}}$mouse platelets, it remains unknown whether both are required for platelet activation or if there are compensatory roles for Akt isoforms in platelets. In the current study, we have detected Akt3 expression in human and mouse platelets, and demonstrate that Akt3 also plays an important role in platelet activation and thrombosis.

Although important roles for Akt1 and Akt2 in platelets have been demonstrated, studies directly comparing the roles of Akt1 and Akt2 in platelet function have not been performed. Thus, it remains unknown whether Akt1 and Akt2 have distinct or compensatory roles in regulating platelet signaling 
pathways. Although there are many reported Akt substrates in the literature, only a few have been shown to be expressed in platelets. Furthermore, there is a limited amount of information about the roles of Akt substrates in regulating platelet function. However, two major Akt substrates have been recently shown to play important roles in platelet activation. These are endothelial nitric oxide synthase (eNOS) and Glycogen Synthase Kinase-3 $\beta$ (GSK-3 $\beta)$.

eNOS is activated by phosphorylation at Ser1177 by Akt, and upon activation, eNOS synthesizes nitric oxide (NO) (Dimmeler et al., 1999). NO stimulates soluble guanylyl cyclase (sGC) and induces cyclic guanosine monophosphate (cGMP) elevation and activation of cGMP-dependent protein kinase (PKG). The NO-cGMP-PKG pathway is also important for the sequential activation of the MAPKs, p38 and extracellular signal-regulated kinase (ERK) (Li et al., 2001; Li et al., 2006). MAPKs are important in thromboxane production, platelet granule secretion, and activation of integrin (Garcia et al., 2005; Li et al., 2001; Li et al., 2006). In platelets, NO production and cGMP elevation plays an important role in PKG dependent platelet granule secretion and the second wave of platelet aggregation ( $\mathrm{Li}$ et al., 2003a; Li et al., 2004; Marjanovic et al., 2005; Marjanovic et al., 2008; Zhang et al., 2011a). The role of NO and cGMP in platelet activation is biphasic: stimulatory at low concentrations of NO and cGMP synthesized following agonist stimulation, and inhibitory when platelets are exposed to high concentrations of cGMP ( $\mathrm{Li}$ et al., 2003a; Li et al., 2004; Marjanovic et al., 2005; Marjanovic et al., 2008; Zhang et al., 2011a). Previous 
studies from our laboratory have demonstrated that Akt $1^{-/-}$mouse or Akt inhibitortreated platelets have reduced NO production and cGMP elevation (Stojanovic et al., 2006). Akt1 $1^{-/}$mouse, Akt inhibitor, or PI3K inhibitor treated platelets also showed reduced platelet secretion and aggregation in response to low concentrations of agonist, which could be reversed by low concentrations of 8bromo-cGMP or NO donor (Stojanovic et al., 2006). Thus, PI3K-mediated Akt activation plays an important role in agonist stimulated platelet NO synthesis and cGMP elevation (Figure 4). We have also recently shown that Akt1 and Akt2 both play important roles in early GPIb-IX signaling leading to platelet activation and that a major mechanism for the role of Akt is mediated by the cGMP-PKG signaling pathway (Yin et al., 2008b).

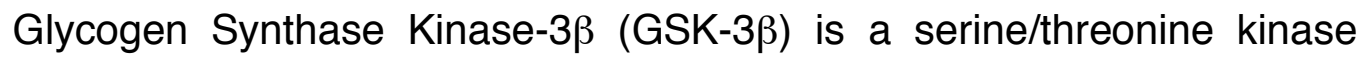
that catalyzes the phosphorylation of a variety of substrates. Some of the key molecules mediating GSK-3 $\beta$ function include glycogen synthase, tau protein, and beta catenin (Embi et al., 1980; Ishiguro et al., 1993; Rubinfeld et al., 1996). GSK-3 $\beta$ plays important roles in many cellular processes including regulation of glycogen synthesis, the canonical Wnt pathway, and microtubule dynamics (Forde and Dale, 2007). GSK-3 $\beta$ is phosphorylated by Akt at its Ser9 residue, which is known to inhibit its activity (Cross et al., 1995). In platelets, one group reported that GSK-3 $\beta$ plays a stimulatory role in platelet aggregation induced by collagen through the use of multiple inhibitors of GSK-3 (Barry et al., 2003). PI3K inhibitors also abrogated GSK-3 $\beta$ phosphorylation, indicating that GSK-3 $\beta$ 
inhibition is dependent on PI3K/Akt pathway (Barry et al., 2003). More recently, GSK-3 $\beta$ was described as an important negative regulator of platelet function (Li et al., 2008). Li, et al reported that haplo-insufficiency of GSK-3 $\beta$ in mice results in enhanced platelet aggregation and secretion in PAR4 agonist peptide stimulated platelets (Li et al., 2008). Human platelets treated with GSK inhibitors and stimulated with PAR1 agonist peptide showed similar enhancement of platelet aggregation ( $\mathrm{Li}$ et al., 2008). Phosphorylation of GSK-3 $\beta$ was also reduced in platelets from $\mathrm{Akt}^{++-} \mathrm{Akt2}{ }^{--}$mice, indicating Akt1/2 are important for inhibition of GSK-3 $\beta$ ( $\mathrm{Li}$ et al., 2008). The mechanism by which GSK-3 $\beta$ negatively regulates platelet activation is unknown at this time. One group recently suggested that GSK-3 $\beta$ may play a role in Wnt signaling in platelets (Steele et al., 2009); however, further studies are needed to investigate the mechanism of GSK-3 $\beta$ in this pathway. In the current study, we have identified GSK-3 $\beta$ as a downstream effector of Akt3-mediated thrombin-induced platelet aggregation and integrin outside-in signaling. 


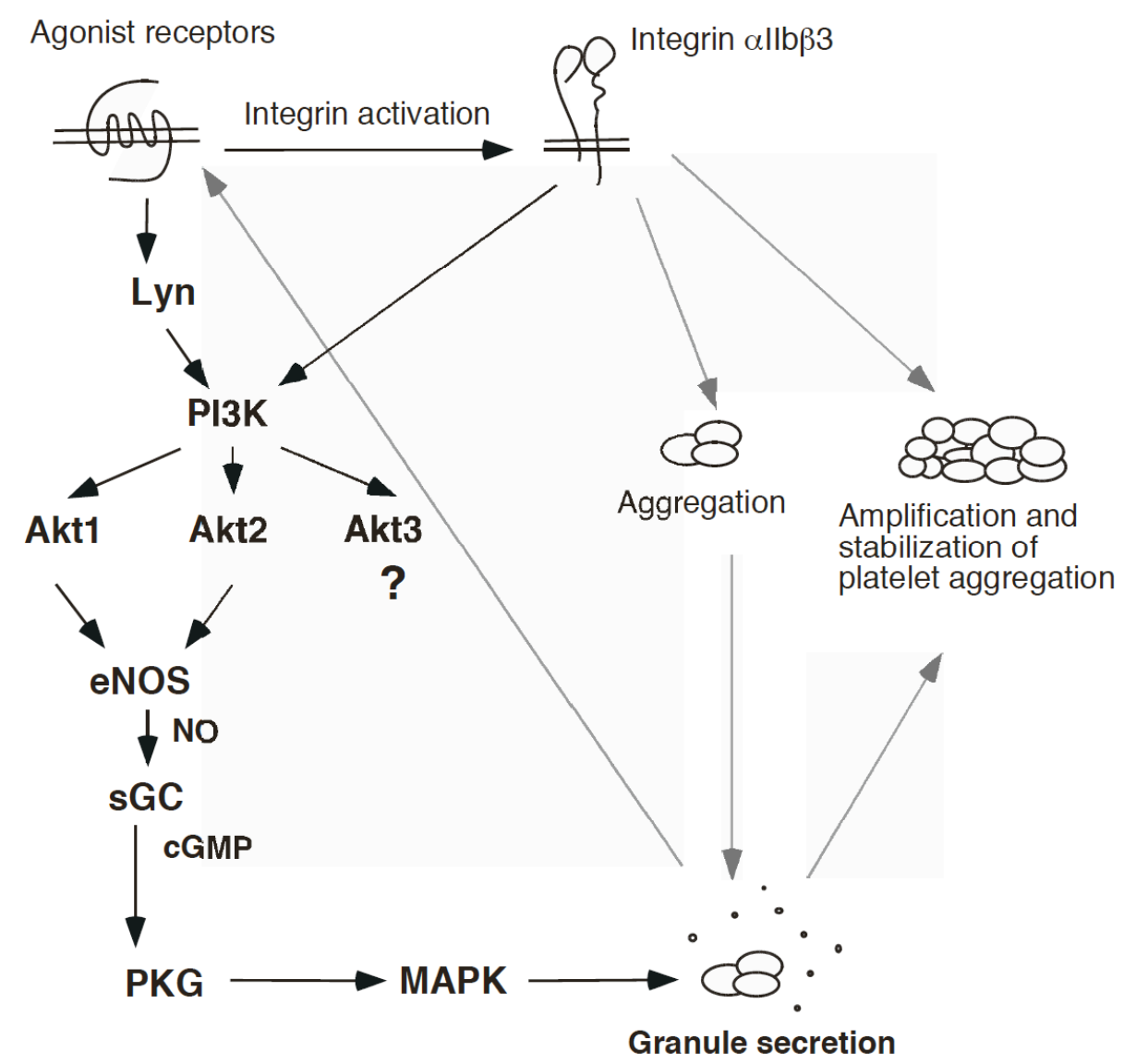

Figure 4. The role of Akt isoforms in platelet activation 


\section{PURPOSE OF STUDY}

Understanding the mechanisms regulating platelet activation is critically important for the development of novel therapeutics for the prevention and treatment of thrombosis. PI3Ks have been shown to be common and key mediators of platelet activation in all platelet signaling pathways. Akt is among the most well known effectors of PI3Ks. Akt has three isoforms: Akt1, Akt2, and Akt3. Previous studies have demonstrated important roles of Akt1 and Akt2 isoforms in amplifying platelet activation. However, Akt3 has not previously been detected in platelets. The first aim of this study is to determine if Akt3 is expressed in platelets and contributes to PI3K-mediated platelet activation. We show for the first time that Akt3 is expressed in human and mouse platelets. Furthermore, we determined that Akt3 has a novel role in stimulating platelet activation and identified GSK-3 $\beta$ as one effector mediating Akt3 signaling.

PI3Ks play a critical role in integrin outside-in signaling and platelet spreading; however, the mechanisms of PI3K activation and function in outside-in signaling are unclear. The second aim of this study is to determine if different isoforms of Akt play a role downstream from PI3K in regulating integrin outside-in signaling and platelet spreading. We determined that Akt promotes PI3K dependent integrin outside-in signaling and platelet spreading and that the role of $\mathrm{PI} 3 \mathrm{~K}$ and Akt (particularly Akt3) in platelet spreading is at least partially mediated by inhibition of GSK-3 $\beta$. We demonstrate that integrin-dependent activation of the PI3K-Akt pathway requires SFK. In addition, integrin-dependent activation of the 
PI3K-Akt pathway is promoted by ADP secretion signaling through P2Y1 and P2Y12 ADP receptors during spreading. Thus, we characterized an integrin outside-in signaling pathway involving SFK-dependent and P2Y12/P2Y1facilitated activation of the PI3K-Akt pathway, which inhibits GSK-3 $\beta$ and promotes platelet spreading.

Taken together, our results reveal novel roles of Akt isoforms, particularly Akt3, in signaling pathways of various aspects of platelet function. Further investigation of the PI3K/Akt signaling pathway in platelet activation may aid in the development of new anti-thrombotic therapeutics in the prevention and treatment of diseases such as heart attack and stroke. 


\section{METHODS}

\section{A. Materials}

Thromboxane $\mathrm{A}_{2}$ analog U46619, Src Family Kinase Inhibitor PP2, Akt inhibitors SH-6 and AktX, PI3K inhibitors LY294002 and wortmannin, Syk inhibitor piceatannol were purchased from Calbiochem. P2Y12 antagonist 2MeSAMP (2-methylthioadenosine 5'-monophosphate triethylammonium salt), P2Y1 antagonist A3P5P (adenosine-3'-phosphate-5'phosphate) and GSK-3 $\beta$ inhibitor SB216763 were purchased from Sigma. $\alpha$-Thrombin and fibrinogen were purchased from Enzyme Research Laboratories. Collagen and luciferase were purchased from Chronolog. Enliten luciferase was purchased from Promega.

\section{B. Animals}

The generation of Akt1 (Chen et al., 2001), Akt2 (Garofalo et al., 2003), Akt3 (Easton et al., 2005), and P2Y12 ${ }^{-/}$(Foster et al., 2001) were previously described. Mice used in this study were 8-15 week-old on C57BL/6 background. Animal usage and protocol was approved by the institutional animal care committee of the University of Illinois at Chicago.

\section{Preparation of platelets}

For studies using human platelets, fresh blood was drawn by venipuncture from healthy volunteers and anti-coagulated with 1-seventh volume of acid-citrate dextrose (ACD) as previously described (Li et al., 2003b). Institutional Review 
Board approval was obtained from the University of Illinois at Chicago, and informed consent was provided according to the Declaration of Helsinki. For the preparation of mouse platelets, fresh blood was drawn from mouse inferior vena cava and anti-coagulated with ACD as previously described (Marjanovic et al., 2005). Blood from 5 to 6 mice of same genotype was pooled and platelets were isolated by differential centrifugation of whole blood with $0.1 \mu \mathrm{g} / \mathrm{mL}$ prostaglandin $\mathrm{E}_{1}$ and $1 \mathrm{U} / \mathrm{mL}$ apyrase (Sigma-Aldrich, St. Louis, MO). Platelets were washed twice with CGS buffer (sodium chloride $0.12 \mathrm{M}$, trisodium citrate $0.0129 \mathrm{M}$, Dglucose $0.03 \mathrm{M}, \mathrm{pH}$ 6.5), resuspended in modified Tyrode's buffer and allowed to rest for at least 1 hour at room temperature before use (Du et al., 1991). For some experiments, platelets were washed and resuspended according to Liu et al (Liu et al., 2005).

\section{RT-PCR from platelet cDNA}

RNA was isolated from human, $\mathrm{Akt}^{+/+}$or $\mathrm{Akt} 3^{-/-}$mouse platelets $\left(3 \times 10^{8}\right)$ using Trizol Reagent (Invitrogen, Carlsbad, CA). Total RNA was reverse transcribed using Thermoscript RT-PCR kit (Invitrogen). Akt3 cDNA was amplified over 35 cycles with a forward 5'ATG AAT TGT AGC CCA GCC TCA CAG ATT3' and reverse 5'CAT GCC GTC GTC GTC ATA CTT TTC3' primer for mouse Akt3; and with a forward 5'GAT GCC TCT ACA ACC CAT CAT3' and reverse 5'GTC CAT GCA GTC CAT ACC ATC CT3' for human Akt3. PCR products were separated on a $1 \%$ agarose gel containing ethidium bromide and 
visualized under UV lamp. Control PCR reaction was performed using the same cDNA preparations using primers specific for GAPDH. To exclude the possibility of contamination from leukocytes, RNA template was isolated from washed leukocytes and RT-PCR was performed using identical primers and PCR conditions as described for platelets. Isolation of leukocytes was performed as previously described (Ulmer and Flad, 1979).

\section{E. Immunoabsorption}

Washed human platelets $\left(1 \times 10^{9} / \mathrm{mL}\right)$ resuspended in Tyrode's buffer were solubilized with an equal amount of solubilization buffer $1 \%$ Triton X-100, 150 $\mathrm{mM} \mathrm{NaCl}$, 50mM Tris, containing $10 \mathrm{mM}$ EGTA, $0.2 \mathrm{mM}$ E64, $1 \mathrm{mM}$ phenylmethylsulfonyl fluoride, and $1 \mathrm{unit} / \mathrm{ml}$ aprotinin and incubated on ice for 20 min. After centrifugation at $13,000 \mathrm{~g}$ for $20 \mathrm{~min}$ at $4^{\circ} \mathrm{C}$, the lysates $(300 \mu \mathrm{l})$ were preincubated with anti-Akt3 antibody or control IgG overnight. After incubation for 1 hour with Protein A/G conjugated Sepharose beads (Santa Cruz), beads were separated from the lysates by centrifugation. This procedure was repeated once, and then the immunoabsorbed platelet lysates were analyzed by SDS-PAGE and immunoblotted with an anti-Akt3 and anti-total Akt antibody. Experiment was repeated 4 times. Quantitation was performed using NIH Image $\mathrm{J}$ and paired ttest was used for statistical analysis.

\section{F. Immunoblot detection}


Washed mouse platelets $\left(3 \times 10^{8} / \mathrm{mL}\right)$ were incubated with or without agonist in a platelet aggregometer at $37^{\circ} \mathrm{C}$ with stirring for various lengths of time. The reaction was stopped by addition of equal volume of sample buffer containing $2 \%$ SDS, $0.1 \mathrm{M}$ Tris, $2 \%$ glycerol, $2 \mathrm{mM}$ PMSF, $2 \mathrm{mM} \mathrm{Na}_{3} \mathrm{VO}_{4}, 2 \mathrm{mM} \mathrm{NaF}$, and Complete Protease Inhibitor Cocktail (Roche Molecular Biochemicals, Indianapolis, IN). For spreading experiment, washed human or mouse platelets $\left(3 \times 10^{8} / \mathrm{mL}\right)$ were allowed to spread on fibrinogen coated polystyrene dishes (100 $\mu \mathrm{g} / \mathrm{mL}$ in $0.1 \mathrm{M} \mathrm{NaHCO}$, $\mathrm{pH} 8.3$ overnight at room temperature) for various lengths of time. Non-adherent platelets were aspirated and the reaction was stopped by addition of sample buffer noted previously. Proteins were separated by sodium dodecyl sulfate polyacrylamide gel electrophoresis (SDS-PAGE) on a $4-15 \%$ polyacrylamide gel and then transferred to polyvinylidene difluoride membranes. The membranes were immunoblotted with an anti-Akt3 rabbit monoclonal antibody, anti-GSK-3 $\beta$, anti-phospho-GSK-3 $\beta$, anti-phospho-Akt Thr308, anti-phospho-Akt Ser473, anti-Akt1, anti-Akt2, anti p-Syk (Cell Signaling Technology, Beverly, MA), and total Akt (recognizing Akt1, Akt2 and Akt3)(Santa Cruz Biotechnology, Inc).

\section{G. Platelet aggregation and secretion}

Platelet aggregation and secretion was measured in a turbidometric platelet aggregometer (Chronolog, Havertown, PA) at $37^{\circ} \mathrm{C}$ with stirring (1000 rpm). Washed platelets $\left(3 \times 10^{8} / \mathrm{mL}\right)$ in modified Tyrode's buffer were stimulated with 
thrombin (Enzyme Research Laboratories, South Bend, IN), collagen (Chronolog), U46619 (Calbiochem, La Jolla, CA), and vWF and botrocetin (kindly provided by Dr. Michael C. Berndt). Experiments were repeated at least three times. Platelet secretion was monitored in parallel with platelet aggregation as ATP release in a platelet lumiaggregometer (Chronolog) with the addition of luciferin/luciferase reagent (Chronolog) to the platelet suspension. Quantitation was performed using the ATP standard. To test the effects of GSK-3b inhibitor SB216763 (Sigma), SB216763 or dimethylsulfoxide (DMSO) was pre-incubated with platelets at $37^{\circ} \mathrm{C}$ for 2 minutes before addition of agonist. Aspirin (Sigma) was dissolved as $40 \mathrm{mM}$ stock solution in $0.2 \mathrm{M}$ HEPES, $0.15 \mathrm{M} \mathrm{NaCl}, \mathrm{pH} 7.8$ (final $\mathrm{pH}$ 7.2) before added to platelets at $1 \mathrm{mM}$ final concentration.

\section{H. Platelet adhesion under shear stress}

Glass slides were coated with collagen $(50 \mu \mathrm{g} / \mathrm{mL})$ in water with acetic acid added to $\mathrm{pH} 3.0$ overnight. Slides were washed with PBS and blocked with 5\% BSA in PBS for 1 hour and washed again with PBS. Washed mouse platelets $\left(200 \mu \mathrm{L}\right.$ of $\left.3 \times 10^{8} / \mathrm{mL}\right)$ were loaded onto the slides. A cone and plate rheometer (Rheostress 1, Thermo-HAAKE, Paramus, NY) was used to introduce shear stress $\left(800 \mathrm{~s}^{-1}\right)$ to the platelets. Mepacrine (10 $\mu \mathrm{M}$; Sigma), a fluourescent dye was added to the platelets before applying shear stress to the platelets for 5 minutes (Yin et al., 2008b). Slides were rinsed in a container with $200 \mathrm{~mL}$ PBS 3 times to wash out non-stably adherent platelets. Slides were viewed with a Leica 
DMI RB fluorescence microscope (Leica Microsystems) using an N PLAN L lens at $40 \mathrm{x} / 0.55 \mathrm{NA}$ objective with $1.5 \mathrm{X}$ magnification.

\section{In vivo thrombosis}

8-10 week old mice were anesthetized with isoflurane. The right carotid artery was isolated from surrounding tissues (Day et al., 2004; Marjanovic et al., 2005). A MA-0.5SB nanoprobe (Transonic Systems, Ithaca, NY) was hooked to the artery and blood flow was monitored with a TS420 flowmeter (Transonic Systems). After stabilization, $1.2 \mu \mathrm{L}$ of $5 \% \mathrm{FeCl}_{3}$ (Sigma) was applied to a filter paper disc (2 mM diameter) that was placed on top of the artery for 2 minutes. After removing the filter paper, blood flow was monitored continuously until 5 minutes after occlusion. Time to occlusion was calculated as a difference in time between the removal of the filter paper and stable occlusion (no blood flow for 2 minutes). Statistical analysis was performed using the Mann-Whitney test for the evaluation of differences in median occlusion time.

\section{J. Platelet spreading on immobilized fibrinogen}

Microscope cover glasses (Fisher Scientific) were coated with $100 \mu \mathrm{g} / \mathrm{mL}$ fibrinogen (Enzyme Research Laboratories) in $0.1 \mathrm{M} \mathrm{NaHCO}_{3}(\mathrm{pH}$ 8.3) and blocked with $5 \%$ bovine serum albumin (BSA) in phosphate-buffered saline (PBS). Washed mouse platelets $\left(2 \times 10^{7} / \mathrm{mL}\right)$ were allowed to adhere and spread on fibrinogen-coated wells $(300 \mu \mathrm{L} /$ well $)$ at $37^{\circ} \mathrm{C}$ for 2 hours. Washed human 
platelets $\left(1 \times 10^{7} / \mathrm{mL}\right)$ were allowed to adhere and spread on fibrinogen-coated wells $\left(300 \mu \mathrm{L} /\right.$ well) at $37^{\circ} \mathrm{C}$ for 1 hour. Slides were aspirated to remove nonadherent platelets and fixed with $4 \%$ paraformaldehyde, permeabilized, and stained with Alexa Fluor FITC conjugated phalloidin (Invitrogen) as previously described (Flevaris et al., 2009). Adherent platelets were observed with a Leica DM IRB fluorescence microscope (Leica Microsystems) using 100X/1.30 NA oil objective (1.5X magnification factor for mouse platelets, 1.0X for human platelets). Images were acquired using a Cool SNAP HQ CCD camera (Photometrics) and processed with RS Image version 1.4 software (Photometrics) or Micro-Manager version 1.4.

\section{K. Static ATP secretion assay}

Black, 96-well plates were coated with $100 \mu \mathrm{g} / \mathrm{mL}$ fibrinogen or BSA in $0.1 \mathrm{M}$ $\mathrm{NaHCO}_{3}(\mathrm{pH}$ 8.3). Plates were blocked with $\mathrm{BSA}$ and washed human platelets $\left(100 \mu \mathrm{L}\right.$ of $\left.3 \times 10^{8} / \mathrm{mL}\right)$ were added to fibrinogen-coated wells or BSA (control) coated wells at $37^{\circ} \mathrm{C}$ for various time points. ENLITEN luciferase reagent (Promega) was added to wells and luminescence was immediately measured using Wallac Victor2 1420 multilabel counter (Perkin Elmer). 


\section{RESULTS AND DISCUSSION}

\section{A. An important role for Akt3 in platelet activation and thrombosis}

\section{a. Results}

\section{Akt3 is a significant Akt isoform expressed in platelets}

Important roles for Akt1 and Akt2 in platelets have been demonstrated by several groups (Chen et al., 2004; Stojanovic et al., 2006; Woulfe et al., 2004; Woulfe, 2010; Yin et al., 2008b). Akt3 was not detected in platelets in some previous studies (Kroner et al., 2000). However, in our RT-PCR screen, a fragment of Akt3 mRNA was amplified using cDNA from purified platelets and oligonucleotide primers annealing to an Akt3-specific DNA sequence, and appeared to be present in human platelets (Figure 5A) and wild type mouse platelets, but was not detected in $\mathrm{Akt}^{-/-}$mouse platelets (Figure 5B). It is unlikely that the detected Akt3 mRNA was from contaminating leukocytes in the platelet preparation, because Akt3 was not detected when RNA from the same numbers of leukocytes as that contaminating platelet samples was used as a template (Figure 5B). Consistent with the expression of Akt3 mRNA in platelets, we also detected Akt3 protein in human and wild type mouse platelets, but not in $\mathrm{Akt3}^{-/-}$ platelets by western blot with an Akt3-specific monoclonal antibody (Figure 6A). These data indicate that Akt3 is indeed expressed in human and mouse platelets. 

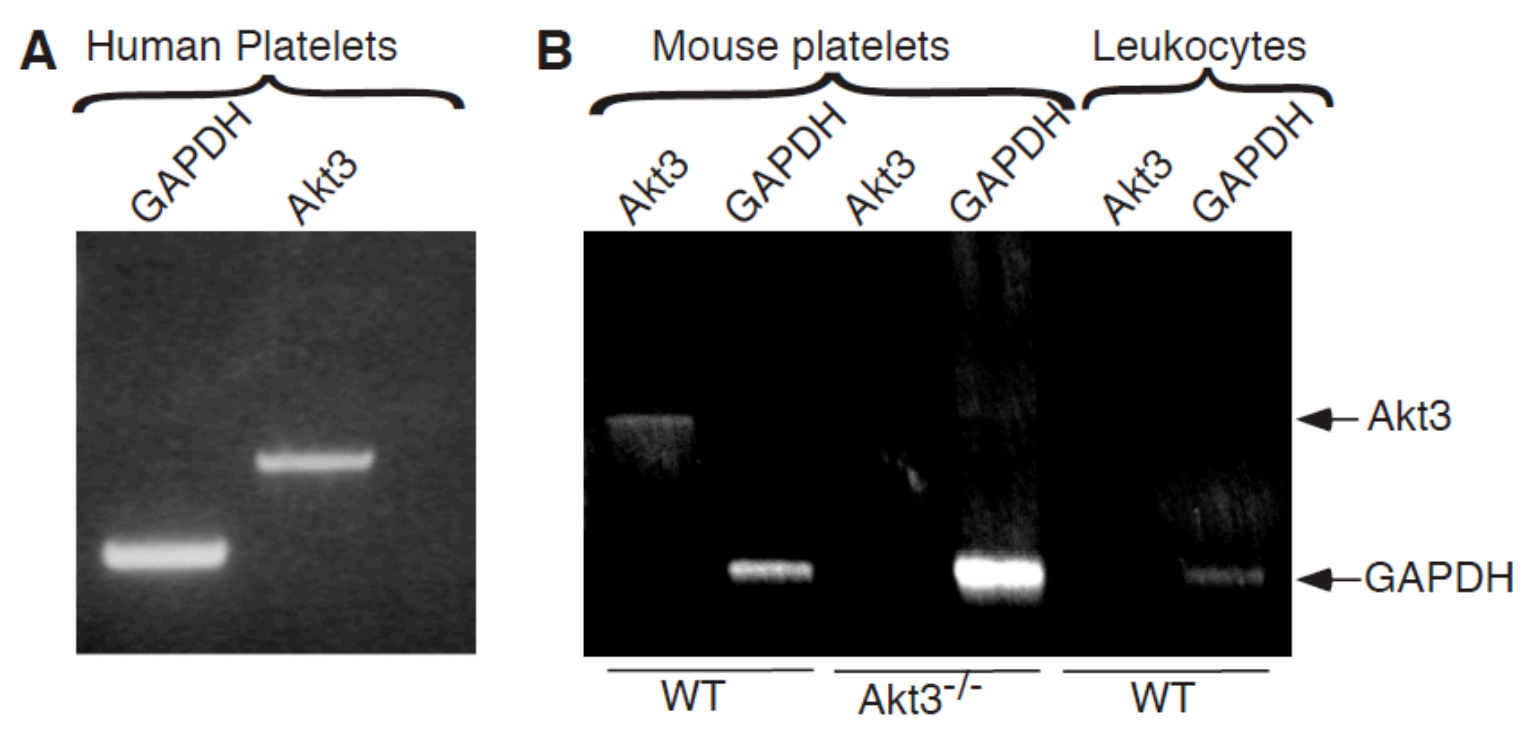

Figure 5. Expression of Akt3 mRNA in platelets. (A) RT-PCR was performed using human platelet RNA and primers specific for Akt3 or a housekeeping gene, GAPDH. (B) RT-PCR was performed similarly with mouse platelet RNA from WT or Akt3-/- platelets. Leukocyte contamination of platelet preparation was $4 \mathrm{x}$ $10^{4} / \mathrm{mL}$ as determined using Hemavet blood cell analyzer. RNA was isolated from $4 \times 10^{4} / \mathrm{mL}$ of WT mouse leukocytes and was also analyzed by RT-PCR using Akt3 specific primers under the same conditions as for platelet preparations to verify that the Akt3 fragment was not from leukocyte contamination. 
A

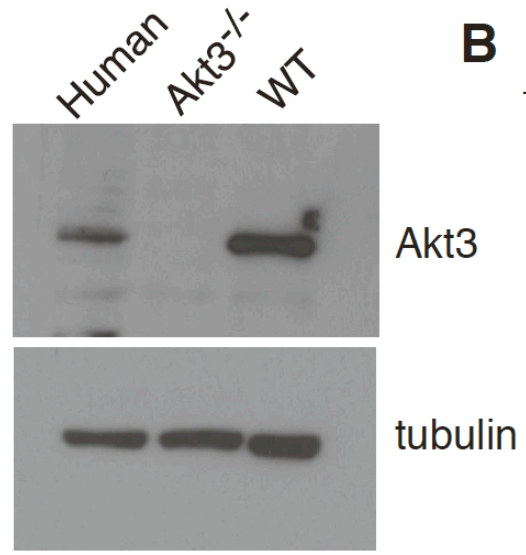

B

Immuno-absorption

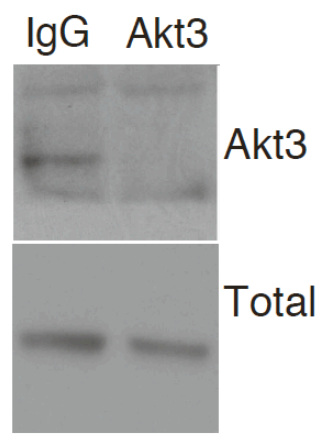

C

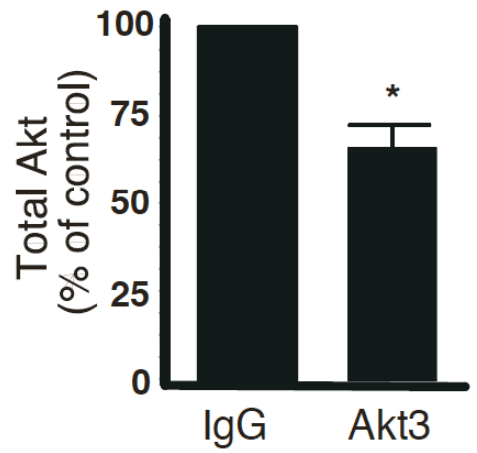

Figure 6. Expression of Akt3 protein in platelets. (A) Human platelets, wild type and $\mathrm{Akt}^{-/-}$mouse platelets were solubilized and immunoblotted with a rabbit antibody specifically recognizing Akt3, and $\alpha$-tubulin is used as loading control.

(B) Human platelets were solubilized, and immunoabsorbed with anti-Akt3 to remove Akt3 from lysates or with control rabbit lgG, and then immunoblotted with anti-Akt3 or an antibody recognizing all Akt isoforms (Total Akt). (C) Experiments in (B) were scanned and quantified using NIH Image $\mathrm{J}$ for uncalibrated optical density (mean \pm SE, 4 experiments). The difference in \% of total Akt between IgG and Akt3 immunoabsorbed lysates is significant $(p<0.0125)$, as determined using paired $t$-test. 
To determine the relative amount of Akt3 expressed in human platelets, washed human platelets were solubilized and the lysates were immunoprecipitated with an anti-Akt3 monoclonal antibody to deplete the Akt3 protein (Figure 6B, 6C). As shown in Figure 6A, this antibody is specific for Akt3 and does not cross react with Akt1 or Akt2, because no reactions were observed in $\mathrm{Akt}^{-/-}$platelets, in which Akt1 and Akt2 are expressed normally. The levels of total Akt (all isoforms) or Akt3 that remained in platelet lysates were then determined by immunoblotting. Immunoabsorption with anti-Akt3 antibody, but not control lgG, depleted Akt3 from platelet lysates (Figure 6B), and resulted in an approximate $35 \%$ reduction in total Akt; therefore, Akt3 constitutes approximately $35 \%$ of total Akt in human platelets (Figure $6 \mathrm{C}$ ). To assess the relative amount of Akt3 present in mouse platelets, total Akt and phosphorylated Akt levels in wild type and $\mathrm{Akt}^{-{ }^{-}}$platelets were measured by Western blot analysis using an antibody that recognizes all three isoforms and antibodies that recognize $\mathrm{Thr}^{308}$ and $\mathrm{Ser}^{473}$ phosphorylation sites of Akt, which are conserved among all Akt isoforms. Compared to wild type platelets, $\mathrm{Akt}^{-{ }^{-/}}$platelets exhibit a $\sim 70 \%$ reduction in total Akt (Figure $7 \mathrm{~A}, 7 \mathrm{C}$ ). In wild type platelets, thrombin stimulates a time-dependent increase in phosphorylated Akt (at $\mathrm{Thr}^{308}$ and $\mathrm{Ser}^{473}$ ), which was also reduced by $\sim 70 \%$ in $\mathrm{Akt3}^{-/}$platelets (Figure 7A, 7B and 7D). To exclude the possibility that Akt3 knockout caused dramatic changes in the expression levels of other Akt isoforms, we also analyzed Akt1 and Akt2 expression levels in wild type and $\mathrm{Akt}^{-/-}$mouse platelets using isoform-specific 
antibodies against Akt1 or Akt2. No significant difference in Akt1 or Akt2 expression was observed in $\mathrm{Akt}^{-/-}$mouse platelets compared to wild type (Figure $7 \mathrm{E})$, indicating that the loss of total Akt protein observed in Akt3-- mouse platelets is not due to loss of Akt1 or Akt2 proteins. Thus, our data indicates that Akt3 is expressed in a significant amount in platelets, and activated by platelet agonists. 

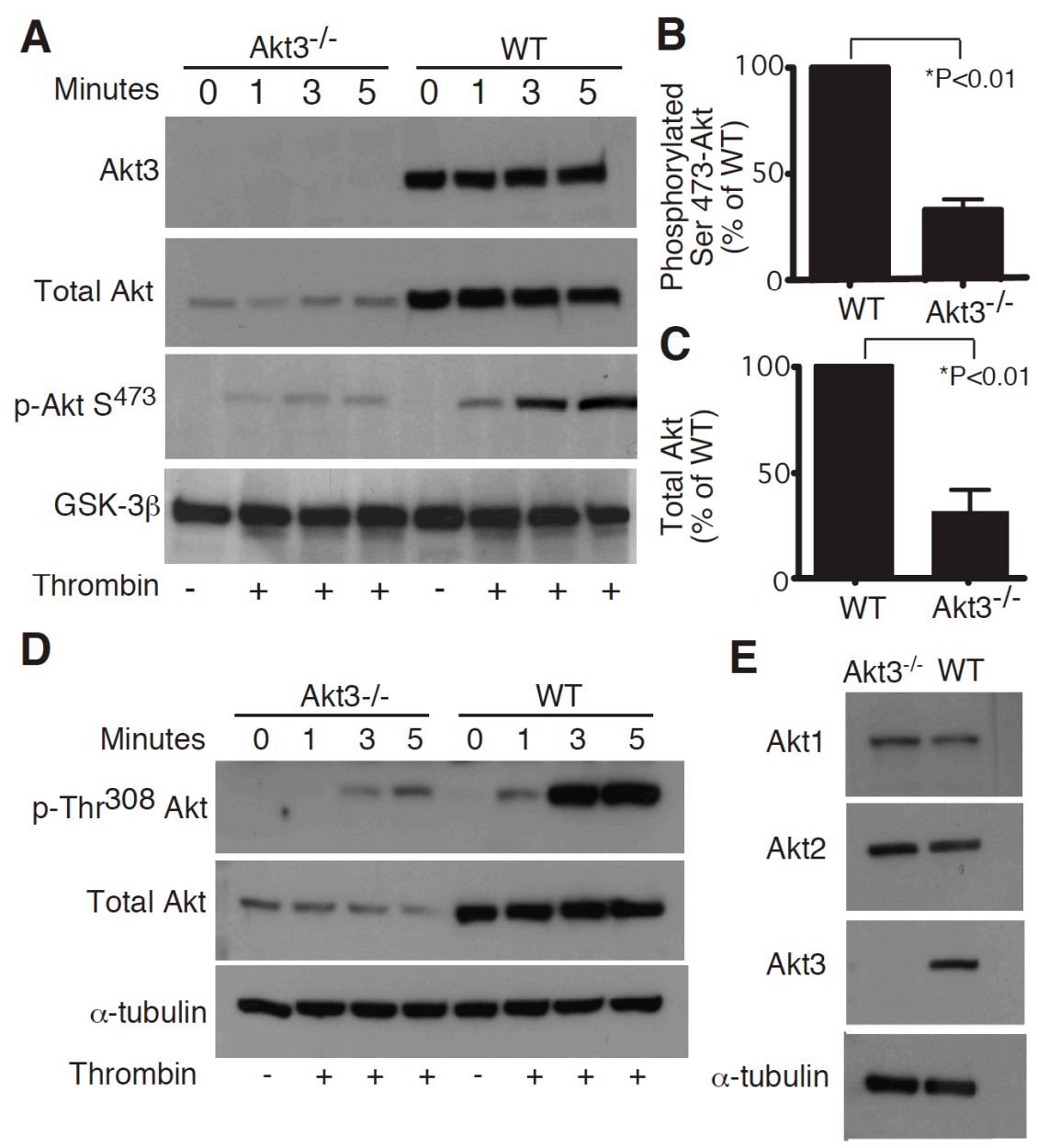

Figure 7. Total and phosphorylated Akt in WT and Akt3 $3^{-/-}$platelets. (A and D) $A k t 3^{-/}$and WT mouse platelets were stimulated with thrombin $(0.018 \mathrm{U} / \mathrm{mL})$ for 1,3 , and 5 minutes, solubilized, and immunoblotted with antibodies directed against: (A) Akt3, total Akt (Akt1, Akt2 and Akt3), phosphorylated Ser ${ }^{473}$ of Akt, and GSK-3 $\beta$ (loading control); and (D) phosphorylated Thr ${ }^{308}$ of Akt, total Akt and $\alpha$-tubulin (loading control). ( $B$ and $C$ ) Western blot results from each of three experiments as shown in $(A)$ were quantitated. The relative quantity of phosphorylated Ser ${ }^{473}$ of Akt at 5 min time point (B) and total Akt (C) in WT and $\mathrm{Akt}^{-/-}$platelets are shown (mean $\pm \mathrm{SE}$ ). (E) Akt $3^{-{ }_{-1}}$ and WT mouse platelets were solubilized and immunoblotted with antibodies directed against Akt1, Akt2, and Akt3 and $\alpha$-tubulin (loading control). 


\section{The role of Akt3 in platelet secretion and aggregation}

$\mathrm{Akt}^{-/-}$mice were used to investigate the role of Akt3 in platelet activation. Akt3 ${ }^{-/-}$mice exhibit no obvious abnormality in major hematological parameters such as blood cell counts and hemoglobin levels. The size and counts of platelets in $\mathrm{Akt}^{-/-}$mice are similar to that of wild type mice. Akt3 ${ }^{-/-}$ platelets showed a partial reduction and reversal in platelet aggregation induced by a low dose of thrombin $(0.02 \mathrm{U} / \mathrm{mL})$ (Figure $8 \mathrm{~A})$, which is characteristic of a defect in platelet granule secretion. Platelet granule secretion is inhibited at this thrombin concentration (Figure 8B). Correspondingly, the defects in aggregation and secretion in Akt3 knockout platelets were also observed at low concentrations of PAR4 agonist peptide $(60 \mu \mathrm{M})$, AYPGKF (Figure 8C, 8D). At higher thrombin concentrations, the defect in platelet aggregation was overcome (Figure 8A). However, the granule secretion in $\mathrm{Akt}^{-/-}$platelets is still reduced compared to wild type platelets, indicating that the primary defect is in granule secretion (Figure 8B). Indeed, supplementing with a low concentration of granule content ADP $(1 \mu \mathrm{M})$, insufficient to induce aggregation on its own, reversed the inhibitory effect of Akt3 deficiency on thrombin-stimulated platelet aggregation (Figure 8E). Thus, Akt3 plays an important stimulatory role in mediating platelet secretion, and the secretion-dependent second wave of platelet aggregation induced by thrombin. $\mathrm{Akt3}^{-/-}$platelets also show a partial decrease in granule secretion induced by $\mathrm{TXA}_{2}$ analog, U46619 (Figure 9A), and a delay in U46619induced platelet aggregation (Figure 9A). However, the defects of $\mathrm{Akt3}^{-/-}$platelets 
in secretion and aggregation induced by thrombin appear to be independent of $\mathrm{TXA}_{2}$ signaling pathway because $\mathrm{Akt}^{-/-}$platelets showed decreased thrombininduced platelet aggregation compared to wild type platelets in the presence of a high concentration of aspirin (Figure 10). Also, at the thrombin concentration in which aspirin reduced aggregation of wild type platelets, $\mathrm{Akt3}^{-/-}$platelet aggregation was further reduced by aspirin (Figure 10). The roles of Akt3 appear additive with that of Akt1/Akt2 because when SH-6, an isoform-nonselective inhibitor, is added to $\mathrm{Akt}^{-{ }^{-}}$platelets, platelet aggregation is further inhibited compared to $\mathrm{Akt3}^{-/-}$platelets alone (Figure 8F). Thus, different isoforms of Akt all play important roles in thrombin- and $\mathrm{TXA}_{2}$-induced platelet granule secretion and the secretion-dependent second wave of platelet aggregation. In fact, the defects of platelet aggregation stimulated with thrombin in $A k t 1^{-\nu_{-}}, \mathrm{Akt}^{-{ }^{-}}$, and $\mathrm{Akt3}^{-{ }^{-}}$platelets appear very similar in direct comparison (Figure 11), all showing a defective second wave and stability of aggregation. However, $\mathrm{Akt}^{-{ }^{-}}$platelets do not show significant defects in platelet aggregation and secretion induced by collagen (Figure 9B), ADP (Figure 9C), and VWF/botrocetin (Figure 9D) even at very low concentrations. This selectivity is distinct from $A k t 1^{-/-}$platelets, which are defective in platelet activation induced by all these agonists (Chen et al., 2004; Yin et al., 2008b), and also different from $\mathrm{Akt2}^{-/-}$platelets, which are defective in platelet activation induced by VWF, thrombin, and $\mathrm{TXA}_{2}$ (Woulfe et al., 2004; Yin et al., 2008b). Of the three isoforms, only Akt1 is required in platelet aggregation induced by low dose collagen, while neither Akt2 nor Akt3 knockouts showed 
significant effects on collagen-induced platelet activation (also see Figure 11B, 9B) (Woulfe et al., 2004). Thus, our data indicate that Akt3 plays a stimulatory role selectively in the G protein-coupled thrombin receptor and the $\mathrm{TXA}_{2}$ receptor signaling pathways, which is distinct from Akt1 and Akt2. The difference in the roles of the 3 Akt isoforms in different platelet activation pathways suggests the different mechanisms of action of Akt1, Akt2, and Akt3 in stimulating platelet activation. Nevertheless, there may also be overlapping functions of different Akt isoforms. 

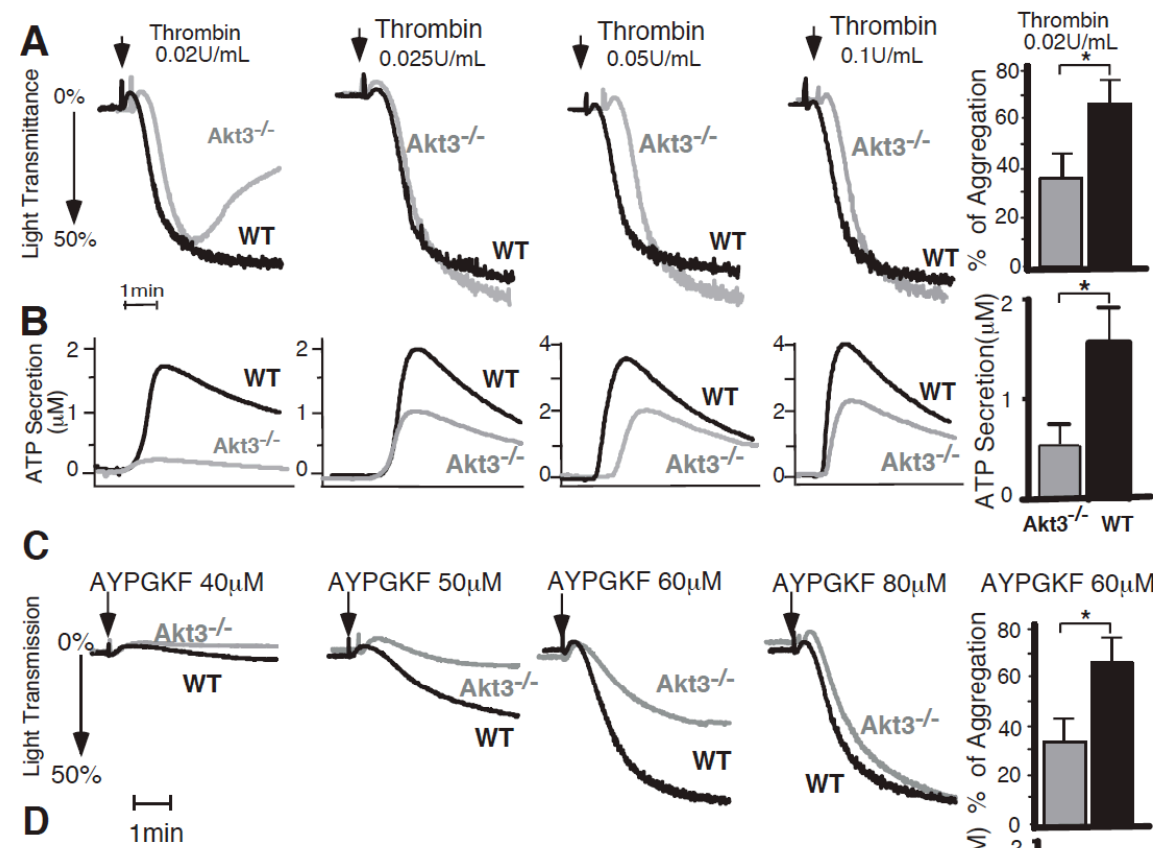

\section{AYPGKF $60 \mu \mathrm{M}$}
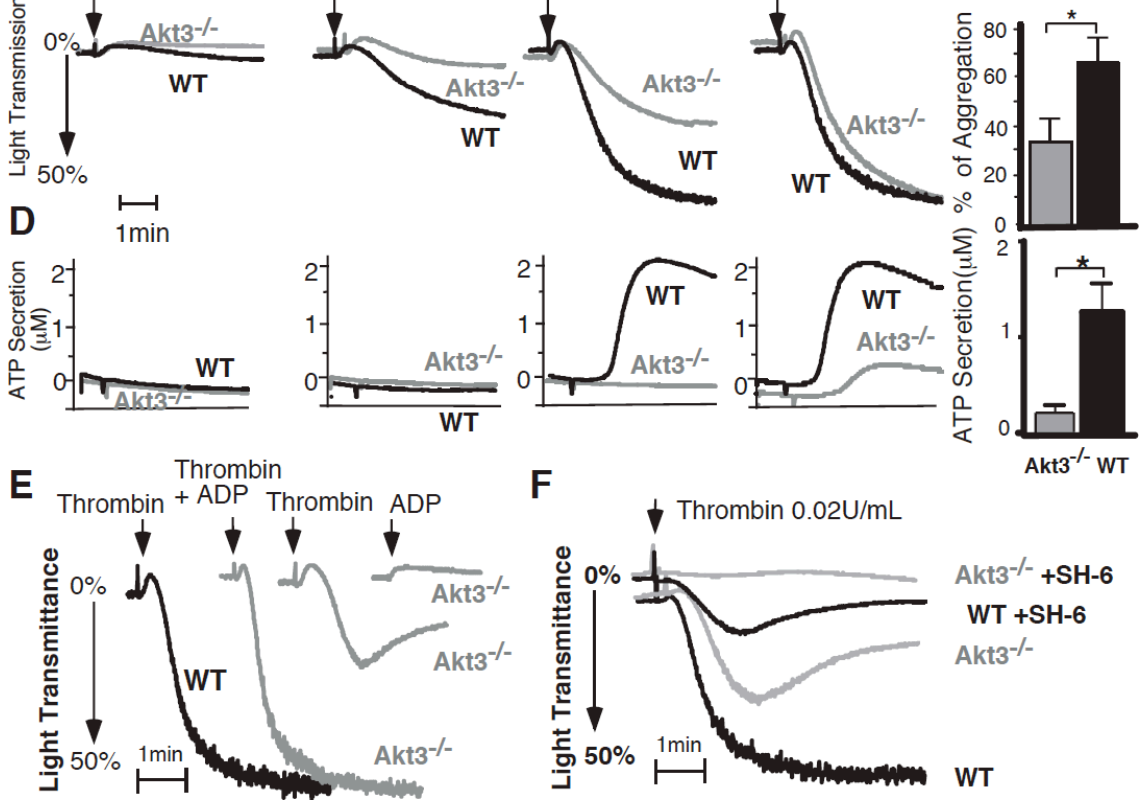

Figure 8. Stimulatory role of Akt3 in platelet aggregation and secretion in response to thrombin and PAR4 agonist peptide. (A, B, C, D) WT and Akt3 $3^{-/-}$ platelets were stimulated with thrombin (A and B) or PAR4 agonist peptide AYPGKF (C and D). Platelet aggregation ( $A$ and $C$ ) and secretion of ATP was recorded concomitantly in the presence of luciferin-luciferase agent ( $B$ and $D)$. Experiments described in $A, B, C$, and $D$ were repeated three times at a low dose of thrombin $(0.02 \mathrm{U} / \mathrm{mL})$ or AYPGKF $(60 \mu \mathrm{M})$ with the results quantified at the maximal percentage of light transmission (mean $\pm \mathrm{SE}$ ) or at maximal concentration of secreted ATP (mean $\pm \mathrm{SE}$ ). (E) A low concentration of ADP (1 $\mu \mathrm{M})$, insufficient to induce aggregation on its own, reversed the inhibitory effect of Akt $^{-/-}$platelets on thrombin-stimulated aggregation. (F) Akt $^{-/-}$and WT mouse platelets were treated with vehicle DMSO or SH-6 $(15 \mu \mathrm{M})$ for 2 minutes and aggregation was recorded as shown in (A). 


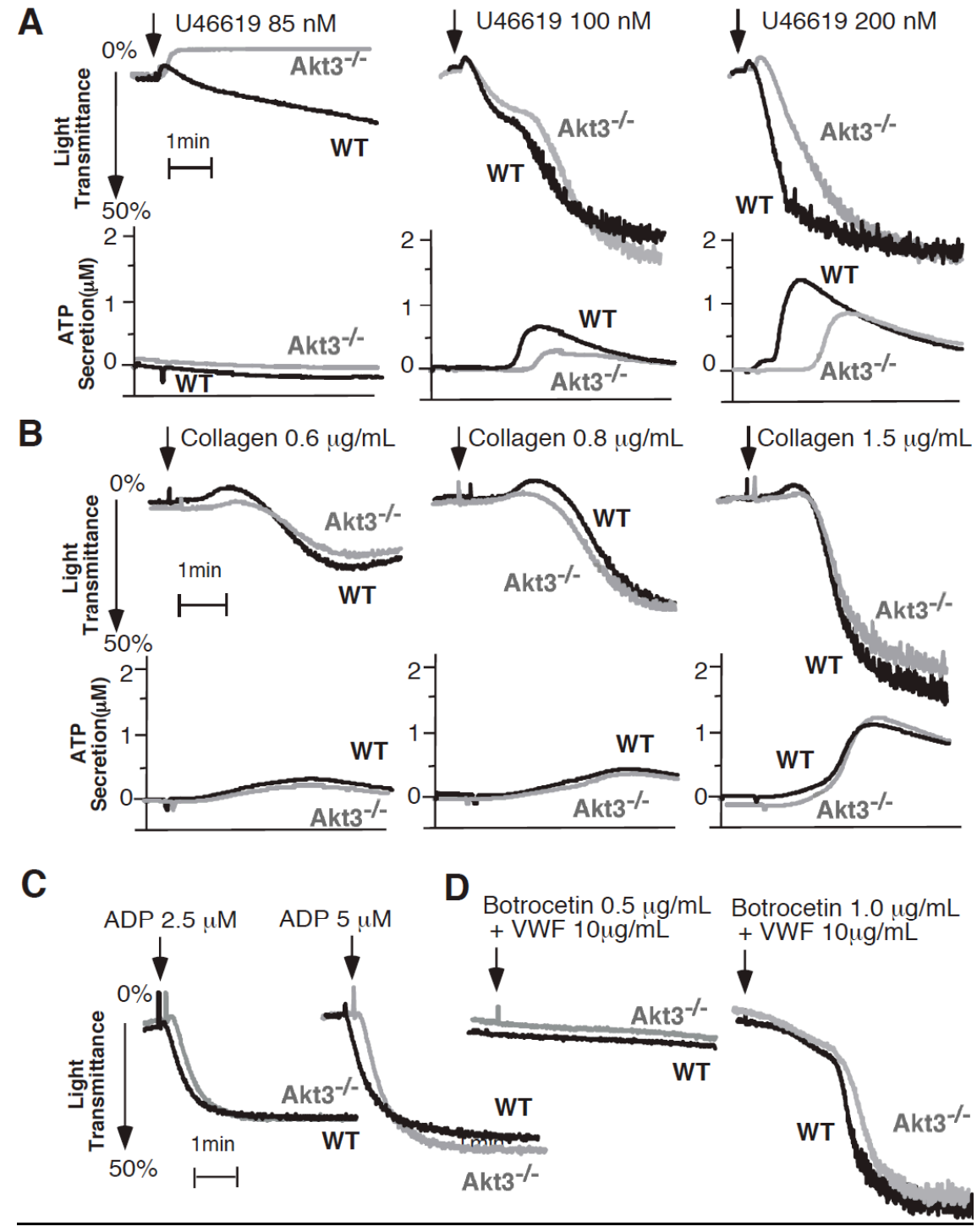

Figure 9. Responses of $\mathbf{A k t 3}^{-/-}$platelets to other platelet agonists. (A) WT and $\mathrm{Akt}^{-/-}$platelets were stimulated with (A) U46619. Platelet aggregation and secretion was recorded concomitantly in the presence of luciferin-luciferase agent. Platelet aggregation was also measured following stimulation with (B) collagen (For $0.8 \mu \mathrm{g} / \mathrm{mL}, \mathrm{n}=6, \mathrm{p}=0.909$ ), (C) ADP (For $2.5 \mu \mathrm{M}, \mathrm{n}=4, \mathrm{p}=0.1646$ ) and (D) botrocetin and VWF (For Botrocetin 1.0 $\mathrm{g} / \mathrm{mL}, \mathrm{n}=3, p=0.837$ ). Quantitation was performed using student's t-test. 

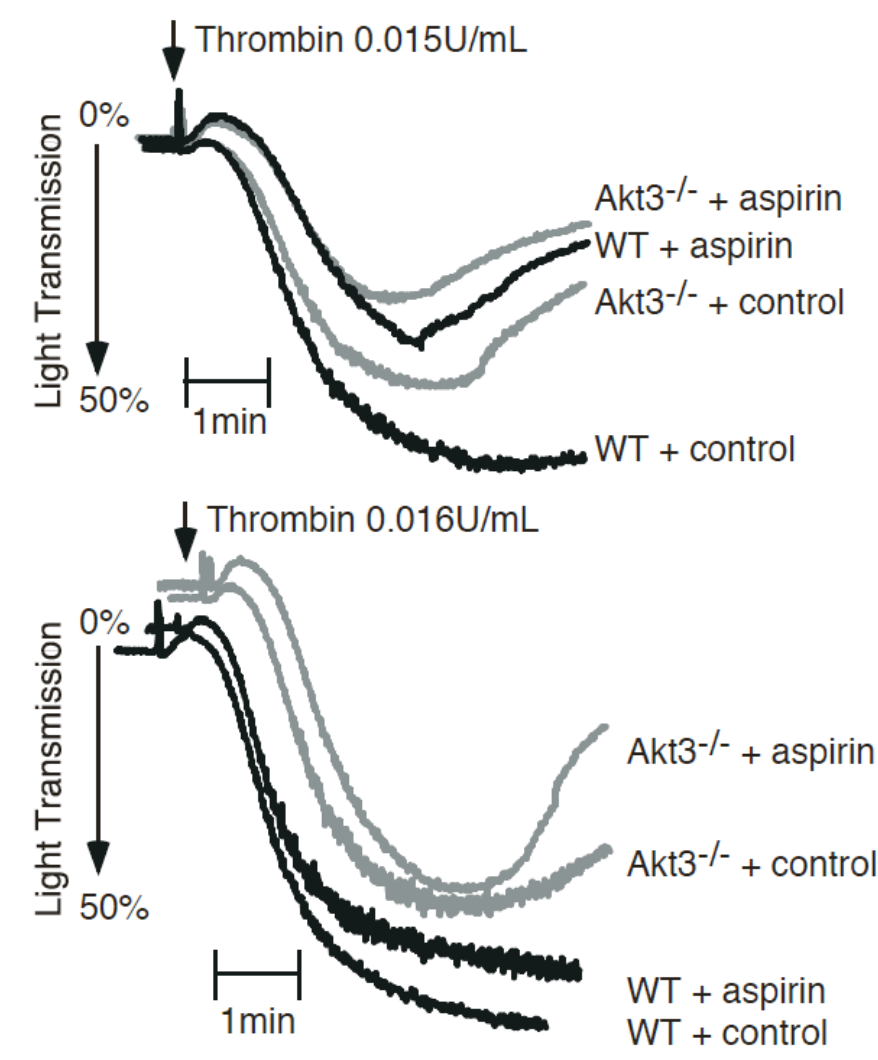

Figure 10. Effect of aspirin treatment on WT and Akt3 ${ }^{-/-}$platelets. WT and $\mathrm{Akt}^{-/-}$platelets were stimulated with low doses of thrombin and treated with buffer control or aspirin $(1 \mathrm{mM})$. Platelet aggregation and secretion was recorded concomitantly. Note that aspirin reduced aggregation of either wild type or $\mathrm{Akt}^{-/-}$ platelets at a very low thrombin concentration. A slight increase in thrombin concentration diminished the inhibitory effect of aspirin, but $\mathrm{Akt}^{-/-}$platelets still showed reduced aggregation compared to WT platelets in the presence or absence of aspirin. 


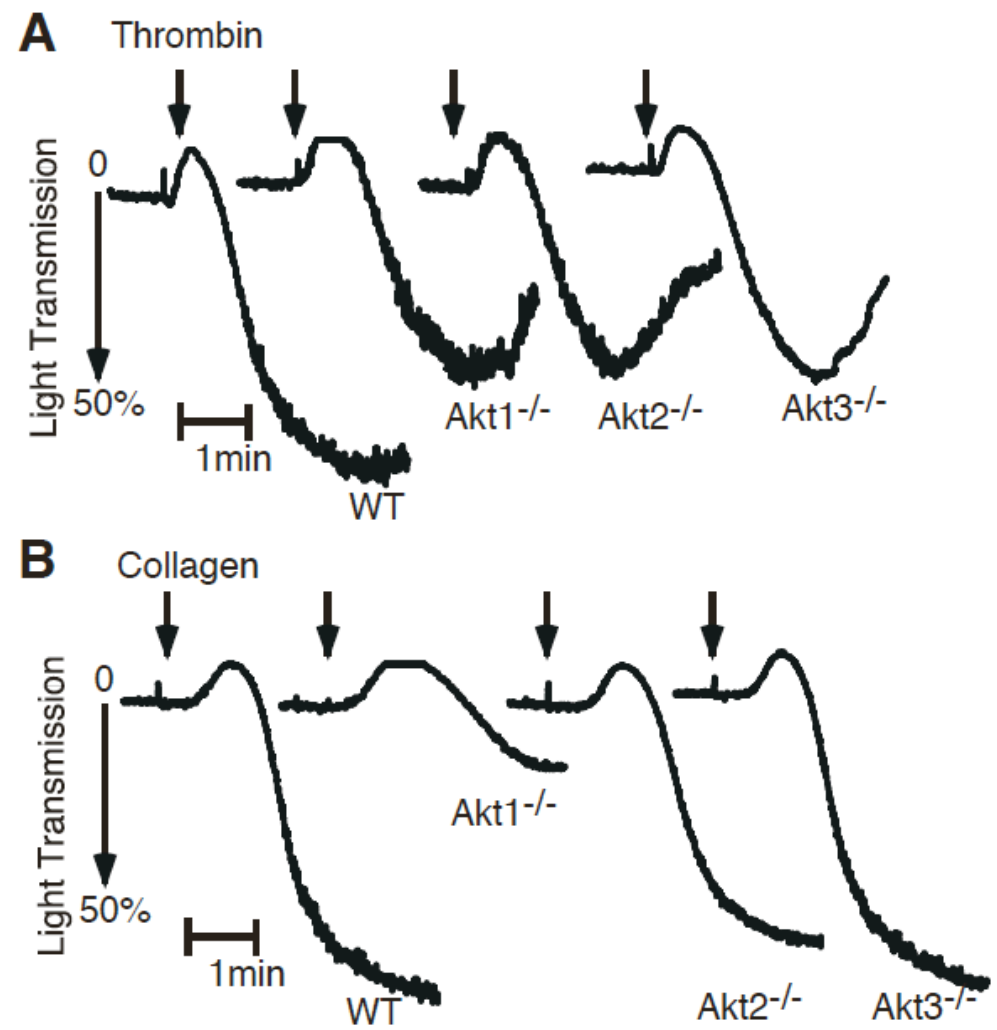

Figure 11. Comparison of knockouts of different Akt isoforms in platelet aggregation. Washed platelets from WT(C57), Akt1, Akt2, or Akt3 (C57 backcrossed) mice were stimulated with $(A)$ thrombin $(0.014 \mathrm{U} / \mathrm{mL})$ or $(B)$ collagen $(0.6 \mu \mathrm{g} / \mathrm{mL})$ and platelet aggregation was recorded in a turbidometric aggregometer. 


\section{The role of Akt3 in mediating GSK-3 $\beta$ phosphorylation}

Akt has numerous substrates. We have previously shown that the role of Akt1 in stimulating platelet secretion and aggregation is mainly mediated by the NO/cGMP signaling pathway (Stojanovic et al., 2006). Our data also suggest that the role of Akt2 in GPIb-IX-dependent platelet activation is also mainly mediated via the cGMP pathway (Yin et al., 2008b). The role of Akt1 in the NO/cGMP pathway is consistent with the data that Akt $1^{-/-}$platelets showed defects in platelet granule secretion induced by nearly all tested platelet agonists (Chen et al., 2004; Stojanovic et al., 2006; Woulfe et al., 2004), as cGMP is elevated by all of these platelet agonists (Li et al., 2003a; Li et al., 2004). However, $\mathrm{Akt}^{-/-}$platelets selectively showed a defect in thrombin- and $\mathrm{TXA}_{2}$ induced platelet secretion and aggregation, suggesting a possibly different downstream effector. It has been established that phosphorylation of GSK-3 $\beta$ at

Ser $^{9}$ by Akt negatively regulates GSK-3 $\beta$ function (Cross et al., 1995). Interestingly, previous studies showed that GSK-3 $\beta$ plays a negative regulatory role selectively in thrombin-induced platelet aggregation (Li et al., 2008), but plays a stimulatory role in collagen-induced platelet aggregation (Barry et al., 2003). Thus, we investigated the possibility that GSK-3 $\beta$ is a downstream effector of Akt3. Indeed, thrombin induced a significant increase in the phosphorylation levels of GSK-3 $\beta$ in wild type platelets, which was partially, but significantly inhibited in Akt3 knockout platelets (Figure 12A, 12B). The role of Akt3 in phosphorylation of GSK-3 $\beta$ is not limited to the thrombin pathway. 
Phosphorylation of GSK-3 $\beta$ induced by other agonists such as collagen and ADP was also partially inhibited in $\mathrm{Akt}^{-{ }^{-}}$platelets (Figure 13). In contrast to the partial inhibition of GSK-3 $\beta$ phosphorylation in $\mathrm{Akt3}^{-/-}$platelets, treatment of platelets with the pan Akt inhibitor SH6 completely inhibited low-dose thrombin stimulated phosphorylation of GSK-3 $\beta$ at high SH6 concentrations (Figure 12C), suggesting the involvement of other Akt isoforms in addition to Akt3. Previously, It has been shown that platelets lacking 3 alleles of Akt $\left(A k t 1^{+/} A k t 2^{-/}\right)$exhibit a significant decrease in GSK-3 $\beta$ phosphorylation in PAR4 agonist peptide stimulated platelets compared to WT mouse platelets (Li et al., 2008). Together, these data indicate that Akt3 plays an important role in mediating GSK-3 $\beta$ phosphorylation, but Akt isoforms other than Akt3 are also important in agonist-stimulated GSK-3 $\beta$ phosphorylation. 

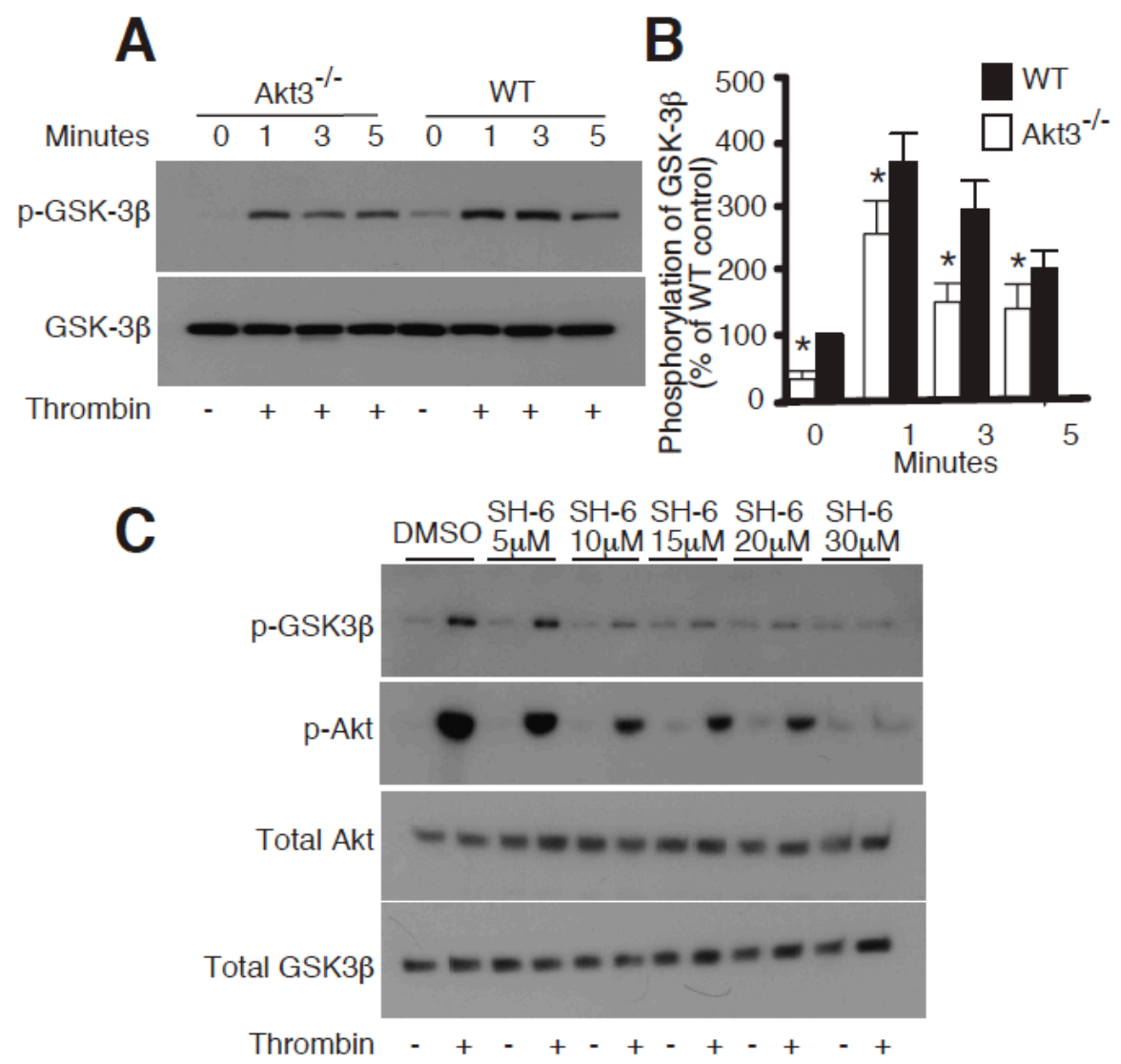

Figure 12. Phosphorylation of GSK-3 $\beta$. (A) $A k t 3^{-/-}$and WT mouse platelets were stimulated with thrombin $(0.018 \mathrm{U} / \mathrm{mL})$ for 1,3 , and 5 minutes, solubilized, and immunoblotted with antibodies against phosphorylated $\operatorname{Ser}^{9}$ of GSK-3 $\beta$, and total GSK-3 $\beta$ (loading control). (B) Results from three experiments as shown in (A) were quantified. The relative quantity of phospho-GSK-3 $\beta$ in stimulated $A k t 3^{-/-}$ vs. WT platelets is expressed as the percentage of WT (mean $\pm \mathrm{SE}, 5$ experiments). The difference in GSK-3 $\beta$ phosphorylation at resting, $1 \mathrm{~min}, 3 \mathrm{~min}$, and 5 min time points are significant between WT and Akt3 ${ }^{-/-}(p<0.05)$, as determined using Student's $t$ test. (C) WT mouse platelets were preincubated for 2 min with increasing doses of SH-6 or control DMSO and stimulated with thrombin $(0.018 \mathrm{U} / \mathrm{mL})$ for 3 minutes, solubilized, and immunoblotted with antibodies against phospho-Ser ${ }^{9}$ of GSK-3 $\beta$, phospho-Ser473 of Akt, total Akt, and total GSK-3 $\beta$ (loading control). 

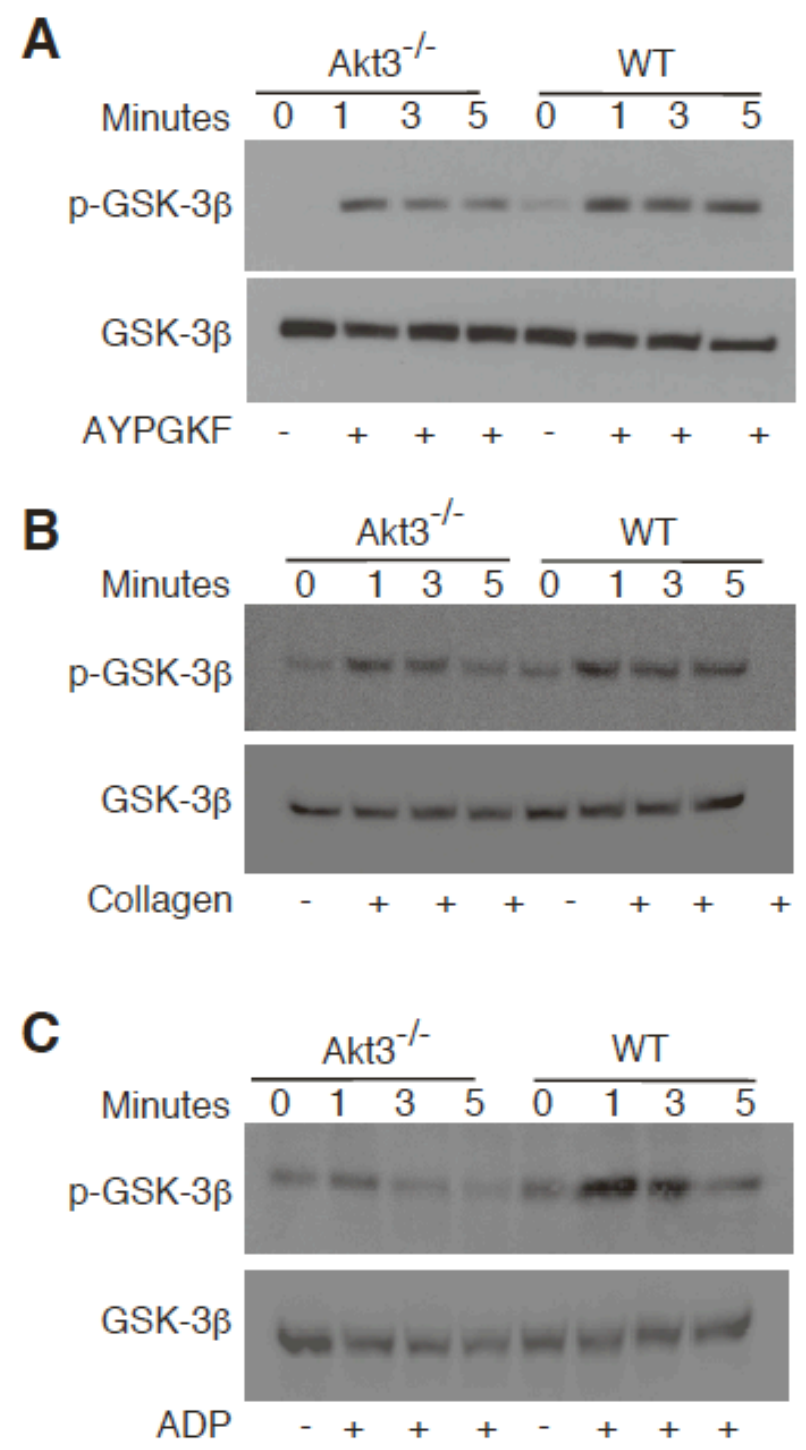

Figure 13. Phosphorylation of GSK-3 $\beta$ in response to PAR agonist peptide, collagen, and ADP. Akt3 $3^{-/}$and WT mouse platelets were stimulated with (A) PAR4 agonist peptide, AYPGKF $(50 \mu \mathrm{M})(B)$ collagen $(1 \mu \mathrm{g} / \mathrm{mL})$, and $(C)$ ADP (10 $\mu \mathrm{M}$ in the presence of $10 \mu \mathrm{g} / \mathrm{mL}$ fibrinogen) for 1,3 , and 5 minutes, solubilized, and immunoblotted with antibodies against phosphorylated $\operatorname{Ser}^{9}$ of GSK-3 $\beta$, and total GSK-3 $\beta$ (loading control). 
To further investigate whether the role of Akt3 in GSK-3 $\beta$ phosphorylation explains the selective role of Akt3 in thrombin-induced platelet aggregation, we tested the effects of a GSK-3 $\beta$ selective inhibitor, SB216763, on platelet aggregation induced by thrombin and collagen in wild type and $\mathrm{Akt}^{-{ }^{-}}$ platelets. Consistent with a previous report (Li et al., 2008), SB216763 enhanced platelet aggregation and secretion induced by subthreshold concentrations of thrombin (Figure $14 \mathrm{~A}$ and $\mathrm{B}$ ). At higher concentrations of thrombin when platelet aggregation in normal platelets is already near maximal, there was no obvious effect of SB216763 on platelet aggregation (not shown). As expected, Akt3-platelets showed a decrease in platelet aggregation in response to low dose thrombin compared to wild type platelets. In contrast, Akt $3^{-/}$platelets treated with SB216763 $(10 \mu \mathrm{M})$ totally rescued the defect of $\mathrm{Akt3}^{-/-}$platelets in thrombininduced platelet aggregation (Figure 14A). Because we have shown that Akt3 is important in mediating phosphorylation of GSK-3 $\beta$, which inhibits GSK-3 $\beta$ function, and that inhibition of GSK-3 $\beta$ function enhances thrombin-induced platelet aggregation, the rescue of the aggregation defect in $\mathrm{Akt}^{-/-}$platelets by GSK-3 $\beta$ inhibitor suggests that Akt3-mediated regulation of GSK-3 $\beta$ function is likely to be sufficient for the role of Akt3 in promoting thrombin-induced platelet aggregation. In contrast to thrombin-induced platelet aggregation, collageninduced platelet aggregation and secretion was significantly inhibited by SB216763 (Figure 14C), suggesting that GSK-3 $\beta$ does not promote platelet activation induced by the GPVI pathway. An inhibitory effect of SB216763 on 
platelet aggregation was also seen when ADP was used as an agonist (Figure 14D). These data suggest that GSK-3 $\beta$ positively regulates GPVI and ADP receptor signaling pathways. However, Akt3 knockout did not enhance platelet aggregation induced by collagen and ADP (Figure 9), despite of a role of Akt3 in GSK-3 $\beta$ phosphorylation (Figure 13), and SB216763 inhibited ADP-induced platelet aggregation in $\mathrm{Akt3}^{-/}$platelets as in wild type platelets (Figure 14D). These data suggest either that the partial phosphorylation of GSK-3 $\beta$ by other Akt isoforms are sufficient to mediate its regulation in collagen and ADP signaling pathways or an uncharacterized stimulatory role of Akt3 in these pathways masked the functional effect of Akt3 knockout on GSK-3 $\beta$ phosphorylation. Together, our data indicate that the selective role for Akt3 in promoting thrombininduced platelet aggregation may be mainly mediated by the Akt3-dependent phosphorylation of GSK-3 $\beta$ and consequent inhibition of the negative regulatory signal of GSK-3 $\beta$, although we do not exclude that other possible downstream effectors of Akt3 may also contribute to its role in platelet activation. 

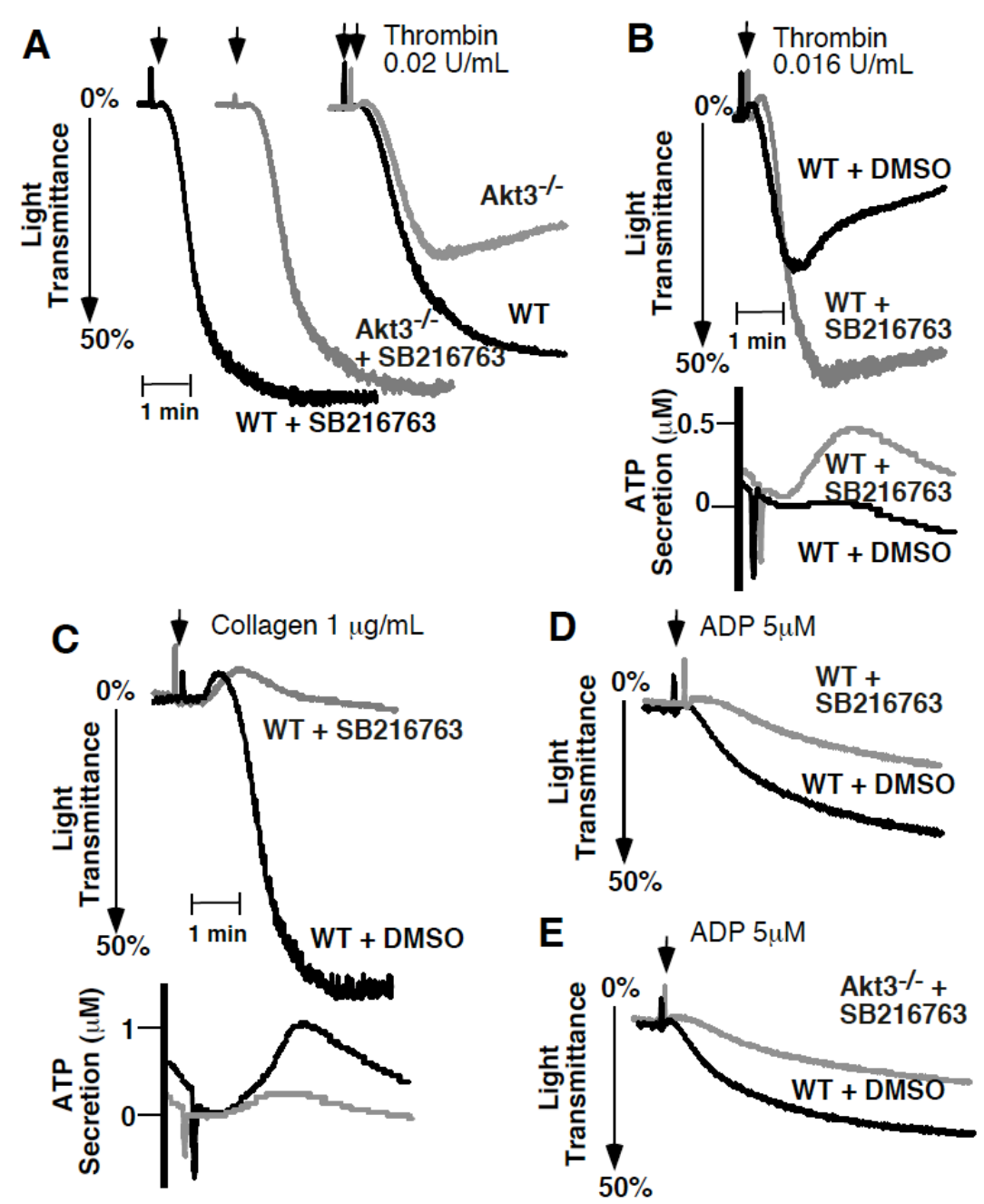

Figure 14. Reversal of the inhibitory effect of Akt3 knockout on platelet aggregation by GSK-3 $\beta$ inhibitor SB216763. (A) WT and $\mathrm{Akt}^{-/-}$platelets were pre-incubated for $2 \mathrm{~min}$ with $10 \mu \mathrm{M}$ of SB216763 or vehicle DMSO. Platelets were then stimulated with thrombin in a platelet aggregometer. (B) Washed WT mouse platelets were pre-incubated for 2 min with $10 \mu \mathrm{M}$ of SB216763 or vehicle DMSO and stimulated with a subthreshold concentration of thrombin in a platelet aggregometer. Secretion was recorded concomitantly with aggregation and ATP release was recorded. (C) Mouse platelets were pre-incubated for 2 min with 10 $\mu \mathrm{M}$ of SB216763 or vehicle DMSO and then stimulated with collagen. Secretion was measured concomitantly. (D) WT mouse platelets or $\mathrm{Akt}^{-/-}$platelets were pre-incubated with $10 \mu \mathrm{M}$ of SB216763 or vehicle DMSO and then stimulated with ADP $(5 \mu M)$ in the presence of fibrinogen $(10 \mu \mathrm{g} / \mathrm{mL})$ and platelet aggregation was recorded. 


\section{The role of Akt3 in platelet adhesion and thrombus formation}

\section{under flow conditions in vitro}

The important roles of different platelet activation pathways are to facilitate platelet adhesion and thrombus formation on exposed collagen surfaces of damaged blood vessel walls. To investigate whether the role of Akt3 in selective platelet activation pathways are relevant to thrombus formation on collagen surfaces under flow, we employed a cone and plate rheometer to introduce flow with controlled shear rates to platelets on a collagen coated surface. A shear rate of $800 \mathrm{~s}^{-1}$ was used to mimic the physiological shear rates of the arteries and arterioles. Washed platelets from both the wild type or Akt3 ${ }^{-/}$ mice stably adhered to the collagen-coated surface under this flow condition, suggesting that $\mathrm{Akt}^{-{ }^{-}}$platelets are not defective in adhesion to collagen. However, in contrast to wild type platelets that formed large thrombi on the collagen coated surface, $\mathrm{Akt}^{-{ }^{-}}$platelets only formed smaller aggregates (Figure $15 \mathrm{~A}, \mathrm{~B})$, suggesting that $\mathrm{Akt3}^{-{ }^{-}}$platelets are deficient in recruiting platelets into thrombi under high shear rate conditions.

\section{Akt3 promotes in vivo thrombosis}

In order to determine the in vivo physiological relevance of the role of Akt3 in promoting platelet secretion and aggregation, we compared the in vivo thrombosis of wild type and $\mathrm{Akt}^{-/-}$mice using the $\mathrm{FeCl}_{3}$-induced carotid artery thrombosis model. The time to the formation of stable occlusive thrombus in the 
carotid artery is significantly prolonged in $\mathrm{Akt}^{-{ }^{--}}$mice compared with wild type control mice $\left(p=0.0007, n=10\right.$ for Akt3 $^{-/}, n=10$ for WT) (Figure $15 C$ ). However, $\mathrm{FeCl}_{3}$-induced carotid artery thrombosis still occurred in $\mathrm{Akt}^{-/-}$mice after a delay. This significant, but relatively mild anti-thrombotic effect of Akt3 knockout is consistent with its in vitro effect on thrombin and $\mathrm{TXA}_{2}$ induced platelet secretion and aggregation. These data suggest that Akt3 plays an important regulatory role in thrombus formation in vivo. 

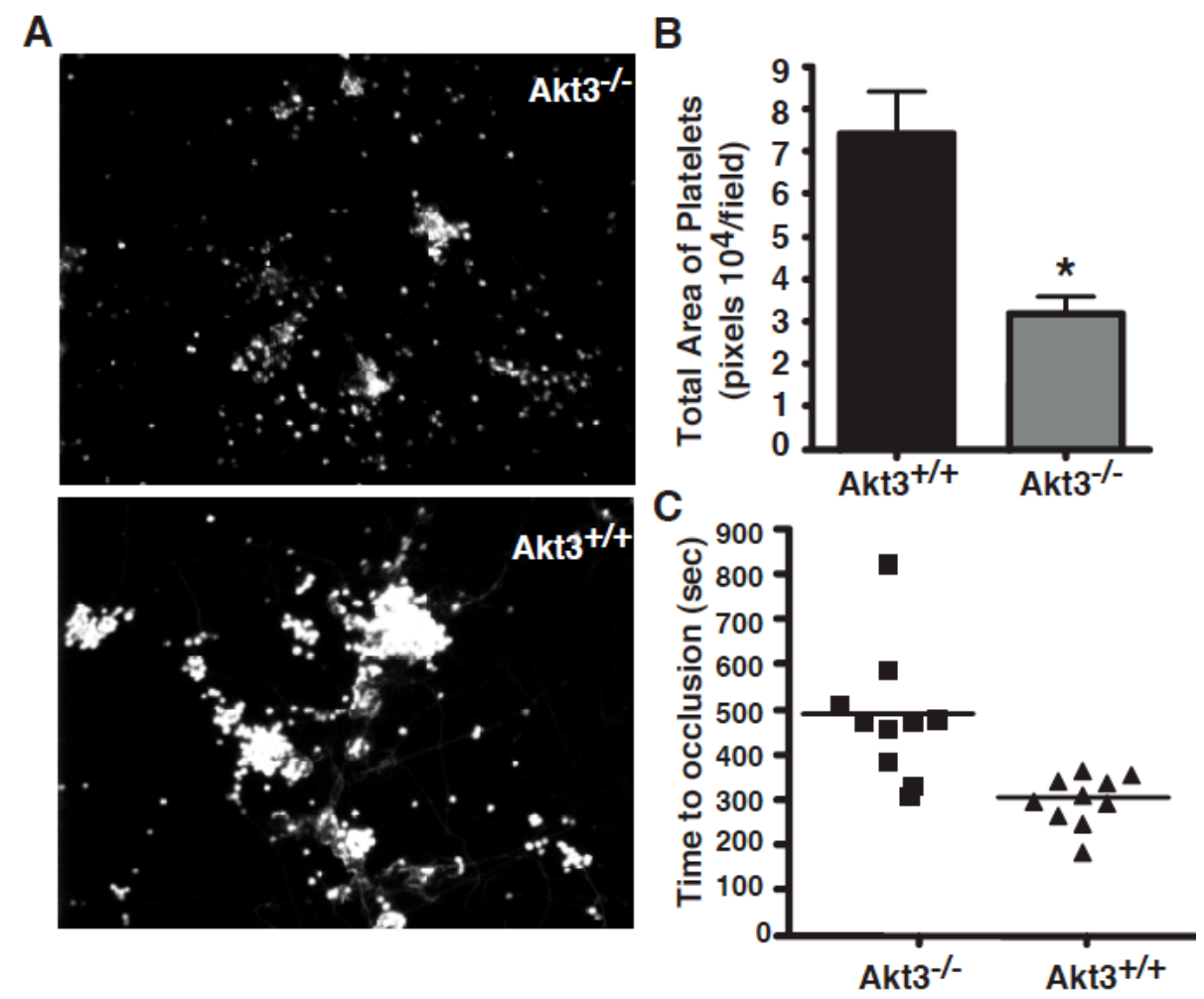

Figure 15. Akt $^{-/-}$delays formation of stable thrombi. (A) Mouse platelets $\left(200 \mu \mathrm{L}, 3 \times 10^{8} / \mathrm{mL}\right)$ were loaded onto slides coated with $50 \mu \mathrm{g} / \mathrm{mL}$ collagen and a cone and plate rheometer was used to introduce shear stress $\left(800 \mathrm{~s}^{-1}\right)$ for 5 minutes to the platelets. Mepacrine was added to the platelets before applying shear stress. Slides were rinsed with PBS to wash out non-stably adherent platelets. Slides were viewed with a fluorescence microscope. (B) Quantitation of (A) using t-test $(\mathrm{p}<0.001)$. (C) $\mathrm{FeCl}_{3}$ - induced carotid artery injury was performed and time to occlusive thrombosis was recorded. The occlusion time of each mouse is shown as squares $\left(A k t 3^{-/-}, n=10\right)$ and triangles $\left(A k t 3^{+/+}, n=10\right)$. The bars represent the median occlusion time. Statistical analysis was performed using the Mann-Whitney test to evaluate the differences in median occlusion time $(p=$ 0.0007). 


\section{b. Discussion}

In this study, we show that Akt3 is a significant Akt isoform expressed in platelets and plays an important role in platelet activation that is different from that of Akt1 and Akt2. We show that the role of Akt3 in platelets is likely mediated by phosphorylating and thus, negatively regulating GSK-3 $\beta$. Furthermore, we demonstrate an important role for Akt3 in promoting stable thrombus formation in vivo.

It is well established that the PI3K signaling pathway has a critical function in platelet activation (Kovacsovics et al., 1995; Li et al., 2003b; Rittenhouse, 1996). The Akt family of protein kinases is an important downstream effector of PI3K signaling. Recent studies have shown that Akt1 and Akt2 play important stimulatory roles in platelet activation induced by low concentrations of platelet agonists (Chen et al., 2004; Stojanovic et al., 2006; Woulfe et al., 2004; Yin et al., 2008b). The role of Akt3 in platelets has never been studied, possibly due to a previous report that Akt3 was not detectable in platelets (Kroner et al., 2000). However, our data clearly show that Akt3 is expressed in platelets in a substantial amount. Furthermore, our data indicate that $\mathrm{Akt}^{-{ }^{--}}$platelets have defects in thrombin (and $\mathrm{TXA}_{2}$ )-induced platelet granule secretion and aggregation in vitro, and in thrombus formation in vivo, which are consistent with

previous data that $G$ protein-coupled thrombin receptor and $\mathrm{TXA}_{2}$ receptor pathways are important in thrombosis in vivo. Thus, we conclude that Akt3 plays important roles in platelet function and thrombosis. Together with previous 
findings of important roles of Akt1 and Akt2 in platelets, and additive roles of Akt3 and other Akt isoforms, our data further suggest that all three isoforms of Akt are important in promoting platelet granule secretion and thrombus formation, regardless of their relative quantities.

The role of Akt3 in promoting platelet activation appears to be selective for some of the platelet activation pathways, but is not involved in a general signaling pathway. Akt3 $^{-/-}$platelets showed significant defects in platelet activation induced by thrombin receptor agonists and (to a lesser degree) $\mathrm{TXA}_{2}$ mediated platelet secretion and aggregation, but had no defect in platelet secretion and aggregation induced by collagen, ADP and VWF/botrocetin. The defect of $\mathrm{Akt}^{-{ }^{-}}$platelets selectively in certain platelet activation pathways is clearly different from Akt ${ }^{-1-}$ platelets, which have been shown to be defective in platelet secretion and aggregation induced by all tested agonists including VWF, collagen, and ADP (Chen et al., 2004; Stojanovic et al., 2006; Woulfe et al., 2004; Yin et al., 2008b), and is also different from $\mathrm{Akt}^{-/-}$platelets which is involved in VWF/GPIb-mediated platelet activation, in addition to thrombin and $\mathrm{TXA}_{2}$ pathway. Thus, the three isoforms of Akt play different roles in different platelet activation signaling pathways. The aggregation defects of Akt isoform knockout mice in response to platelet agonists are summarized in Table 1. Most of our current knowledge on the roles of Akt family of kinases in physiology and pathology were obtained with the prototype Akt isoform, Akt1 and to a degree, 
Akt2. Akt3 has been the least characterized, perhaps because Akt3 was thought to be a "redundant" Akt isoform. The functional redundancy between different Akt isoforms is evident, since more dramatic defects and early death only occur in mice with the genes of at least two Akt isoforms deleted. However, deletion of different individual Akt isoforms results in different phenotypes, suggesting that different Akt isoforms may also play distinct roles. Although, it is also possible that the distinct phenotype results from different tissue distribution patterns or localization of Akt isoforms. Our studies provide novel evidence of distinct roles of different Akt isoforms in the same cell.

Akt family of protein kinases has many substrates, and plays multiple roles in many aspects of life and in many types of cells. For example, Akt1 has been shown to phosphorylate and activate endothelial nitric oxide synthase (eNOS) (Dimmeler et al., 1999), and thus stimulate nitric oxide (NO)cGMP signaling pathway in many types of cells including platelets (Stojanovic et al., 2006). We have shown that Akt1 is important in platelet cGMP elevation induced by all tested agonists, and promotes platelet activation, particularly granule secretion, via the NO/cGMP pathway (Stojanovic et al., 2006; Yin et al., 2008b). Akt2 has been shown to be important in GPIb-IX-mediated cGMP elevation. However, how Akt2 plays a role in platelet activation remains unclear. The data presented in this study suggest that Akt3 mediates platelet activation mainly by negative regulation of another Akt substrate, GSK-3 $\beta$. 
TABLE I

UNIQUE AND OVERLAPPING ROLES OF AKT ISOFORMS IN PLATELET ACTIVATION

\begin{tabular}{|l|l|l|l|}
\hline \multicolumn{1}{|c|}{ Agonist } & \multicolumn{1}{|c|}{ Akt1 $^{-{ }^{-}}$} & \multicolumn{1}{c|}{ Akt2 $^{-{ }^{-}}$} & \multicolumn{1}{c|}{ Akt3 $^{-{ }^{-}}$} \\
\hline Thrombin & Defective $^{\mathrm{a}, \mathrm{c}, \mathrm{e}}$ & Defective $^{\mathrm{b}, \mathrm{e}}$ & Defective $^{\mathrm{e}}$ \\
\hline Collagen & Defective $^{\mathrm{a}, \mathrm{c}, \mathrm{e}}$ & No effect $^{\mathrm{b}, \mathrm{e}}$ & No effect $^{\mathrm{e}}$ \\
\hline Thromboxane & Defective $^{\mathrm{c}}$ & Defective $^{\mathrm{b}}$ & Defective $^{\mathrm{e}}$ \\
\hline ADP & Defective $^{\mathrm{a}, \mathrm{c}}$ & No effect $^{\mathrm{b}}$ & No effect $^{\mathrm{e}}$ \\
\hline VWF & Defective $^{\mathrm{d}}$ & Defective $^{\mathrm{d}}$ & No effect $^{\mathrm{e}}$ \\
\hline
\end{tabular}

${ }^{a}$ Chen et al., 2004

${ }^{\text {b }}$ Woulfe et al., 2004

${ }^{c}$ Stojanovic et al., 2006

${ }^{d}$ Yin et al., 2008b

${ }^{\text {e }}$ O'Brien et al., 2011 
It has been established that phosphorylation of GSK-3 $\beta$ at $\operatorname{Ser}^{9}$ by Akt family of kinases negatively regulates GSK-3 $\beta$ function (Cross et al., 1995). The role of GSK-3 $\beta$ in platelet activation has been examined by several groups. Some studies showed that pharmacological inhibition of GSK-3 $\beta$ reduced platelet aggregation induced by collagen (Barry et al., 2003), but another group showed that both pharmacological GSK-3 $\beta$ inhibitors and partial reduction of GSK-3 $\beta$ in heterozygous GSK-3 $\beta$ knockout platelets enhanced platelet aggregation induced by thrombin receptor agonists (Li et al., 2008). In our studies, GSK-3 $\beta$ selective inhibitor SB216763 inhibited collagen- and ADP-induced platelet activation, but enhanced platelet aggregation induced by a subthreshold concentration of thrombin, suggesting that GSK-3 $\beta$ plays differential roles in different platelet activation pathways, which explains previous controversies. The differential roles of GSK-3 $\beta$ in different platelet activation pathways are consistent with the selective role of Akt3 in different platelet activation pathways. Indeed, we observed a significant reduction in GSK-3 $\beta$ phosphorylation in $\mathrm{Akt3}^{-/-}$platelets stimulated with thrombin, indicating that Akt3 is an important kinase responsible for GSK-3 $\beta$ Ser $^{9}$ phosphorylation. Furthermore, treatment of $A k t 3^{-/-}$platelets with GSK-3 $\beta$ inhibitor SB216763 completely corrected the defect in thrombin-induced platelet aggregation in $\mathrm{Akt}^{-/-}$platelets. These data suggest that Akt3 is likely to play a stimulatory role in low dose thrombin-induced platelet activation by inactivating the negative regulatory role of GSK-3 $\beta$. It is important to note that GSK-3 $\beta$ is regulated not only by Akt3, but also by other Akt isoforms, which may 
also contribute to its function. However, clearly different functional phenotypes between three different Akt isoforms suggest that other downstream effectors, such as the NO/cGMP pathway, may be important in the functional effects of these Akt isoforms. Also, we do not exclude the possibility that Akt3 may also regulate other unidentified substrates, which is interesting for further study. The mechanism by which GSK-3 $\beta$ exerts its effects is unclear at this stage. A recent study suggests a role for GSK-3 $\beta$ in the Wnt signaling pathway in platelets (Steele et al., 2009). Thus, more detailed studies to determine the roles of GSK$3 \beta$ on platelet function downstream from Akt isoforms are warranted.

This research was originally published in Blood. O'Brien KA, StojanovicTerpo A, Hay N, Du X. An important role for Akt3 in platelet activation and thrombosis. Blood. 2011 Oct 13; 118(15):4215-23. (C) The American Society of Hematology.

Portions of the publication are reproduced here with permission of the American Society of Hematology. 


\section{B. ADP-stimulated activation of Akt during integrin outside-in signaling promotes platelet spreading}

a. Results

\section{The role of Akt isoforms as downstream effectors of PI3K in} mediating platelet spreading

We sought to determine whether the PI3K effector, Akt, plays an important role in integrin outside-in signaling. To inhibit the functions of all Akt isoforms, a pan Akt inhibitor, AktX, was used. AktX is a phenoxazine that selectively inhibits the phosphorylation of Akt, thus suppressing its kinase reactivity (Thimmaiah et al., 2005). This Akt inhibitor is not a phosphoinositide analog, and thus does not directly affect functions of other phosphoinositideregulated proteins (Thimmaiah et al., 2005). This excludes the possible nonspecific inhibition of other PI3K effectors, which is a potential complication with previously used Akt inhibitors such as SH-6, a competitive inhibitor of phosphoinositide binding to Akt. Human platelets were treated with increasing doses of AktX, and allowed to spread on immobilized fibrinogen. AktX dosedependently inhibited human platelet spreading (Figure 16, A and B). At $10 \mu \mathrm{M}$, AktX completely abolished platelet spreading on fibrinogen. A similar dosedependent defect in spreading was observed using mouse platelets treated with increasing concentrations of AktX (Figure 16, C and D), suggesting that platelets from humans and mice similarly require Akt to promote integrin outside-in signaling and platelet spreading. To confirm the effectiveness of AktX on Akt 
activation and function in our experimental system, wild type mouse platelets were treated with increasing doses of AktX and allowed to spread on fibrinogen. After 30 minutes of spreading, platelets were harvested for western blot analysis of Akt phosphorylation at Ser473. Akt is phosphorylated following platelet spreading on a fibrinogen-coated surface, indicating that Akt becomes activated during integrin outside-in signaling. AktX dose-dependently inhibited phosphorylation of Akt at Ser473 (Figure 16E). Altogether, these data suggest Akt is activated and plays an important role in mediating human and mouse platelet spreading. 

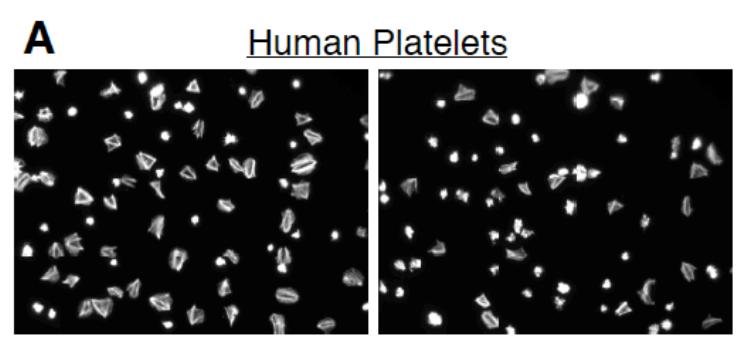

C Mouse Platelets
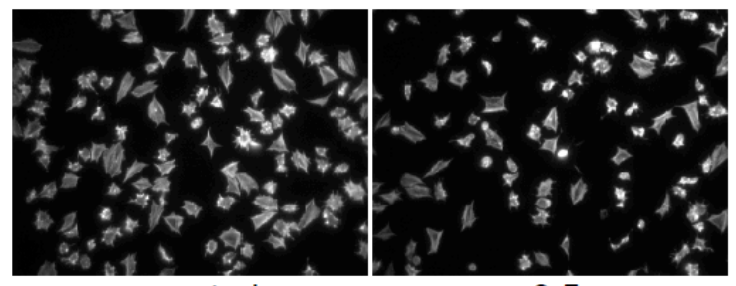

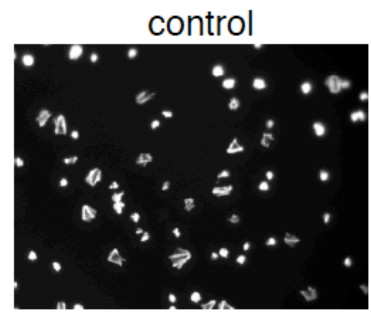

5

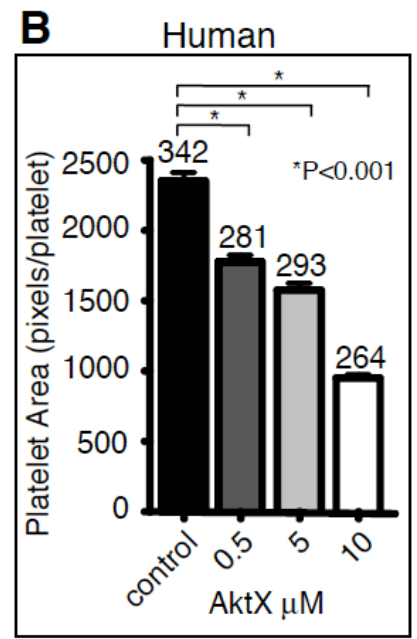

D

10
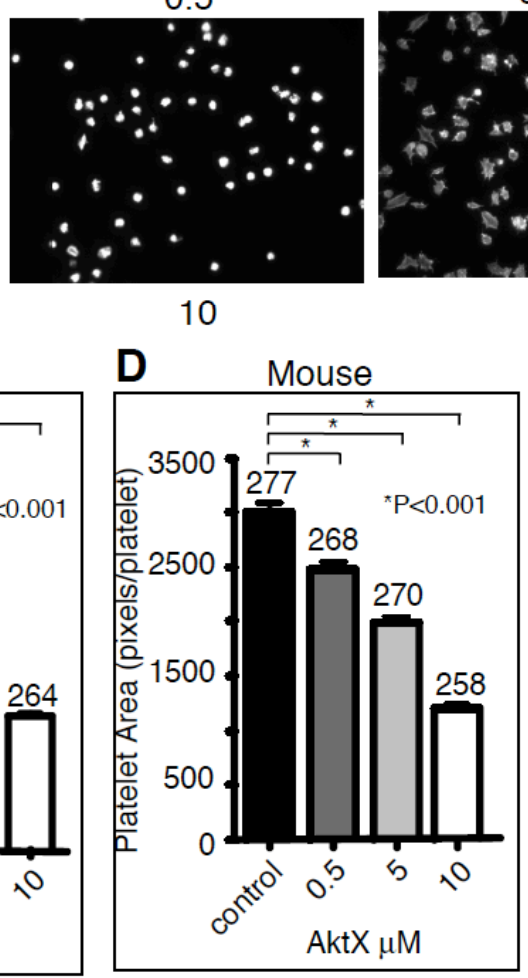

control

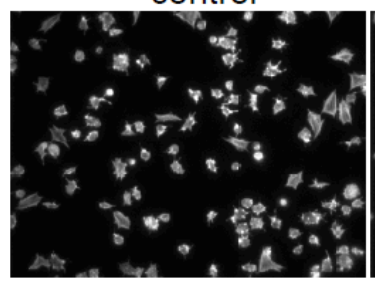

5

E

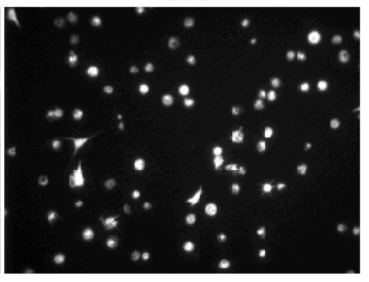

10

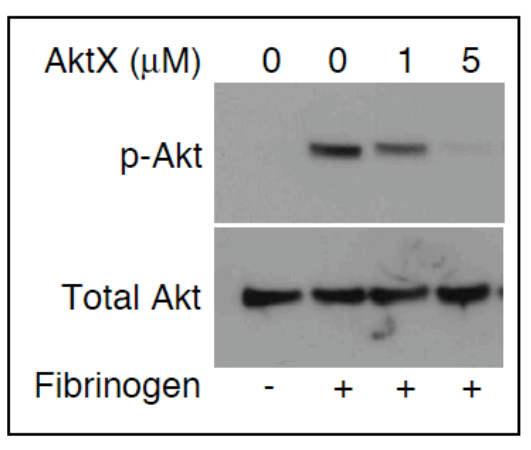

Figure 16. Effect of an Akt inhibitor on platelet spreading. (A) Human platelets were allowed to spread on fibrinogen for 1 hour. Adherent platelets were fixed, permeabilized, stained with phalloidin, and then observed with a fluorescence microscope. (B) The surface area of single platelets as described in (A) was measured (mean surface area \pm SE). Shown in the figure are representative pictures from one of three experiments, and are from at least 3 randomly selected fields. Difference between groups was analyzed using Student's $t$ test. Numbers of platelets analyzed for each group are indicated above the bars. (C) Washed mouse platelets were spread on fibrinogen for 2 hours, and analyzed as described in (A). (D) Quantitation of surface area as described in $(C)$. (E) Washed human platelets were incubated with increasing concentrations of AktX and added to fibrinogen to spread for 30 minutes or kept in suspension. Adherent platelets or control platelets were solubilized, and analyzed for phosphorylation of Akt at $\operatorname{Ser}^{473}$ and total Akt by Western blot. 
Platelets express three different Akt isoforms: Akt1, Akt2 and Akt3. Our recent results suggest that Akt3 is a major Akt isoform in platelets ( $70 \%$ of total Akt in mouse platelets, 35\% in human platelets) (O'Brien et al., 2011). We therefore evaluated whether Akt3 plays a role in the integrin outside-in signaling pathway. Figure 16A shows that Akt is robustly phosphorylated in wild type platelets spread on a fibrinogen-coated surface as detected by an anti-phosphoAkt S473 antibody recognizing all three Akt isoforms. Integrin-dependent phosphorylation of Akt was significantly inhibited in $\mathrm{Akt}^{-/-}$platelets, indicating that Akt3 is a major Akt isoform phosphorylated downstream of integrin signaling in mouse platelets (Figure 17A). Phosphorylation of Akt at T308 was also significantly reduced in $\mathrm{Akt3}^{-/-}$mouse platelets adherent on fibrinogen (Figure 16A). Thus, we further investigated the role of Akt3 in platelet spreading using $\mathrm{Akt3}^{-{ }^{-}}$mice. As shown in Figure 17, B and C, Akt3 $3^{-/}$partially, but significantly reduced platelet spreading on fibrinogen, suggesting that Akt3 is important in promoting platelet spreading. However, the incomplete inhibition by $\mathrm{Akt}^{-{ }^{--}}$is in contrast to the complete inhibition of platelet spreading by a higher dose of AktX, which inhibits all Akt isoforms. We also assessed the spreading of Akt1 ${ }^{-/-}$or Akt2 ${ }^{\text {- }}$ mouse platelets. Akt1 ${ }^{-/}$mouse platelets showed a partial reduction in spreading compared to WT, while no difference was observed using Akt2 ${ }^{--}$mouse platelets (Figure 18A and B). Combined with the data obtained with pan Akt inhibitors, our results suggest that Akt3 is an important isoform mediating integrin outside-in 
signaling. In addition, Akt1 is also important for full platelet spreading, although Akt2 does not appear to be required in the presence of Akt1 and Akt3.

\section{Akt-dependent phosphorylation of GSK-3 $\beta$ is a downstream} mechanism of integrin outside-in signaling

Akt is known to phosphorylate GSK-3 $\beta$, which negatively regulates GSK-3 $\beta$ function (Cross et al., 1995). GSK-3 $\beta$ was shown to negatively regulate thrombin receptor-mediated platelet activation and in vivo thrombosis ( $\mathrm{Li}$ et al., 2008). To determine whether Akt3 mediates integrin outside-in signaling and platelet spreading by phosphorylating and inactivating GSK-3 $\beta$, wild type and $\mathrm{Akt}^{-/-}$platelets were allowed to spread on fibrinogen and phosphorylation of Ser9 of GSK-3 $\beta$ was assessed by immunoblot with an antibody specifically recognizing phosphorylation at Ser9 site. Compared to wild type platelets spread on fibrinogen, $\mathrm{Akt}^{-/-}$platelets showed a significant reduction in GSK-3 $\beta$ phosphorylation, indicating that Akt3 is important for mediating GSK-3 $\beta$ phosphorylation during integrin outside-in signaling (Figure 17A). Akt1 $1^{-/-}$mouse platelets also showed a trend of reduced GSK-3 $\beta$ phosphorylation, but was not 


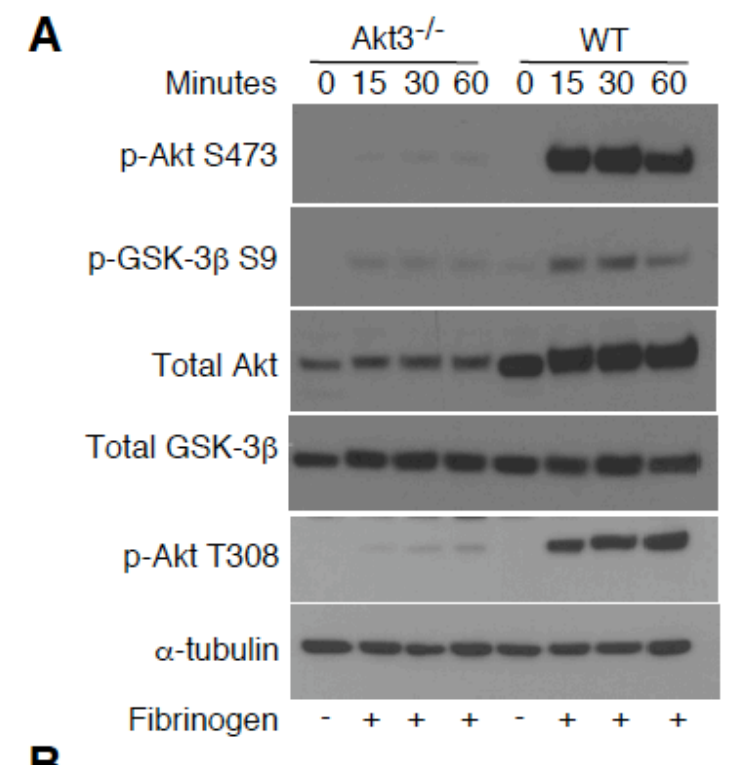

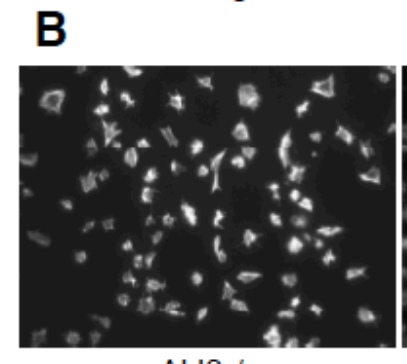

Akt3-/-

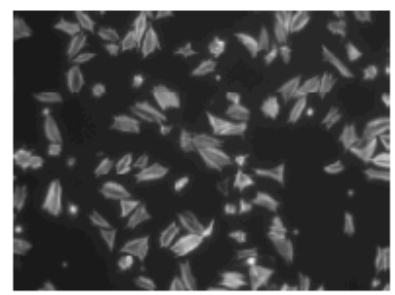

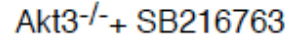

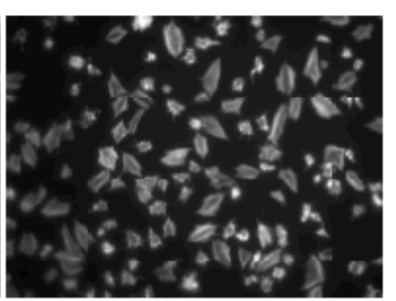

WT

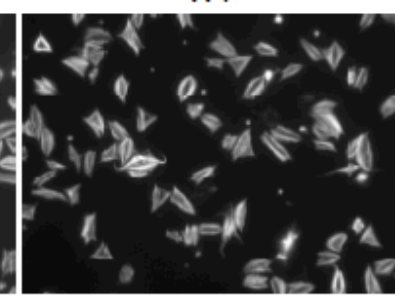

WT + SB216763

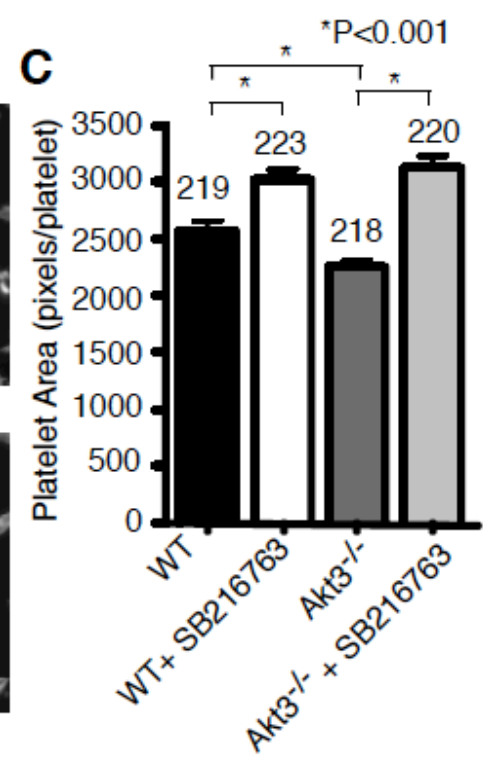

Figure 17. Effects of Akt3 knockout on integrin outside-in signaling and the role of GSK-3 $\beta$. (A) WT or Akt3 ${ }^{-1-}$ mouse platelets were allowed to spread on fibrinogen for indicated lengths of time or kept in suspension. Adherent platelets or control platelets were solubilized. Phosphorylation of Akt at S473 and T308, and GSK-3 $\beta$ at S9, and total Akt and GSK-3 $\beta$ levels were analyzed by western blot. (B) $\mathrm{Akt3}^{-/-}$or WT mouse platelets were preincubated with GSK-3 $\beta$ inhibitor SB216763 or control DMSO and spread on fibrinogen for 2 hours. Adherent platelets were fixed, permeabilized, and stained with phalloidin and observed with a fluorescence microscope. (C) The surface area of single platelets in (B) was measured, and graphed as the average surface area $( \pm S E)$ of individual platelets. Difference between groups was analyzed using Student's $t$ test. Shown in the figure are representative pictures from one of three experiments, and are from atleast 3 randomly selected fields. Numbers of platelets analyzed for each group are indicated above the bars. 


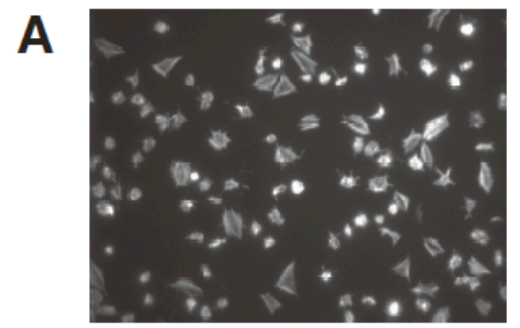

Akt1-/-

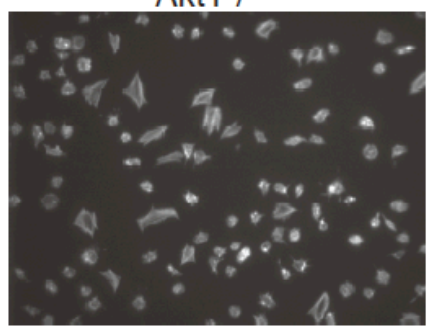

Akt3-/-

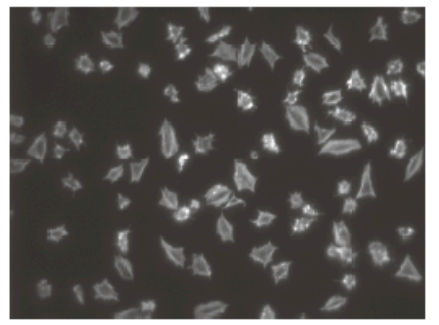

Akt2-/-

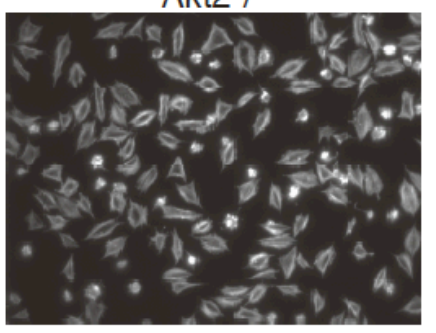

WT

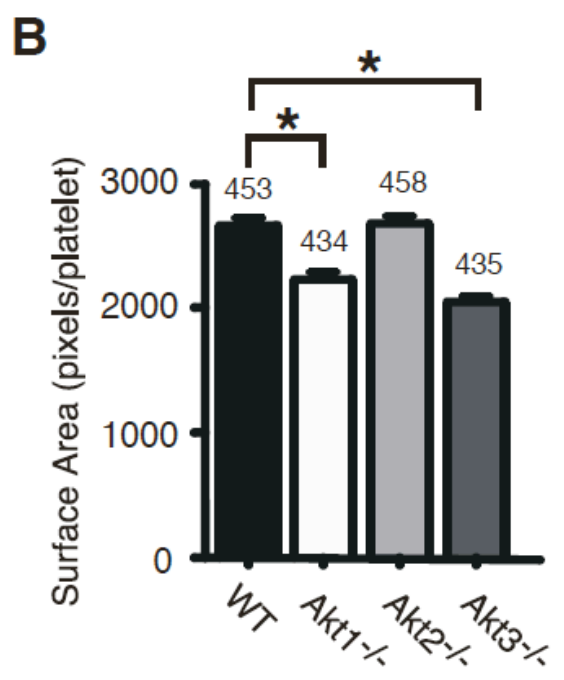

Figure 18. Spreading of Akt isoform knockout mouse platelets. (A) WT, $\mathrm{Akt}^{-/-}$, Akt2 ${ }^{--}$, or $\mathrm{Akt}^{-1-}$ mouse platelets were spread on fibrinogen for 2 hours. Adherent platelets were fixed, permeabilized, and stained with phalloidin. Platelets were observed with a fluorescence microscope. (B) Surface area of single platelets was quantitated (average surface area $\pm S E$ ). Statistical significance of the difference between groups was analyzed using Student's $t$ test $(p<0.05)$. Shown in the figure are representative pictures from one of three experiments, and at least 3 randomly selected fields. Numbers of platelets analyzed for each group are indicated above the bars. 
statistically significant (data not shown). In order to further investigate whether negative regulation of GSK-3 $\beta$ is important in promoting integrin-dependent platelet spreading, we assessed the effect of GSK-3 $\beta$ selective inhibitor SB216763 on platelet spreading on fibrinogen-coated surfaces. Treatment of platelets with SB216763 significantly promoted platelet spreading compared to DMSO control, indicating that GSK-3 $\beta$ negatively regulates platelet spreading and thus, inhibition of GSK-3 $\beta$ promotes platelet spreading (Figure 17, B and C). Because Akt3 $^{-/-}$has reduced GSK-3 $\beta$ phosphorylation, which presumably results in increased GSK-3 $\beta$ activity, we sought to determine whether the spreading defect of $\mathrm{Akt3}^{-{ }^{-}}$platelets could be corrected by treatment with GSK-3 $\beta$ inhibitor SB216763. Akt3 $^{-/-}$platelets were treated with the GSK-3 $\beta$ inhibitor and allowed to spread on fibrinogen. Indeed, the inhibitory effect of Akt3 knockout on platelet spreading was reversed by GSK-3 $\beta$ inhibitor SB216763 (Figure 17, B and C). Interestingly, spreading of platelets treated with the pan Akt inhibitor AktX or with the PI3K inhibitor LY294002 was partially rescued by treatment with SB216763 (Figure $19, A$ and B). Thus, negative regulation of GSK-3 $\beta$ is a likely mechanism downstream of $\mathrm{PISK}$ and Akt3 that promotes integrin-dependent platelet spreading, although we do not exclude possible additional mechanisms, particularly for other Akt isoforms. 
A
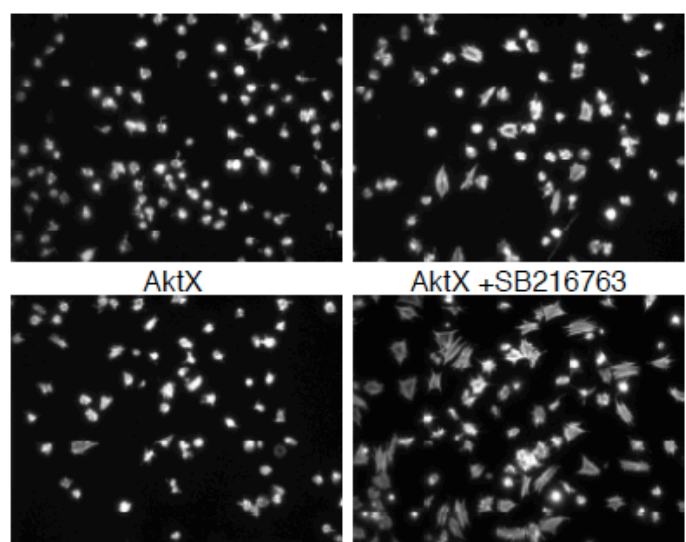

AktX +SB216763

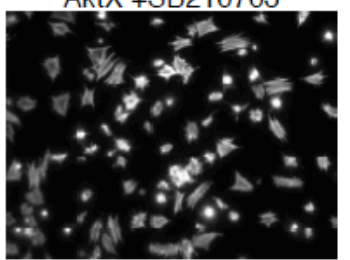

LY294002

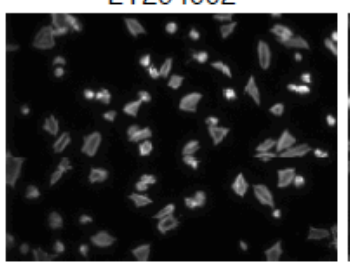

LY294002 +SB216763

DMSO

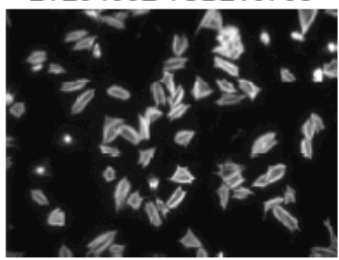

SB216763

B

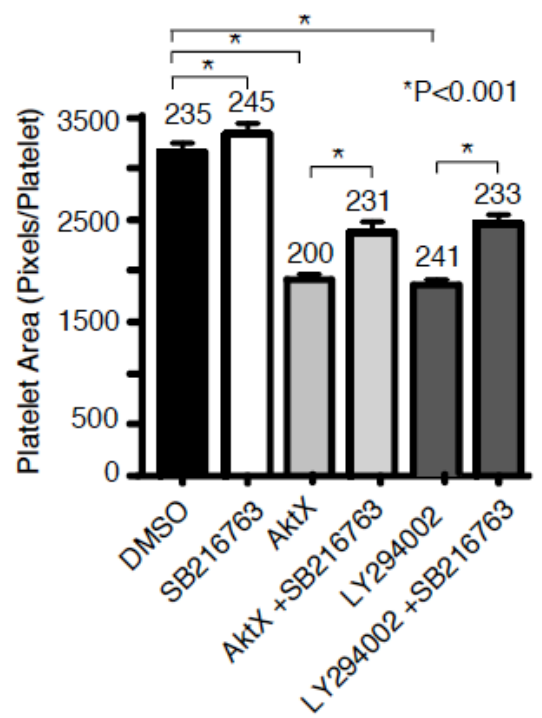

Figure 19. Reversal of the inhibitory effect of PI3K/Akt inhibitors on platelet spreading by GSK-3 $\beta$ inhibitor. (A) WT mouse platelets were preincubated with AktX $(5 \mu \mathrm{M})$, LY294002 $(20 \mu \mathrm{M})$, or DMSO control in the presence and absence of GSK-3 $\beta$ inhibitor SB216763 $(10 \mu \mathrm{M})$ and allowed to adhere and spread on fibrinogen for 2 hours. Adherent platelets were fixed, permeabilized, stained with phalloidin, and observed with a fluorescence microscope. (B) The surface area of single platelets was quantitated (average surface area \pm SE). Statistical significance of the difference between groups was analyzed using Student's $t$ test. Shown in the figure are representative pictures from one of three experiments, and are from atleast 3 randomly selected fields. Numbers of platelets analyzed for each group are indicated above the bars. 


\section{Src and ADP receptor-dependent activation of the PI3K-Akt} signaling pathway during integrin signaling

Thus far, our experiments reveal an important role for the PI3K-AktGSK-3 $\beta$ signaling pathway in promoting platelet spreading. To understand the molecular mechanisms that are responsible for the activation of this pathway during integrin outside-in signaling, we examined whether phosphorylation of Akt can be affected by inhibitors of intracellular signaling molecules involved in integrin outside-in signaling. As expected, Akt is phosphorylated following spreading of human platelets on integrin ligand fibrinogen. PI3K inhibitor wortmannin or LY294002 totally abolished Akt phosphorylation, indicating that $\mathrm{PI} 3 \mathrm{~K}$ is indeed responsible for Akt phosphorylation and thus, Akt phosphorylation is an indicator of PI3K activation under our experimental conditions (Figure 20, A and B). PP2, an inhibitor of Src family kinases (SFKs), also abolished integrindependent Akt phosphorylation, indicating that SFK is required for integrininduced activation of the PI3K/Akt signaling pathway (Figure 20C). In order to determine whether activation of the ITAM and Syk signaling pathway, which are important in amplifying integrin signaling, are required for integrin-induced PI3KAkt activation, we tested the effect of the Syk inhibitor piceatannol on phosphorylation of Akt. Akt phosphorylation in human platelets spread on fibrinogen was not affected by piceatannol at $10 \mu \mathrm{M}$ (Figure 20D), which inhibited collagen-induced platelet aggregation (data not shown). This result indicates the ITAM/Syk pathway is not required for Akt activation induced by integrin outside-in 
signaling. Thus, the PI3K/Akt pathway is downstream from SFKs, but not ITAM/Syk, in the integrin outside-in signaling pathway.

Interestingly, integrin-mediated Akt phosphorylation was reduced in human platelets by an antagonist of ADP receptor P2Y12, 2-MeSAMP, and was further reduced when 2-MeSAMP was used together with A3P5P, an antagonist of the other platelet ADP receptor, P2Y1 (Figure 21A). To exclude the possible nonspecific effects of ADP receptor antagonists, we also examined integrindependent Akt phosphorylation in mouse platelets deficient in the P2Y12 receptor (P2Y12 knockout). Indeed, Akt phosphorylation in $\mathrm{P} 2 \mathrm{Y} 12^{-/-}$platelets was also reduced (Figure 21B). P2Y12/- mouse platelets treated with A3P5P further inhibited phosphorylation of Akt, as well as GSK-3 $\beta$ (Figure 21C). Thus, we conclude that ADP receptor signaling, particularly P2Y12 signaling, is important in integrin-induced and Src-dependent activation of the PI3K/Akt signaling pathway. It is important to note that there is still residual phosphorylation of Akt and GSK-3 $\beta$ in the presence of P2Y1/P2Y12 blockade, indicating a small pool of Akt and GSK-3 $\beta$ may be activated by ADP-independent mechanisms. 

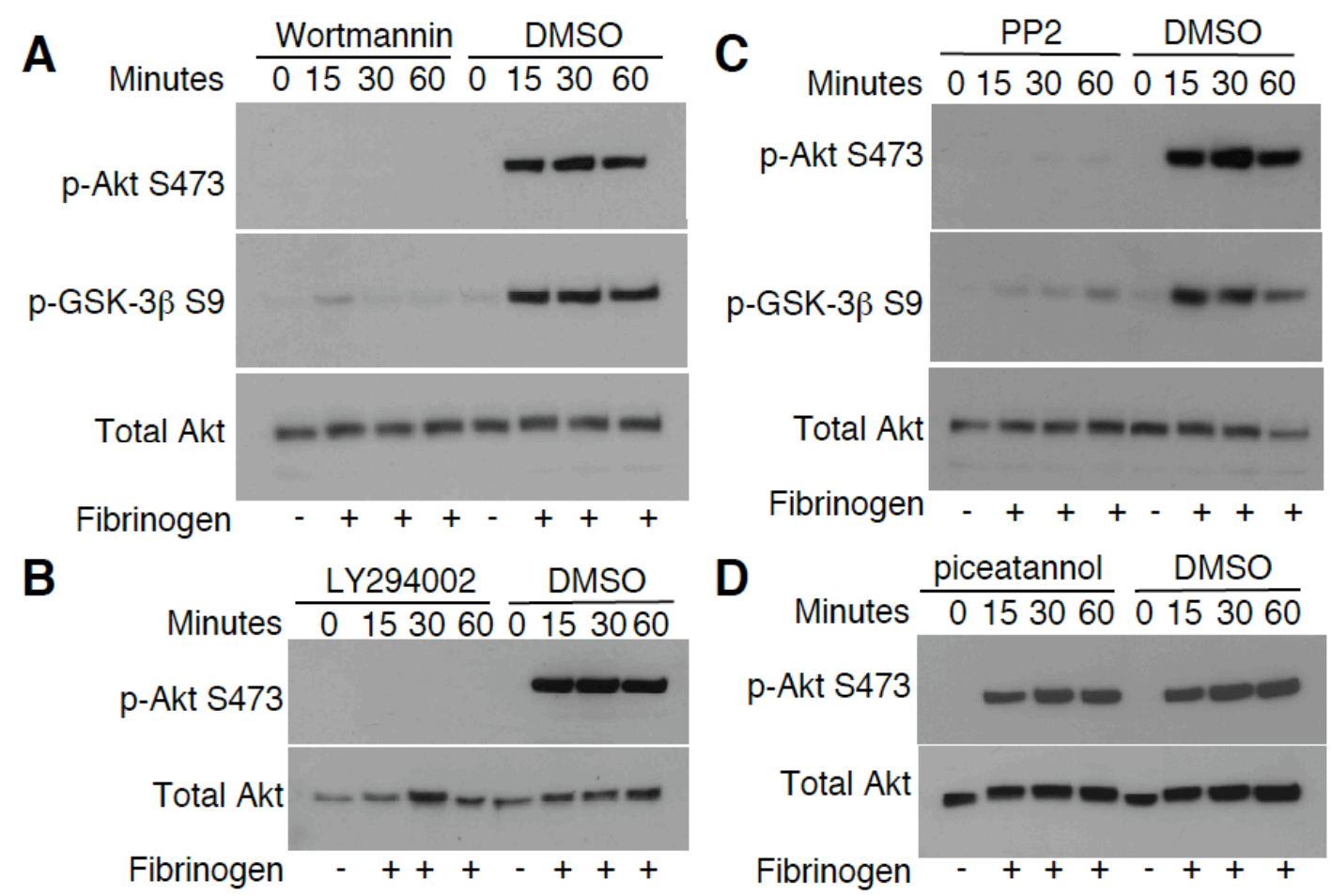

D Minutes $\frac{\text { piceatannol }}{0153060} \frac{\text { DMSO }}{0153060}$

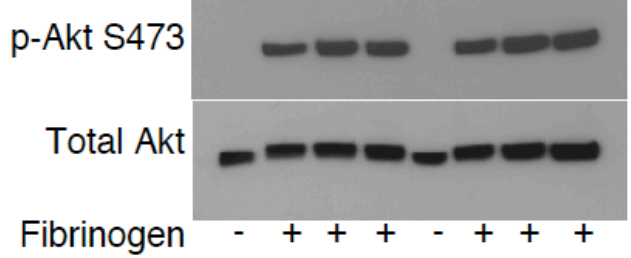

Figure 20. Upstream molecules important in Akt activation. Human platelets were treated with (A) PI3K inhibitor wortmannin (100 nM) (B) PI3K inhibitor

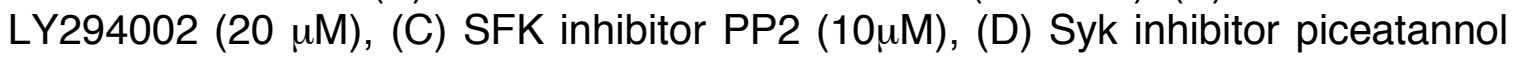
$(10 \mu \mathrm{M})$, or DMSO control, and spread on fibrinogen or kept in suspension. Adherent platelets were solubilized and western blot analysis was performed for indicated proteins. 
To directly address whether integrin ligation with fibrinogen induces dense granule secretion, we measured ATP release of platelets spread on fibrinogen using a luciferase assay. There was a significant increase in ATP release that was detected in platelets spread on fibrinogen, compared to platelets added to BSA control wells (Figure 21D). Integrin-dependent platelet adhesion does not require prior stimulation by exogenous agonists; therefore, our data indicates that ADP receptor signaling that stimulates activation of the PI3K/Akt pathway is likely to be induced by endogenously secreted ADP during platelet spreading on integrin ligands. 

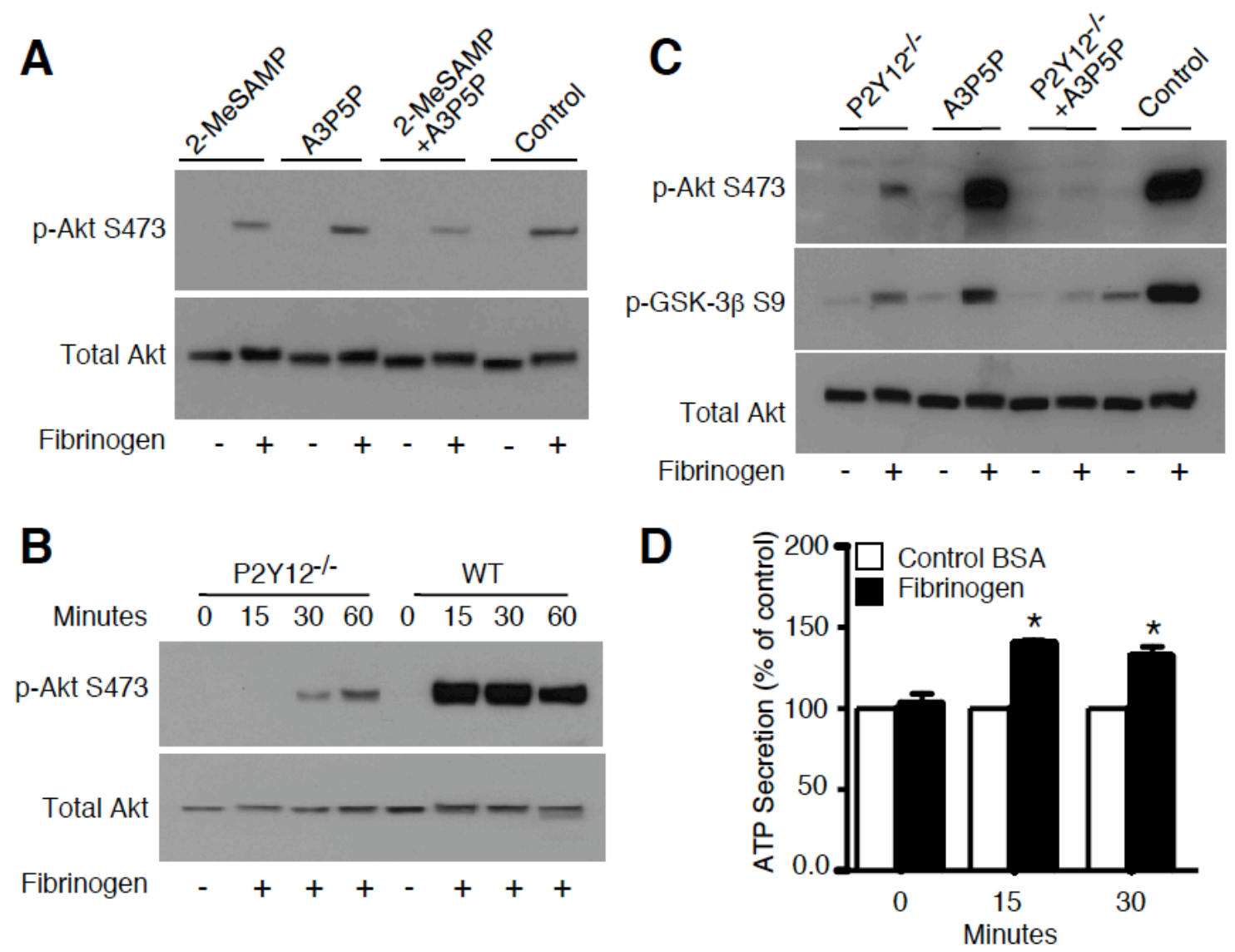

Figure 21. Effect of P2Y12 knockout and ADP receptor antagonists on integrin-dependent Akt activation. (A) Human platelets were pre-incubated with 2-MeSAMP $(50 \mu \mathrm{M})$, A3P5P $(0.5 \mathrm{mM})$, both, or control, and allowed to adhere and spread on fibrinogen for 30 minutes. Adherent and control platelets in suspension were solubilized. Phosphorylation of Akt, and total Akt were analyzed by western blot. (B) WT or P2Y12 $2^{-/}$mouse platelets were added to fibrinogen. Spreading and western blot were performed as in (A). (C) WT or P2Y12 ${ }^{-/}$mouse platelets were treated with A3P5P $(0.5 \mathrm{mM})$ or control, and spreading and western blot was performed as indicated in (A). (D) Human platelets were added to BSA or fibrinogen coated wells for indicated times. Luciferase was added and ATP secretion was detected using a luminometer. The relative quantity of ATP secretion is expressed as the percentage increase of BSA control (mean \pm SE, $\mathrm{n}=3$ ). The difference between control and fibrinogen at 15 and 30 minutes time point are significant $(\mathrm{P}<0.03)$, as determined by student's t-test. 
To determine whether the effects of ADP receptor signaling on PI3K/Akt pathway is functionally important in integrin-dependent platelet spreading, we compared the spreading of $\mathrm{P} 2 \mathrm{Y}_{12} 2^{-/}$platelets and $\mathrm{P} 2 \mathrm{Y} 12$ antagonist 2-MeSAMP treated platelets with wild type platelets. $\mathrm{P} 2 \mathrm{Y} 12^{-/}$platelets and $\mathrm{P} 2 \mathrm{Y} 12$ antagonisttreated platelets showed a significant, but partial inhibition of platelet spreading compared to control platelets, indicating that $\mathrm{P} 2 \mathrm{Y} 12$ signaling is important in promoting integrin outside-in signaling leading to platelet spreading (Figure 22, AD). We also tested the effect of the P2Y1 antagonist A3P5P on spreading of control or $\mathrm{P} 2 \mathrm{Y}_{12} 2^{--}$mouse platelets. Consistent with the relatively minor defects caused by A3P5P in the activation of the PI3K-Akt pathway, only a minor spreading defect was observed in wild type or human platelets treated with A3P5P. However, A3P5P significantly further inhibited platelet spreading in $\mathrm{P} 2 \mathrm{Y}_{12}{ }^{-/}$mouse platelets (Figure 22, A and B). Human platelets treated with ADP receptor P2Y12 antagonist 2-MeSAMP (and to a similar degree A3P5P) similarly inhibited platelet spreading on fibrinogen (Figure 22, C and D). These results suggest an important role for $\mathrm{P} 2 \mathrm{Y} 12$ and $\mathrm{P} 2 \mathrm{Y} 1$ receptors in promoting integrin outside-in signaling leading to platelet spreading. 


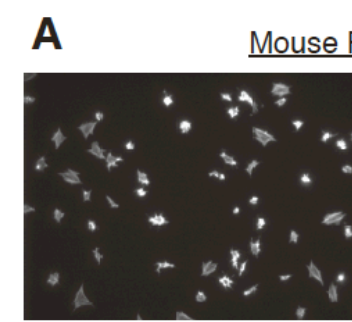

$\mathrm{P} 2 \mathrm{Y} 12^{-/-}$

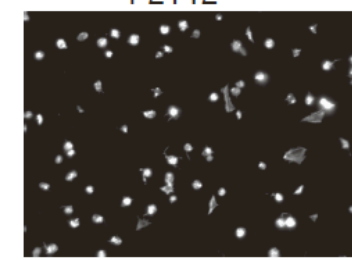

$\mathrm{P} 2 \mathrm{Y} 12^{-/-}$ $+\mathrm{A} 3 \mathrm{P} 5 \mathrm{P}$

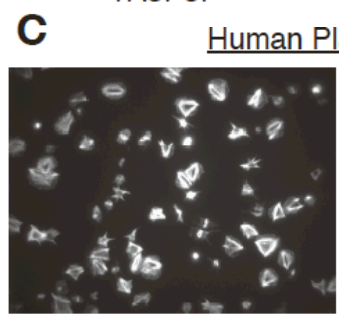

2Me-SAMP

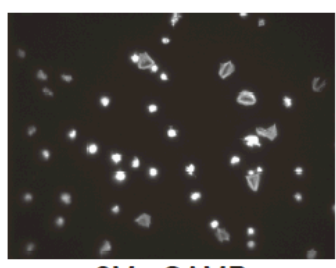

2Me-SAMP

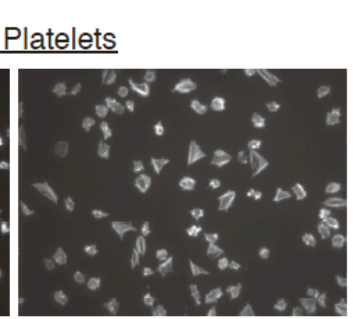

A3P5P

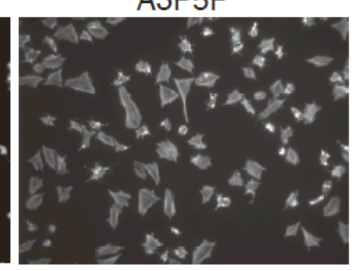

WT

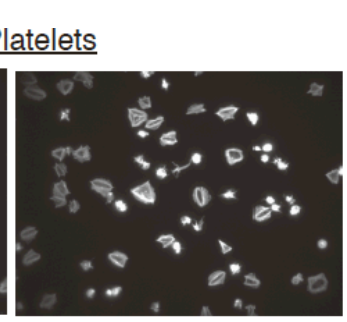

A3P5P

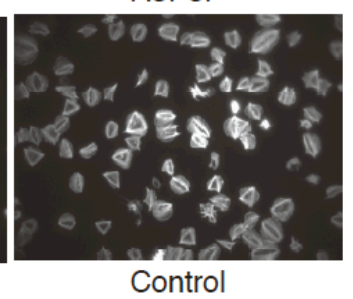

B
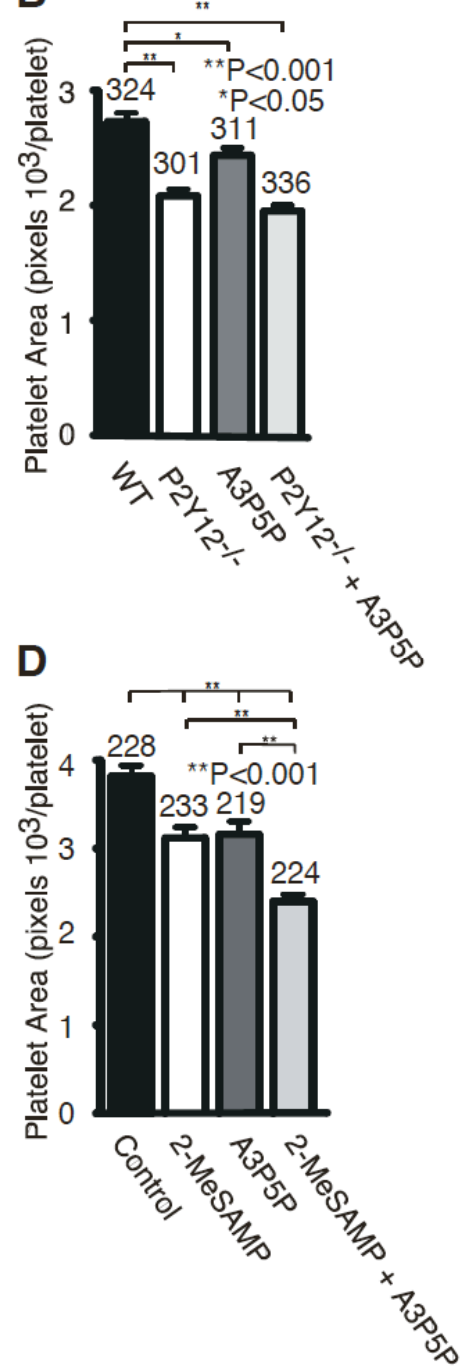

Figure 22. Effect of P2Y12 knockout and ADP receptor antagonists on platelet spreading. (A) WT or P2Y12 ${ }^{-/}$mouse platelets were treated with A3P5P $(0.5 \mathrm{mM})$ or control and spread on fibrinogen for 2 hours. Adherent platelets were stained with phalloidin and observed as described in previous figures. (B) The surface area of single platelets was measured and average surface area $( \pm S E)$ of individual platelets is graphed. Difference between groups was analyzed using Student's $t$ test. Shown in the figure are representative pictures from one of three experiments, and are from at least 3 randomly selected fields. Numbers of platelets analyzed for each group are indicated above the bars. (C) Human platelets were treated with 2-MeSAMP $(50 \mu \mathrm{M})$, A3P5P $(0.5 \mathrm{mM})$, both, or control, and spread on fibrinogen for 1 hour. Adherent platelets were stained with phalloidin as described in previous figures. (D) Quantitation was performed as in (B). 


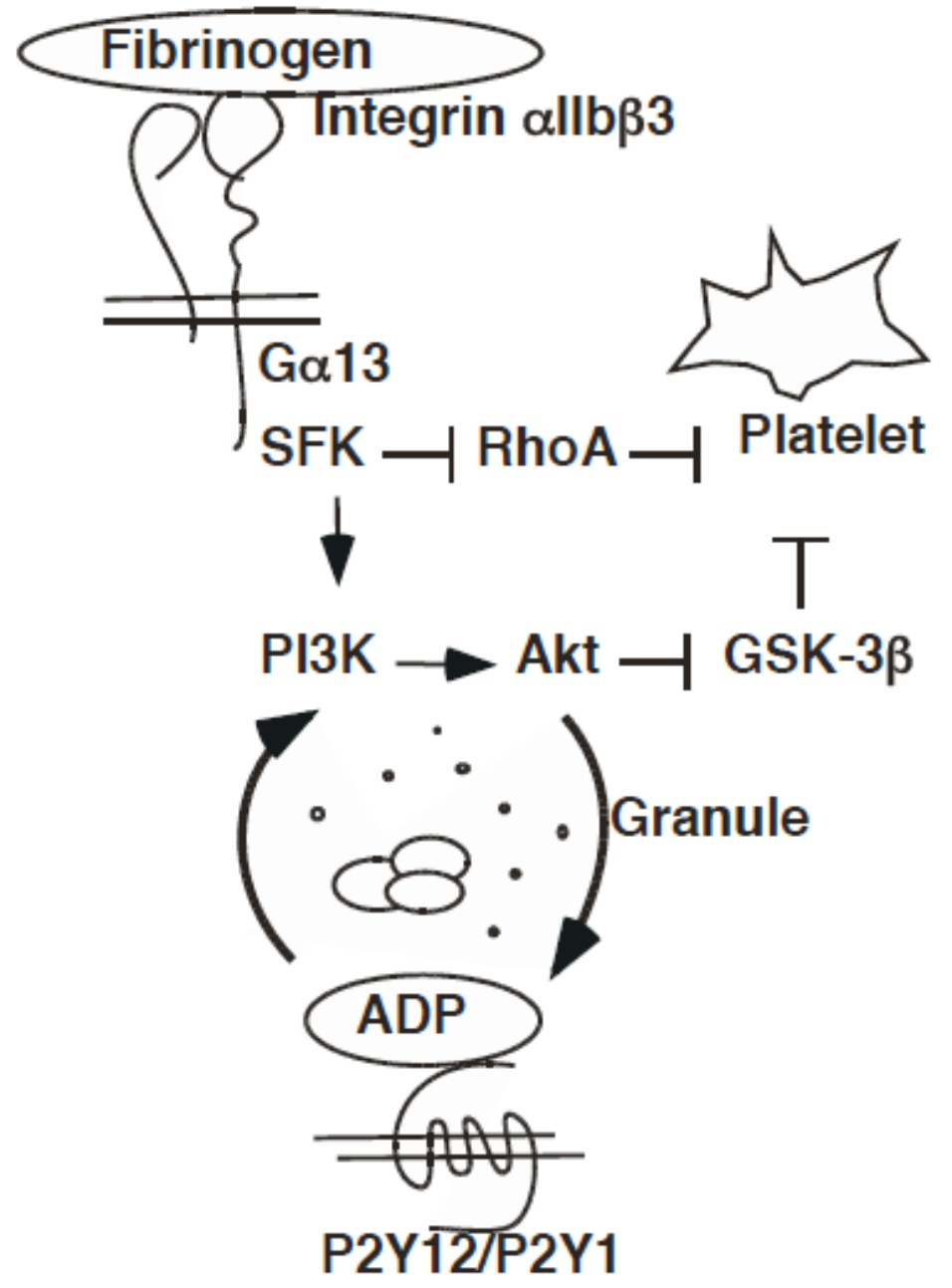

Figure 23. Integrin $\alpha$ llb $\beta 3$-mediated activation of the PI3K-Akt-GSK-3 $\beta$ pathway important in outside-in signaling 


\section{b. Discussion}

In this study, we show that (1) Akt, as a downstream effector of PI3K, plays an important role in mediating integrin outside-in signaling leading to platelet spreading; (2) Akt promotes platelet spreading by phosphorylating and inhibiting GSK-3 $\beta$; and (3) activation of PI3K-Akt-GSK-3 $\beta$ pathway is downstream from SFK and requires platelet secretion of ADP and ADP receptor signaling. Taken together, our results reveal a novel outside-in signaling pathway involving sequential activation of Src, ADP secretion, P2Y12/P2Y1-dependent activation of PI3K and Akt, and Akt-mediated inhibition of GSK-3 $\beta$, leading to stimulation of platelet spreading (Figure 23). Our study also demonstrates a novel mutually amplifying relationship between the G-protein-coupled P2Y12/P2Y1 receptor signaling pathways and integrin outside-in signaling pathways.

It has been shown by several groups that PI3Ks, including both type I and type II, play an important role in integrin signaling (Banfic et al., 1998; Canobbio et al., 2009; Jackson et al., 2004; Kovacsovics et al., 1995; Zhang et al., 1998). However, the downstream effector that is important in mediating PI3K signals promoting platelet spreading is unclear. Among potential PI3K effectors, all three Akt isoforms have been shown to be expressed in platelets and to be important in mediating platelet granule secretion, and secretion-dependent amplification of platelet aggregation (Chen et al., 2004; O'Brien et al., 2011; Stojanovic et al., 2006; Woulfe et al., 2004). However, it is unclear whether Akt isoforms are also important in integrin outside-in signaling. In this study, we have shown that 
treatment of human or mouse platelets with a pan Akt inhibitor, AktX, that is a non-phosphoinositide competitor, potently inhibits platelet spreading on fibrinogen (Figure 16). Furthermore, the spreading of $\mathrm{Akt}^{-/-}$platelets was also partially inhibited (Figure 17, B and C). Therefore, we conclude that Akt is an important downstream effector that mediates PI3K-dependent integrin outside-in signaling. Our data further indicate that the Akt3 isoform is important in outside-in signaling, but also suggest the involvement of other Akt isoforms.

Our data suggest that phosphorylation and inhibition of GSK-3 $\beta$, a known Akt substrate, is an important downstream mechanism responsible for the role of Akt3 in promoting platelet spreading. This is supported by the data that $A k t 3^{-/-}$ platelets spread on fibrinogen showed a significant reduction in GSK-3 $\beta$ phosphorylation (Figure 17A) and that GSK-3 $\beta$ inhibition by SB216763 was sufficient to completely rescue the defect in $\mathrm{Akt}^{-/}$platelet spreading. These data indicate that the role of Akt3 in platelet spreading is mainly mediated by GSK-3 $\beta$ (Figure 17, B and C). Consistently, inhibition of GSK-3 $\beta$ also partially rescued spreading defects of platelets treated with pan-Akt inhibitor AktX or PI3K inhibitor LY294002 (Figure 19, A and B). However, partial rescue by SB216763 suggests the possible presence of other integrin-dependent Akt-mediated signaling pathways that are independent of GSK-3 $\beta$. Further study is needed to resolve how GSK-3 $\beta$ negatively regulates platelet spreading.

It is known that ADP secretion can promote platelet spreading on immobilized fibrinogen and scavengers of ADP such as apyrase can inhibit platelet spreading 
(Haimovich et al., 1993; Jirouskova et al., 2007). It has also been reported that platelets from a patient deficient in ADP receptor $\mathrm{P} 2 \mathrm{Y} 12$ have defective spreading on fibrinogen (Shiraga et al., 2005). Correspondingly, our data demonstrating defective spreading in $\mathrm{P} 2 \mathrm{Y} 12^{-/-}$mouse platelets and $\mathrm{P} 2 \mathrm{Y} 12$ or P2Y1 inhibitor treated platelets support the implication of ADP in amplifying integrin outside-in signaling and spreading (Figure 22). However, the mechanism by which ADP promotes platelet spreading has been unclear. It is both possible that the roles of ADP can be due to increasing either integrin activation (insideout signaling) or outside-in signaling. Our data clearly show that the role of ADP in promoting platelet spreading is due to its role in amplifying the PI3K-Akt-GSK$3 \beta$ signaling pathway during outside-in signaling, and thus provide a plausible molecular mechanism for the role of ADP in promoting platelet spreading (Figure 21). It is important to note that because integrin-dependent platelet adhesion does not require prior stimulation by agonists and we have used carefully prepared resting platelets without exogenous agonists, ADP receptor signaling that stimulates activation of the PI3K/Akt pathway is likely to be induced by endogenously secreted ADP during platelet spreading on integrin ligands. Indeed, we, for the first time, detected granule secretion from platelets adherent on a fibrinogen coated surface (Figure 21D). Thus, we conclude that granule secretion induced by integrin outside-in signaling plays an important role in stimulating activation of the PI3K/Akt pathway and thus platelet spreading. 
Interestingly, our data also show that, while ADP receptors play a major role in PI3K/Akt activation, activation of a small pool of Akt is independent of ADP receptors, but clearly requires the function of SFKs (Figure 20C). The spreading defect in platelets treated with a high dose of AktX (Figure 16) also appears to be greater than that in $\mathrm{P} 2 \mathrm{Y} 12^{-/}$platelets treated with $\mathrm{P} 2 \mathrm{Y} 1$ antagonists (Figure 22), which is consistent with an ADP-independent activation of Akt in promoting spreading. In other platelet signaling pathways, such as thrombin receptor and GPIb-IX pathways, it has previously been shown that SFKs are important in stimulating the activation of PI3K/Akt pathway (Cho et al., 2002; Li et al., 2010b; Yin et al., 2008a). Furthermore, in the platelet activation pathways induced by thrombin and $\mathrm{TXA}_{2}$, PI3K/Akt activation involves a P2Y12-independent mechanism that accounts for a small fraction of Akt activation and a major amplification role of P2Y12/Gi signaling (Li et al., 2003b; Xiang et al.). Thus, a small, initial SFK-dependent activation of PI3K/Akt and an ADP-dependent amplification of PI3K/Akt activation may be a general mechanism in which the PI3K/Akt pathway becomes fully functional during platelet activation induced by not only soluble agonist receptors, but also integrins and other adhesion receptors. It is interesting to note that a major role of Akt isoforms in regulating platelet function downstream from soluble agonists is to promote platelet dense granule secretion (Chen et al., 2004; O'Brien et al., 2011; Stojanovic et al., 2006; Woulfe et al., 2004; Yin et al., 2008b). Thus, we hypothesized that one of the roles of SFK-dependent initial activation of Akt isoforms in regulating platelet 
spreading may be to induce platelet granule secretion. Secreted ADP then greatly augments the PI3K-Akt-GSK-3 $\beta$ pathway, resulting in stronger amplification of integrin outside-in signaling and enhancement of platelet spreading. Nonetheless, the precise mechanism by which the PI3K-Akt-GSK-3 $\beta$ pathway promotes outward movement of the platelet membrane and spreading requires further examination.

This research study was originally published in Arteriosclerosis, Thrombosis, and Vascular Biology. O'Brien KA, Gartner TK, Hay N, Du X. ADPstimulated activation of Akt during integrin outside-in signaling promotes platelet spreading by inhibiting glycogen synthase kinase-3 $\beta$. Arterioscler Thromb Vasc Biol. 2012 Jul 19. In press. (c) American Heart Association.

Portions of the publication are reproduced here with permission of the American Heart Association. 


\section{CONCLUSIONS}

From the data presented in this study, we can derive several conclusions. First, Akt3 is expressed in platelets and plays an important role in platelet function and thrombosis. Second, the role of Akt3 in platelets is different from the previous characterized Akt isoforms Akt1 and Akt2 in that Akt3 selectively plays a stimulatory role in the signaling pathways of two $G q / G 13$ coupled receptors (thrombin receptors PAR4 and $\mathrm{TXA}_{2}$ receptor), but is not required in the signaling pathways mediated by collagen receptor, ADP receptor and VWF receptor. Therefore, different isoforms of Akt have distinct and shared roles in platelet activation. Third, Akt (specifically Akt3) plays an important role in integrin outside-in signaling and is important in promoting platelet spreading on integrin ligands. The role of Akt provides a mechanism why PI3K is important for cell spreading in platelets and other cell types. In addition, we have shown that a major mechanism by which Akt3 mediates platelet activation signaling is its phosphorylation and inhibition of GSK-3 $\beta$. This is different from the major mechanisms responsible for the roles of Akt1 and Akt2, which are to stimulate the cGMP-dependent protein kinase pathway. Furthermore, GSK-3 $\beta$ plays an inhibitory role in thrombin-induced platelet activation and a novel role in negatively regulating platelet spreading, which is regulated by Akt3. Finally, we have shown that full activation of Src/PI3K/Akt pathway during integrin outside-in signaling requires integrin-mediated ADP secretion and ADP signaling through P2Y12/P2Y1 receptors. This provides a mechanism to explain the importance of 
ADP secretion in platelet spreading. Taken together, these studies have identified a novel role for Akt3 in platelet activation, thrombosis, and integrin outside-in signaling (Figure 24).

In conclusion, this study contributes to the mechanistic understanding of the signaling pathways that are important for platelet activation, adhesion and thrombus formation. Understanding of the signaling pathways may aid in the development of new targets for anti-thrombotics that inhibit thrombosis, yet minimize adverse bleeding side effects. Thus, identifying the signaling mechanisms that are important for amplification of platelet activation, but do not affect primary aggregation and adhesion may prove beneficial. This study also provides novel insight into the signaling mechanisms of integrin signaling and the PI3K/Akt pathway that are of significance to our understanding of molecular cell biology and human diseases.

The data presented here raise several important questions. How are Akt isoforms involved in different pathways, despite their structural similarity? Are they localized to distinct compartments in platelets? Are there other Akt substrates expressed in platelets that mediate its effects? How does GSK-3 $\beta$ mediate platelet spreading and granule secretion? What is downstream from GSK-3 $\beta$ ? Future studies may aid in further understanding the mechanisms of Akt and GSK-3 $\beta$ in regulating platelet activation signaling. 


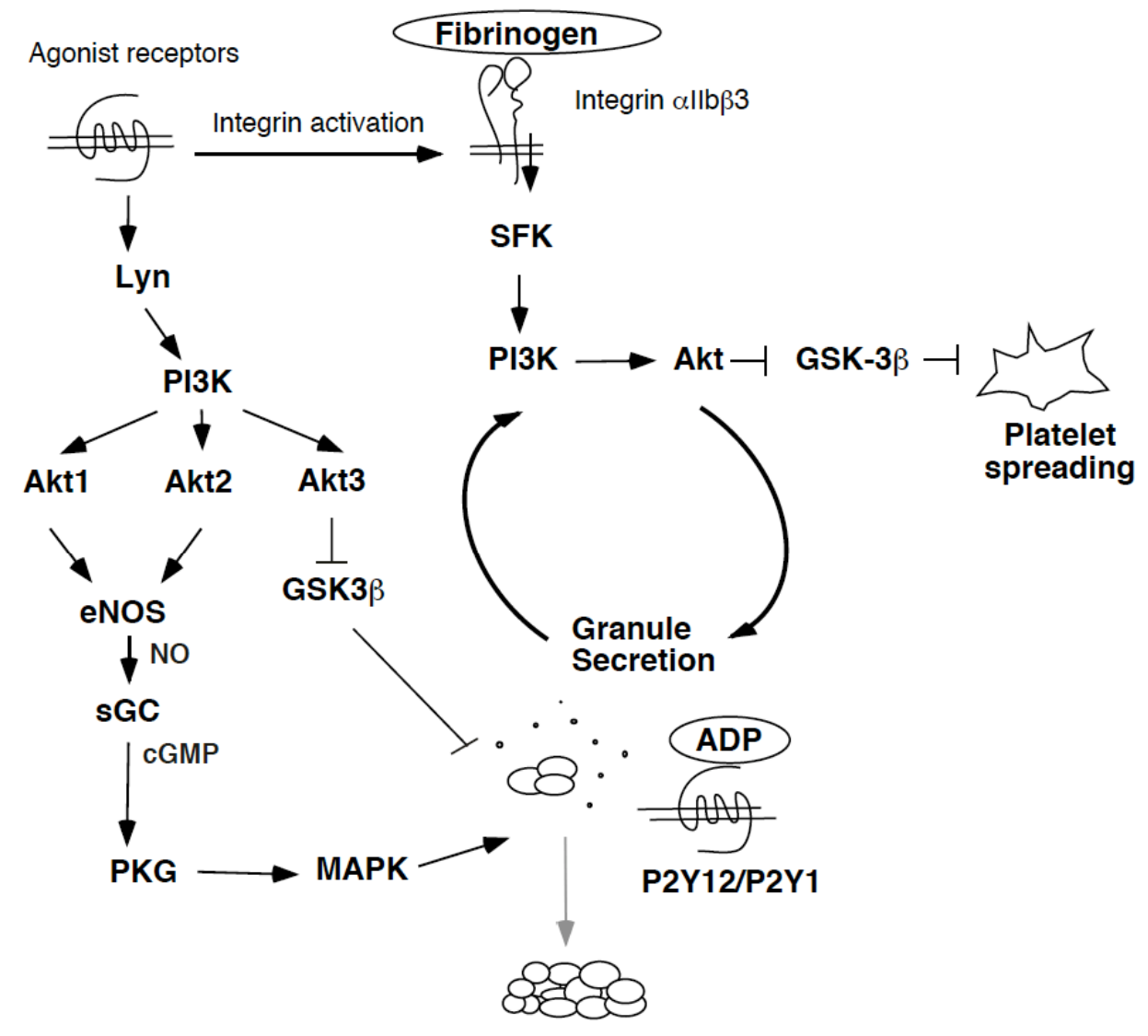

Amplification and stabiilization of platelet aggregation

Figure 24. Summary of the role of Akt isoforms in platelet activation 


\section{CITED LITERATURE}

Alessi, D.R., S.R. James, C.P. Downes, A.B. Holmes, P.R. Gaffney, C.B. Reese, and P. Cohen. 1997. Characterization of a 3-phosphoinositide-dependent protein kinase which phosphorylates and activates protein kinase Balpha. Curr Biol. 7:261-9.

Altomare, D.A., G.E. Lyons, Y. Mitsuuchi, J.Q. Cheng, and J.R. Testa. 1998. Akt2 mRNA is highly expressed in embryonic brown fat and the AKT2 kinase is activated by insulin. Oncogene. 16:2407-11.

Andrews, R.K., and J.E. Fox. 1991. Interaction of purified actin-binding protein with the platelet membrane glycoprotein Ib-IX complex. J Biol Chem. 266:7144-7.

Andrews, R.K., A.D. Munday, C.A. Mitchell, and M.C. Berndt. 2001. Interaction of calmodulin with the cytoplasmic domain of the platelet membrane glycoprotein Ib-IX-V complex. Blood. 98:681-7.

Arias-Salgado, E.G., S. Lizano, S. Sarkar, J.S. Brugge, M.H. Ginsberg, and S.J. Shattil. 2003. Src kinase activation by direct interaction with the integrin beta cytoplasmic domain. Proc Natl Acad Sci U S A. 100:13298-302.

Arthur, W.T., and K. Burridge. 2001. RhoA inactivation by p190RhoGAP regulates cell spreading and migration by promoting membrane protrusion and polarity. Mol Biol Cell. 12:2711-20.

Baglia, F.A., C.N. Shrimpton, J. Emsley, K. Kitagawa, Z.M. Ruggeri, J.A. Lopez, and P.N. Walsh. 2004. Factor XI interacts with the leucine-rich repeats of glycoprotein Ibalpha on the activated platelet. J Biol Chem. 279:49323-9.

Banfic, H., X. Tang, I.H. Batty, C.P. Downes, C. Chen, and S.E. Rittenhouse. 1998. A novel integrin-activated pathway forms PKB/Akt-stimulatory phosphatidylinositol 3,4-bisphosphate via phosphatidylinositol 3phosphate in platelets. $J$ Biol Chem. 273:13-6.

Barry, F.A., and J.M. Gibbins. 2002. Protein kinase B is regulated in platelets by the collagen receptor glycoprotein VI. J Biol Chem. 277:12874-8.

Barry, F.A., G.J. Graham, M.J. Fry, and J.M. Gibbins. 2003. Regulation of glycogen synthase kinase 3 in human platelets: a possible role in platelet function? FEBS Lett. 553:173-8. 
Bergmeier, W., T. Goerge, H.W. Wang, J.R. Crittenden, A.C. Baldwin, S.M. Cifuni, D.E. Housman, A.M. Graybiel, and D.D. Wagner. 2007. Mice lacking the signaling molecule CalDAG-GEFI represent a model for leukocyte adhesion deficiency type III. J Clin Invest. 117:1699-707.

Bhaskar, P.T., and N. Hay. 2007. The two TORCs and Akt. Dev Cell. 12:487-502.

Blake, R.A., G.L. Schieven, and S.P. Watson. 1994. Collagen stimulates tyrosine phosphorylation of phospholipase C-gamma 2 but not phospholipase Cgamma 1 in human platelets. FEBS Lett. 353:212-6.

Boylan, B., C. Gao, V. Rathore, J.C. Gill, D.K. Newman, and P.J. Newman. 2008. Identification of FcgammaRIla as the ITAM-bearing receptor mediating alphallbbeta3 outside-in integrin signaling in human platelets. Blood. 112:2780-6.

Bradford, H.N., R.A. Dela Cadena, S.P. Kunapuli, J.F. Dong, J.A. Lopez, and R.W. Colman. 1997. Human kininogens regulate thrombin binding to platelets through the glycoprotein Ib-IX-V complex. Blood. 90:1508-15.

Bradford, H.N., R.A. Pixley, and R.W. Colman. 2000. Human factor XII binding to the glycoprotein $\mathrm{Ib}-\mathrm{IX}-\mathrm{V}$ complex inhibits thrombin-induced platelet aggregation. J Biol Chem. 275:22756-63.

Buensuceso, C.S., A. Obergfell, A. Soriani, K. Eto, W.B. Kiosses, E.G. AriasSalgado, T. Kawakami, and S.J. Shattil. 2005. Regulation of outside-in signaling in platelets by integrin-associated protein kinase $\mathrm{C}$ beta. $\mathrm{J}$ Biol Chem. 280:644-53.

Canobbio, I., L. Stefanini, L. Cipolla, E. Ciraolo, C. Gruppi, C. Balduini, E. Hirsch, and M. Torti. 2009. Genetic evidence for a predominant role of PI3Kbeta catalytic activity in ITAM- and integrin-mediated signaling in platelets. Blood. 114:2193-6.

Chen, J., S. De, D.S. Damron, W.S. Chen, N. Hay, and T.V. Byzova. 2004. Impaired platelet responses to thrombin and collagen in AKT-1-deficient mice. Blood. 104:1703-10.

Chen, J., T.G. Diacovo, D.G. Grenache, S.A. Santoro, and M.M. Zutter. 2002. The alpha(2) integrin subunit-deficient mouse: a multifaceted phenotype including defects of branching morphogenesis and hemostasis. Am $J$ Pathol. 161:337-44. 
Chen, J., P.R. Somanath, O. Razorenova, W.S. Chen, N. Hay, P. Bornstein, and T.V. Byzova. 2005. Akt1 regulates pathological angiogenesis, vascular maturation and permeability in vivo. Nat Med. 11:1188-96.

Chen, J., H. Tang, N. Hay, J. Xu, and R.D. Ye. 2010. Akt isoforms differentially regulate neutrophil functions. Blood. 115:4237-46.

Chen, W.S., P.Z. Xu, K. Gottlob, M.L. Chen, K. Sokol, T. Shiyanova, I. Roninson, W. Weng, R. Suzuki, K. Tobe, T. Kadowaki, and N. Hay. 2001. Growth retardation and increased apoptosis in mice with homozygous disruption of the Akt1 gene. Genes Dev. 15:2203-8.

Cho, M.J., T.I. Pestina, S.A. Steward, C.A. Lowell, C.W. Jackson, and T.K. Gartner. 2002. Role of the Src family kinase Lyn in TxA2 production, adenosine diphosphate secretion, Akt phosphorylation, and irreversible aggregation in platelets stimulated with gamma-thrombin. Blood. 99:24427.

Chung, S.H., J. Polgar, and G.L. Reed. 2000. Protein kinase C phosphorylation of syntaxin 4 in thrombin-activated human platelets. $J$ Biol Chem. 275:25286-91.

Clemetson, J.M., J. Polgar, E. Magnenat, T.N. Wells, and K.J. Clemetson. 1999. The platelet collagen receptor glycoprotein $\mathrm{VI}$ is a member of the immunoglobulin superfamily closely related to FcalphaR and the natural killer receptors. J Biol Chem. 274:29019-24.

Coughlin, S.R. 2005. Protease-activated receptors in hemostasis, thrombosis and vascular biology. J Thromb Haemost. 3:1800-14.

Crittenden, J.R., W. Bergmeier, Y. Zhang, C.L. Piffath, Y. Liang, D.D. Wagner, D.E. Housman, and A.M. Graybiel. 2004. CalDAG-GEFI integrates signaling for platelet aggregation and thrombus formation. Nat Med. 10:982-6.

Cross, D.A., D.R. Alessi, P. Cohen, M. Andjelkovich, and B.A. Hemmings. 1995. Inhibition of glycogen synthase kinase-3 by insulin mediated by protein kinase B. Nature. 378:785-9.

Datta, S.R., H. Dudek, X. Tao, S. Masters, H. Fu, Y. Gotoh, and M.E. Greenberg. 1997. Akt phosphorylation of BAD couples survival signals to the cellintrinsic death machinery. Cell. 91:231-41. 
Day, S.M., J.L. Reeve, D.D. Myers, and W.P. Fay. 2004. Murine thrombosis models. Thromb Haemost. 92:486-94.

Dimmeler, S., I. Fleming, B. Fisslthaler, C. Hermann, R. Busse, and A.M. Zeiher. 1999. Activation of nitric oxide synthase in endothelial cells by Aktdependent phosphorylation. Nature. 399:601-605.

Djellas, Y., J.M. Manganello, K. Antonakis, and G.C. Le Breton. 1999. Identification of Galpha13 as one of the G-proteins that couple to human platelet thromboxane A2 receptors. J Biol Chem. 274:14325-30.

$\mathrm{Du}, \mathrm{X} .2007$. Signaling and regulation of the platelet glycoprotein Ib-IX-V complex. Curr Opin Hematol. 14:262-9.

Du, X., J.E. Fox, and S. Pei. 1996. Identification of a binding sequence for the 143-3 protein within the cytoplasmic domain of the adhesion receptor, platelet glycoprotein Ib alpha. J Biol Chem. 271:7362-7.

Du, X., S.J. Harris, T.J. Tetaz, M.H. Ginsberg, and M.C. Berndt. 1994. Association of a phospholipase A2 (14-3-3 protein) with the platelet glycoprotein Ib-IX complex. J Biol Chem. 269:18287-90.

Du, X., T.C. Saido, S. Tsubuki, F.E. Indig, M.J. Williams, and M.H. Ginsberg. 1995. Calpain cleavage of the cytoplasmic domain of the integrin beta 3 subunit. J Biol Chem. 270:26146-51.

Du, X.P., E.F. Plow, A.L. Frelinger, 3rd, T.E. O'Toole, J.C. Loftus, and M.H. Ginsberg. 1991. Ligands "activate" integrin alpha Ilb beta 3 (platelet GPIIb-IIla). Cell. 65:409-16.

Dudek, H., S.R. Datta, T.F. Franke, M.J. Birnbaum, R. Yao, G.M. Cooper, R.A. Segal, D.R. Kaplan, and M.E. Greenberg. 1997. Regulation of neuronal survival by the serine-threonine protein kinase Akt. Science. 275:661-5.

Dummler, B., O. Tschopp, D. Hynx, Z.Z. Yang, S. Dirnhofer, and B.A. Hemmings. 2006. Life with a single isoform of Akt: mice lacking Akt2 and Akt3 are viable but display impaired glucose homeostasis and growth deficiencies. Mol Cell Biol. 26:8042-51.

Easton, R.M., H. Cho, K. Roovers, D.W. Shineman, M. Mizrahi, M.S. Forman, V.M. Lee, M. Szabolcs, R. de Jong, T. Oltersdorf, T. Ludwig, A. Efstratiadis, and M.J. Birnbaum. 2005. Role for Akt3/protein kinase Bgamma in attainment of normal brain size. Mol Cell Biol. 25:1869-78. 
Ebbeling, L., C. Robertson, A. McNicol, and J.M. Gerrard. 1992. Rapid ultrastructural changes in the dense tubular system following platelet activation. Blood. 80:718-23.

Eldar-Finkelman, H. 2002. Glycogen synthase kinase 3: an emerging therapeutic target. Trends Mol Med. 8:126-32.

Embi, N., D.B. Rylatt, and P. Cohen. 1980. Glycogen synthase kinase-3 from rabbit skeletal muscle. Separation from cyclic-AMP-dependent protein kinase and phosphorylase kinase. Eur J Biochem. 107:519-27.

Escolar, G., and J.G. White. 1991. The platelet open canalicular system: a final common pathway. Blood Cells. 17:467-85; discussion 486-95.

Eto, K., R. Murphy, S.W. Kerrigan, A. Bertoni, H. Stuhlmann, T. Nakano, A.D. Leavitt, and S.J. Shattil. 2002. Megakaryocytes derived from embryonic stem cells implicate CalDAG-GEFI in integrin signaling. Proc Natl Acad Sci U S A. 99:12819-24.

Falet, H., A.Y. Pollitt, A.J. Begonja, S.E. Weber, D. Duerschmied, D.D. Wagner, S.P. Watson, and J.H. Hartwig. 2010. A novel interaction between FInA and Syk regulates platelet ITAM-mediated receptor signaling and function. J Exp Med. 207:1967-79.

Feng, W., M. Madajka, B.A. Kerr, G.H. Mahabeleshwar, S.W. Whiteheart, and T.V. Byzova. 2011. A novel role for platelet secretion in angiogenesis: mediating bone marrow-derived cell mobilization and homing. Blood. 117:3893-902.

Flevaris, P., Z. Li, G. Zhang, Y. Zheng, J. Liu, and X. Du. 2009. Two distinct roles of mitogen-activated protein kinases in platelets and a novel Rac1-MAPKdependent integrin outside-in retractile signaling pathway. Blood. 113:893901.

Flevaris, P., A. Stojanovic, H. Gong, A. Chishti, E. Welch, and X. Du. 2007. A molecular switch that controls cell spreading and retraction. J Cell Biol. 179:553-65.

Forde, J.E., and T.C. Dale. 2007. Glycogen synthase kinase 3: a key regulator of cellular fate. Cell Mol Life Sci. 64:1930-44. 
Foster, C.J., D.M. Prosser, J.M. Agans, Y. Zhai, M.D. Smith, J.E. Lachowicz, F.L. Zhang, E. Gustafson, F.J. Monsma, Jr., M.T. Wiekowski, S.J. Abbondanzo, D.N. Cook, M.L. Bayne, S.A. Lira, and M.S. Chintala. 2001. Molecular identification and characterization of the platelet ADP receptor targeted by thienopyridine antithrombotic drugs. J Clin Invest. 107:1591-8.

Fox, J.E. 1985. Linkage of a membrane skeleton to integral membrane glycoproteins in human platelets. Identification of one of the glycoproteins as glycoprotein Ib. J Clin Invest. 76:1673-83.

Fox, J.E. 2001. Cytoskeletal proteins and platelet signaling. Thromb Haemost. 86:198-213.

Frenette, P.S., C.V. Denis, L. Weiss, K. Jurk, S. Subbarao, B. Kehrel, J.H. Hartwig, D. Vestweber, and D.D. Wagner. 2000. P-Selectin glycoprotein ligand 1 (PSGL-1) is expressed on platelets and can mediate plateletendothelial interactions in vivo. J Exp Med. 191:1413-22.

Frenette, P.S., R.C. Johnson, R.O. Hynes, and D.D. Wagner. 1995. Platelets roll on stimulated endothelium in vivo: an interaction mediated by endothelial P-selectin. Proc Natl Acad Sci U S A. 92:7450-4.

Furie, B., B.C. Furie, and R. Flaumenhaft. 2001. A journey with platelet Pselectin: the molecular basis of granule secretion, signalling and cell adhesion. Thromb Haemost. 86:214-21.

Gao, T., F. Furnari, and A.C. Newton. 2005. PHLPP: a phosphatase that directly dephosphorylates Akt, promotes apoptosis, and suppresses tumor growth. Mol Cell. 18:13-24.

Garcia, A., T.M. Quinton, R.T. Dorsam, and S.P. Kunapuli. 2005. Src family kinase-mediated and Erk-mediated thromboxane A2 generation are essential for VWF/GPIb-induced fibrinogen receptor activation in human platelets. Blood. 106:3410-4.

Garofalo, R.S., S.J. Orena, K. Rafidi, A.J. Torchia, J.L. Stock, A.L. Hildebrandt, T. Coskran, S.C. Black, D.J. Brees, J.R. Wicks, J.D. McNeish, and K.G. Coleman. 2003. Severe diabetes, age-dependent loss of adipose tissue, and mild growth deficiency in mice lacking Akt2/PKB beta. $J$ Clin Invest. 112:197-208 
George, S., J.J. Rochford, C. Wolfrum, S.L. Gray, S. Schinner, J.C. Wilson, M.A. Soos, P.R. Murgatroyd, R.M. Williams, C.L. Acerini, D.B. Dunger, D. Barford, A.M. Umpleby, N.J. Wareham, H.A. Davies, A.J. Schafer, M. Stoffel, S. O'Rahilly, and I. Barroso. 2004. A family with severe insulin resistance and diabetes due to a mutation in AKT2. Science. 304:1325-8.

Gilio, K., I.C. Munnix, P. Mangin, J.M. Cosemans, M.A. Feijge, P.E. van der Meijden, S. Olieslagers, M.B. Chrzanowska-Wodnicka, R. Lillian, S. Schoenwaelder, S. Koyasu, S.O. Sage, S.P. Jackson, and J.W. Heemskerk. 2009. Non-redundant roles of phosphoinositide 3-kinase isoforms alpha and beta in glycoprotein $\mathrm{VI}$-induced platelet signaling and thrombus formation. J Biol Chem. 284:33750-62.

Ginsberg, M.H., A. Partridge, and S.J. Shattil. 2005. Integrin regulation. Curr Opin Cell Biol. 17:509-16.

Gong, H., B. Shen, P. Flevaris, C. Chow, S.C. Lam, T.A. Voyno-Yasenetskaya, T. Kozasa, and X. Du. 2010. G protein subunit Galpha13 binds to integrin alphallbbeta3 and mediates integrin "outside-in" signaling. Science. 327:340-3.

Gratacap, M.P., J. Guillermet-Guibert, V. Martin, G. Chicanne, H. Tronchere, F. Gaits-lacovoni, and B. Payrastre. 2011. Regulation and roles of PI3Kbeta, a major actor in platelet signaling and functions. Adv Enzyme Regul. 51:106-16.

Gross, B.S., J.R. Lee, J.L. Clements, M. Turner, V.L. Tybulewicz, P.R. Findell, G.A. Koretzky, and S.P. Watson. 1999a. Tyrosine phosphorylation of SLP76 is downstream of Syk following stimulation of the collagen receptor in platelets. J Biol Chem. 274:5963-71.

Gross, B.S., S.K. Melford, and S.P. Watson. 1999b. Evidence that phospholipase C-gamma2 interacts with SLP-76, Syk, Lyn, LAT and the Fc receptor gamma-chain after stimulation of the collagen receptor glycoprotein $\mathrm{VI}$ in human platelets. Eur J Biochem. 263:612-23.

Haimovich, B., L. Lipfert, J.S. Brugge, and S.J. Shattil. 1993. Tyrosine phosphorylation and cytoskeletal reorganization in platelets are triggered by interaction of integrin receptors with their immobilized ligands. $J$ Biol Chem. 268:15868-77 
Harburger, D.S., M. Bouaouina, and D.A. Calderwood. 2009. Kindlin-1 and -2 directly bind the $\mathrm{C}$-terminal region of beta integrin cytoplasmic tails and exert integrin-specific activation effects. J Biol Chem. 284:11485-97.

Harper, M.T., and A.W. Poole. 2010. Diverse functions of protein kinase C isoforms in platelet activation and thrombus formation. $J$ Thromb Haemost. 8:454-62.

Hartwig, J.H., K. Barkalow, A. Azim, and J. Italiano. 1999. The elegant platelet: signals controlling actin assembly. Thromb Haemost. 82:392-8.

Hawkins, P.T., K.E. Anderson, K. Davidson, and L.R. Stephens. 2006. Signalling through Class I PI3Ks in mammalian cells. Biochem Soc Trans. 34:64762.

Haydon, G.B., and D.A. Taylor. 1965. Microtubules in hamster platelets. J Cell Biol. 26:673-6.

Heraud, J.M., C. Racaud-Sultan, D. Gironcel, C. Albiges-Rizo, T. Giacomini, S. Roques, V. Martel, M. Breton-Douillon, B. Perret, and H. Chap. 1998. Lipid products of phosphoinositide 3-kinase and phosphatidylinositol 4',5'bisphosphate are both required for ADP-dependent platelet spreading. $J$ Biol Chem. 273:17817-23.

Hirsch, E., O. Bosco, P. Tropel, M. Laffargue, R. Calvez, F. Altruda, M. Wymann, and G. Montrucchio. 2001. Resistance to thromboembolism in PI3Kgamma-deficient mice. Faseb J. 15:2019-21.

Ho-Tin-Noe, B., M. Demers, and D.D. Wagner. 2011. How platelets safeguard vascular integrity. J Thromb Haemost. 9 Suppl 1:56-65.

Huang, J.S., L. Dong, T. Kozasa, and G.C. Le Breton. 2007. Signaling through $\mathrm{G}$ (alpha)13 switch region I is essential for protease-activated receptor 1mediated human platelet shape change, aggregation, and secretion. $J$ Biol Chem. 282:10210-22.

Irie, H.Y., R.V. Pearline, D. Grueneberg, M. Hsia, P. Ravichandran, N. Kothari, S. Natesan, and J.S. Brugge. 2005. Distinct roles of Akt1 and Akt2 in regulating cell migration and epithelial-mesenchymal transition. J Cell Biol. 171:1023-34. 
Ishiguro, K., A. Shiratsuchi, S. Sato, A. Omori, M. Arioka, S. Kobayashi, T. Uchida, and K. Imahori. 1993. Glycogen synthase kinase 3 beta is identical to tau protein kinase I generating several epitopes of paired helical filaments. FEBS Lett. 325:167-72.

Italiano, J.E., Jr., and E.M. Battinelli. 2009. Selective sorting of alpha-granule proteins. J Thromb Haemost. 7 Suppl 1:173-6.

Jacinto, E., R. Loewith, A. Schmidt, S. Lin, M.A. Ruegg, A. Hall, and M.N. Hall. 2004. Mammalian TOR complex 2 controls the actin cytoskeleton and is rapamycin insensitive. Nat Cell Biol. 6:1122-8.

Jackson, S.P., S.M. Schoenwaelder, I. Goncalves, W.S. Nesbitt, C.L. Yap, C.E. Wright, V. Kenche, K.E. Anderson, S.M. Dopheide, Y. Yuan, S.A. Sturgeon, H. Prabaharan, P.E. Thompson, G.D. Smith, P.R. Shepherd, N. Daniele, S. Kulkarni, B. Abbott, D. Saylik, C. Jones, L. Lu, S. Giuliano, S.C. Hughan, J.A. Angus, A.D. Robertson, and H.H. Salem. 2005. PI 3kinase p110beta: a new target for antithrombotic therapy. Nat Med. 11:507-14.

Jackson, S.P., C.L. Yap, and K.E. Anderson. 2004. Phosphoinositide 3-kinases and the regulation of platelet function. Biochem Soc Trans. 32:387-92.

Jaffe, A.B., and A. Hall. 2005. Rho GTPases: biochemistry and biology. Annu Rev Cell Dev Biol. 21:247-69.

Jain, S., J. Harris, and J. Ware. 2010. Platelets: linking hemostasis and cancer. Arterioscler Thromb Vasc Biol. 30:2362-7.

Jiang, Z.Y., Q.L. Zhou, K.A. Coleman, M. Chouinard, Q. Boese, and M.P. Czech. 2003. Insulin signaling through Akt/protein kinase B analyzed by small interfering RNA-mediated gene silencing. Proc Natl Acad Sci U S A. 100:7569-74.

Jirouskova, M., J.K. Jaiswal, and B.S. Coller. 2007. Ligand density dramatically affects integrin alpha Ilb beta 3-mediated platelet signaling and spreading. Blood. 109:5260-9.

Jurk, K., K.J. Clemetson, P.G. de Groot, M.F. Brodde, M. Steiner, N. Savion, D. Varon, J.J. Sixma, H. Van Aken, and B.E. Kehrel. 2003. Thrombospondin1 mediates platelet adhesion at high shear via glycoprotein Ib (GPIb): an alternative/backup mechanism to von Willebrand factor. FASEB J. 17:1490-2. 
Kahn, M.L., Y.W. Zheng, W. Huang, V. Bigornia, D. Zeng, S. Moff, R.V. Farese, Jr., C. Tam, and S.R. Coughlin. 1998. A dual thrombin receptor system for platelet activation. Nature. 394:690-4.

Kandel, E.S., and N. Hay. 1999. The regulation and activities of the multifunctional serine/threonine kinase Akt/PKB. Exp Cell Res. 253:21029.

Kasirer-Friede, A., M.R. Cozzi, M. Mazzucato, L. De Marco, Z.M. Ruggeri, and S.J. Shattil. 2004. Signaling through GP Ib-IX-V activates alpha Ilb beta 3 independently of other receptors. Blood. 103:3403-11.

Kato, K., T. Kanaji, S. Russell, T.J. Kunicki, K. Furihata, S. Kanaji, P. Marchese, A. Reininger, Z.M. Ruggeri, and J. Ware. 2003. The contribution of glycoprotein $\mathrm{VI}$ to stable platelet adhesion and thrombus formation illustrated by targeted gene deletion. Blood. 102:1701-7.

Katome, T., T. Obata, R. Matsushima, N. Masuyama, L.C. Cantley, Y. Gotoh, K. Kishi, H. Shiota, and Y. Ebina. 2003. Use of RNA interference-mediated gene silencing and adenoviral overexpression to elucidate the roles of AKT/protein kinase B isoforms in insulin actions. J Biol Chem. 278:2831223.

Kenney, D.M., and R.W. Linck. 1985. The cystoskeleton of unstimulated blood platelets: structure and composition of the isolated marginal microtubular band. J Cell Sci. 78:1-22.

Kim, S., P. Mangin, C. Dangelmaier, R. Lillian, S.P. Jackson, J.L. Daniel, and S.P. Kunapuli. 2009. Role of phosphoinositide 3-kinase beta in glycoprotein Vl-mediated Akt activation in platelets. $J$ Biol Chem. 284:33763-72.

Kimura, K., M. Ito, M. Amano, K. Chihara, Y. Fukata, M. Nakafuku, B. Yamamori, J. Feng, T. Nakano, K. Okawa, A. Iwamatsu, and K. Kaibuchi. 1996. Regulation of myosin phosphatase by Rho and Rho-associated kinase (Rho-kinase). Science. 273:245-8.

Kisucka, J., C.E. Butterfield, D.G. Duda, S.C. Eichenberger, S. Saffaripour, J. Ware, Z.M. Ruggeri, R.K. Jain, J. Folkman, and D.D. Wagner. 2006. Platelets and platelet adhesion support angiogenesis while preventing excessive hemorrhage. Proc Natl Acad Sci U S A. 103:855-60. 
Klages, B., U. Brandt, M.I. Simon, G. Schultz, and S. Offermanns. 1999. Activation of G12/G13 results in shape change and Rho/Rho-kinasemediated myosin light chain phosphorylation in mouse platelets. J Cell Biol. 144:745-54.

Knezevic, I., C. Borg, and G.C. Le Breton. 1993. Identification of Gq as one of the G-proteins which copurify with human platelet thromboxane A2/prostaglandin $\mathrm{H} 2$ receptors. J Biol Chem. 268:26011-7.

Kohn, A.D., S.A. Summers, M.J. Birnbaum, and R.A. Roth. 1996. Expression of a constitutively active Akt Ser/Thr kinase in 3T3-L1 adipocytes stimulates glucose uptake and glucose transporter 4 translocation. J Biol Chem. 271:31372-8.

Konishi, H., S. Kuroda, M. Tanaka, H. Matsuzaki, Y. Ono, K. Kameyama, T. Haga, and U. Kikkawa. 1995. Molecular cloning and characterization of a new member of the RAC protein kinase family: association of the pleckstrin homology domain of three types of RAC protein kinase with protein kinase $C$ subspecies and beta gamma subunits of $G$ proteins. Biochem Biophys Res Commun. 216:526-34.

Kovacsovics, T.J., C. Bachelot, A. Toker, C.J. Vlahos, B. Duckworth, L.C. Cantley, and J.H. Hartwig. 1995. Phosphoinositide 3-kinase inhibition spares actin assembly in activating platelets but reverses platelet aggregation. J Biol Chem. 270:11358-66.

Kozasa, T., X. Jiang, M.J. Hart, P.M. Sternweis, W.D. Singer, A.G. Gilman, G. Bollag, and P.C. Sternweis. 1998. p115 RhoGEF, a GTPase activating protein for Galpha12 and Galpha13. Science. 280:2109-11.

Kroll, M.H., T.S. Harris, J.L. Moake, R.I. Handin, and A.I. Schafer. 1991. von Willebrand factor binding to platelet Gplb initiates signals for platelet activation. J Clin Invest. 88:1568-73.

Kroner, C., K. Eybrechts, and J.W. Akkerman. 2000. Dual regulation of platelet protein kinase B. J Biol Chem. 275:27790-8.

Kunapuli, S.P., R.T. Dorsam, S. Kim, and T.M. Quinton. 2003. Platelet purinergic receptors. Curr Opin Pharmacol. 3:175-80.

Lee, H.S., C.J. Lim, W. Puzon-McLaughlin, S.J. Shattil, and M.H. Ginsberg. 2009. RIAM activates integrins by linking talin to ras GTPase membranetargeting sequences. J Biol Chem. 284:5119-27. 
Leon, C., B. Hechler, M. Freund, A. Eckly, C. Vial, P. Ohlmann, A. Dierich, M. LeMeur, J.P. Cazenave, and C. Gachet. 1999. Defective platelet aggregation and increased resistance to thrombosis in purinergic P2Y(1) receptor-null mice. J Clin Invest. 104:1731-7.

Li, D., S. August, and D.S. Woulfe. 2008. GSK3beta is a negative regulator of platelet function and thrombosis. Blood. 111:3522-30.

Li, Z., M.K. Delaney, K.A. O'Brien, and X. Du. 2010a. Signaling during platelet adhesion and activation. Arterioscler Thromb Vasc Biol. 30:2341-9.

Li, Z., X. Xi, and X. Du. 2001. A mitogen-activated protein kinase-dependent signaling pathway in the activation of platelet integrin alpha Ilbbeta3. $J$ Biol Chem. 276:42226-32.

Li, Z., X. Xi, M. Gu, R. Feil, R.D. Ye, M. Eigenthaler, F. Hofmann, and X. Du. 2003a. A stimulatory role for cGMP-dependent protein kinase in platelet activation. Cell. 112:77-86.

Li, Z., G. Zhang, R. Feil, J. Han, and X. Du. 2006. Sequential activation of p38 and ERK pathways by cGMP-dependent protein kinase leading to activation of the platelet integrin alphallb beta3. Blood. 107:965-72.

Li, Z., G. Zhang, G.C. Le Breton, X. Gao, A.B. Malik, and X. Du. 2003b. Two waves of platelet secretion induced by thromboxane A2 receptor and a critical role for phosphoinositide 3-kinases. J Biol Chem. 278:30725-31.

Li, Z., G. Zhang, J. Liu, A. Stojanovic, C. Ruan, C.A. Lowell, and X. Du. 2010 b. An important role of the SRC family kinase Lyn in stimulating platelet granule secretion. J Biol Chem. 285:12559-70.

Li, Z., G. Zhang, J.A. Marjanovic, C. Ruan, and X. Du. 2004. A platelet secretion pathway mediated by cGMP-dependent protein kinase. J Biol Chem. 279:42469-75.

Liu, J., M.E. Fitzgerald, M.C. Berndt, C.W. Jackson, and T.K. Gartner. 2006. Bruton tyrosine kinase is essential for botrocetin/VWF-induced signaling and GPIb-dependent thrombus formation in vivo. Blood. 108:2596-603.

Liu, J., T.I. Pestina, M.C. Berndt, C.W. Jackson, and T.K. Gartner. 2005. Botrocetin/VWF-induced signaling through GPIb-IX-V produces TXA2 in an alphallbbeta3- and aggregation-independent manner. Blood. 106:2750-6. 
Lopez, J.A. 1994. The platelet glycoprotein Ib-IX complex. Blood Coagul Fibrinolysis. 5:97-119.

LoPiccolo, J., G.M. Blumenthal, W.B. Bernstein, and P.A. Dennis. 2008. Targeting the PI3K/Akt/mTOR pathway: effective combinations and clinical considerations. Drug Resist Updat. 11:32-50.

Ma, Y.Q., J. Qin, and E.F. Plow. 2007. Platelet integrin alpha(llb)beta(3): activation mechanisms. J Thromb Haemost. 5:1345-52.

Ma, Y.Q., J. Qin, C. Wu, and E.F. Plow. 2008. Kindlin-2 (Mig-2): a co-activator of beta3 integrins. J Cell Biol. 181:439-46.

Malinin, N.L., L. Zhang, J. Choi, A. Ciocea, O. Razorenova, Y.Q. Ma, E.A. Podrez, M. Tosi, D.P. Lennon, A.I. Caplan, S.B. Shurin, E.F. Plow, and T.V. Byzova. 2009. A point mutation in KINDLIN3 ablates activation of three integrin subfamilies in humans. Nat Med. 15:313-8.

Manning, B.D., and L.C. Cantley. 2007. AKT/PKB signaling: navigating downstream. Cell. 129:1261-74.

Marjanovic, J.A., Z. Li, A. Stojanovic, and X. Du. 2005. Stimulatory roles of nitricoxide synthase 3 and guanylyl cyclase in platelet activation. $J$ Biol Chem. 280:37430-8.

Marjanovic, J.A., A. Stojanovic, V.M. Brovkovych, R.A. Skidgel, and X. Du. 2008. Signaling-mediated functional activation of inducible nitric-oxide synthase and its role in stimulating platelet activation. J Biol Chem. 283:28827-34.

Masure, S., B. Haefner, J.J. Wesselink, E. Hoefnagel, E. Mortier, P. Verhasselt, A. Tuytelaars, R. Gordon, and A. Richardson. 1999. Molecular cloning, expression and characterization of the human serine/threonine kinase Akt3. Eur J Biochem. 265:353-60.

Mayadas, T.N., R.C. Johnson, H. Rayburn, R.O. Hynes, and D.D. Wagner. 1993. Leukocyte rolling and extravasation are severely compromised in $\mathrm{P}$ selectin-deficient mice. Cell. 74:541-54.

Michelson, A.D. 2010. Antiplatelet therapies for the treatment of cardiovascular disease. Nat Rev Drug Discov. 9:154-69. 
Moers, A., B. Nieswandt, S. Massberg, N. Wettschureck, S. Gruner, I. Konrad, V. Schulte, B. Aktas, M.P. Gratacap, M.I. Simon, M. Gawaz, and S. Offermanns. 2003. G13 is an essential mediator of platelet activation in hemostasis and thrombosis. Nat Med. 9:1418-22.

Moser, M., B. Nieswandt, S. Ussar, M. Pozgajova, and R. Fassler. 2008. Kindlin3 is essential for integrin activation and platelet aggregation. Nat Med. 14:325-30.

Mu, F.T., S.L. Cranmer, R.K. Andrews, and M.C. Berndt. 2010. Functional association of phosphoinositide-3-kinase with platelet glycoprotein Ibalpha, the major ligand-binding subunit of the glycoprotein Ib-IX-V complex. J Thromb Haemost. 8:324-30.

Munday, A.D., M.C. Berndt, and C.A. Mitchell. 2000. Phosphoinositide 3-kinase forms a complex with platelet membrane glycoprotein Ib-IX-V complex and 14-3-3zeta. Blood. 96:577-84.

Nakanishi-Matsui, M., Y.W. Zheng, D.J. Sulciner, E.J. Weiss, M.J. Ludeman, and S.R. Coughlin. 2000. PAR3 is a cofactor for PAR4 activation by thrombin. Nature. 404:609-13.

Newman, D.K., C. Hamilton, and P.J. Newman. 2001. Inhibition of antigenreceptor signaling by Platelet Endothelial Cell Adhesion Molecule-1 (CD31) requires functional ITIMs, SHP-2, and p56(Ick). Blood. 97:2351-7.

Newman, P.J. 1994. The role of PECAM-1 in vascular cell biology. Ann N Y Acad Sci. 714:165-74.

Nieswandt, B., C. Brakebusch, W. Bergmeier, V. Schulte, D. Bouvard, R. Mokhtari-Nejad, T. Lindhout, J.W. Heemskerk, H. Zirngibl, and R. Fassler. 2001. Glycoprotein VI but not alpha2beta1 integrin is essential for platelet interaction with collagen. EMBO J. 20:2120-30.

Nieswandt, B., and S.P. Watson. 2003. Platelet-collagen interaction: is GPVI the central receptor? Blood. 102:449-61.

Norman, K.E., K.L. Moore, R.P. McEver, and K. Ley. 1995. Leukocyte rolling in vivo is mediated by P-selectin glycoprotein ligand-1. Blood. 86:4417-21. 
Nurden, A., and P. Nurden. 2011. Advances in our understanding of the molecular basis of disorders of platelet function. J Thromb Haemost. 9 Suppl 1:76-91.

O'Brien, K.A., A. Stojanovic-Terpo, N. Hay, and X. Du. 2011. An important role for Akt3 in platelet activation and thrombosis. Blood. 118:4215-23.

Obergfell, A., K. Eto, A. Mocsai, C. Buensuceso, S.L. Moores, J.S. Brugge, C.A. Lowell, and S.J. Shattil. 2002. Coordinate interactions of Csk, Src, and Syk kinases with [alpha]llb[beta]3 initiate integrin signaling to the cytoskeleton. J Cell Biol. 157:265-75.

Offermanns, S., C.F. Toombs, Y.H. Hu, and M.I. Simon. 1997. Defective platelet activation in $\mathrm{G}$ alpha(q)-deficient mice. Nature. 389:183-6.

Okumura, T., M. Hasitz, and G.A. Jamieson. 1978. Platelet glycocalicin. Interaction with thrombin and role as thrombin receptor of the platelet surface. J Biol Chem. 253:3435-43.

Owens, A.P., 3rd, and N. Mackman. 2011. Microparticles in hemostasis and thrombosis. Circ Res. 108:1284-97.

Pasquet, J.M., R. Bobe, B. Gross, M.P. Gratacap, M.G. Tomlinson, B. Payrastre, and S.P. Watson. 1999a. A collagen-related peptide regulates phospholipase Cgamma2 via phosphatidylinositol 3-kinase in human platelets. Biochem J. 342 ( Pt 1):171-7.

Pasquet, J.M., B. Gross, L. Quek, N. Asazuma, W. Zhang, C.L. Sommers, E. Schweighoffer, V. Tybulewicz, B. Judd, J.R. Lee, G. Koretzky, P.E. Love, L.E. Samelson, and S.P. Watson. 1999b. LAT is required for tyrosine phosphorylation of phospholipase cgamma2 and platelet activation by the collagen receptor GPVI. Mol Cell Biol. 19:8326-34.

Peng, X.D., P.Z. Xu, M.L. Chen, A. Hahn-Windgassen, J. Skeen, J. Jacobs, D. Sundararajan, W.S. Chen, S.E. Crawford, K.G. Coleman, and N. Hay. 2003. Dwarfism, impaired skin development, skeletal muscle atrophy, delayed bone development, and impeded adipogenesis in mice lacking Akt1 and Akt2. Genes Dev. 17:1352-65.

Petrich, B.G., P. Marchese, Z.M. Ruggeri, S. Spiess, R.A. Weichert, F. Ye, R. Tiedt, R.C. Skoda, S.J. Monkley, D.R. Critchley, and M.H. Ginsberg. 2007. Talin is required for integrin-mediated platelet function in hemostasis and thrombosis. J Exp Med. 204:3103-11. 
Pleiman, C.M., W.M. Hertz, and J.C. Cambier. 1994. Activation of phosphatidylinositol-3' kinase by Src-family kinase $\mathrm{SH} 3$ binding to the p85 subunit. Science. 263:1609-12.

Polgar, J., W.S. Lane, S.H. Chung, A.K. Houng, and G.L. Reed. 2003. Phosphorylation of SNAP-23 in activated human platelets. $J$ Biol Chem. 278:44369-76.

Poole, A., J.M. Gibbins, M. Turner, M.J. van Vugt, J.G. van de Winkel, T. Saito, V.L. Tybulewicz, and S.P. Watson. 1997. The Fc receptor gamma-chain and the tyrosine kinase Syk are essential for activation of mouse platelets by collagen. EMBO J. 16:2333-41.

Quek, L.S., J. Bolen, and S.P. Watson. 1998. A role for Bruton's tyrosine kinase (Btk) in platelet activation by collagen. Curr Biol. 8:1137-40.

Quek, L.S., J.M. Pasquet, I. Hers, R. Cornall, G. Knight, M. Barnes, M.L. Hibbs, A.R. Dunn, C.A. Lowell, and S.P. Watson. 2000. Fyn and Lyn phosphorylate the Fc receptor gamma chain downstream of glycoprotein $\mathrm{VI}$ in murine platelets, and Lyn regulates a novel feedback pathway. Blood. 96:4246-53.

Quinton, T.M., F. Ozdener, C. Dangelmaier, J.L. Daniel, and S.P. Kunapuli. 2002. Glycoprotein VI-mediated platelet fibrinogen receptor activation occurs through calcium-sensitive and PKC-sensitive pathways without a requirement for secreted ADP. Blood. 99:3228-34.

Ragab, A., S. Severin, M.P. Gratacap, E. Aguado, M. Malissen, M. JandrotPerrus, B. Malissen, J. Ragab-Thomas, and B. Payrastre. 2007. Roles of the C-terminal tyrosine residues of LAT in GPVI-induced platelet activation: insights into the mechanism of PLC gamma 2 activation. Blood. 110:2466-74.

Ren, Q., C. Wimmer, M.C. Chicka, S. Ye, Y. Ren, F.M. Hughson, and S.W. Whiteheart. 2010. Munc13-4 is a limiting factor in the pathway required for platelet granule release and hemostasis. Blood. 116:869-77.

Ren, Q., S. Ye, and S.W. Whiteheart. 2008. The platelet release reaction: just when you thought platelet secretion was simple. Curr Opin Hematol. 15:537-41.

Rhee, J.S., M. Black, U. Schubert, S. Fischer, E. Morgenstern, H.P. Hammes, and K.T. Preissner. 2004. The functional role of blood platelet components in angiogenesis. Thromb Haemost. 92:394-402. 
Rittenhouse, S.E. 1996. Phosphoinositide 3-kinase activation and platelet function. Blood. 88:4401-14.

Romo, G.M., J.F. Dong, A.J. Schade, E.E. Gardiner, G.S. Kansas, C.Q. Li, L.V. McIntire, M.C. Berndt, and J.A. Lopez. 1999. The glycoprotein Ib-IX-V complex is a platelet counterreceptor for P-selectin. J Exp Med. 190:80314.

Rubinfeld, B., I. Albert, E. Porfiri, C. Fiol, S. Munemitsu, and P. Polakis. 1996. Binding of GSK3beta to the APC-beta-catenin complex and regulation of complex assembly. Science. 272:1023-6.

Ruggeri, Z.M. 1994. Glycoprotein Ib and von Willebrand factor in the process of thrombus formation. Ann N Y Acad Sci. 714:200-10.

Ruggeri, Z.M., A. Zarpellon, J.R. Roberts, R.A. Mc Clintock, H. Jing, and G.L. Mendolicchio. 2010. Unravelling the mechanism and significance of thrombin binding to platelet glycoprotein Ib. Thromb Haemost. 104:894902.

Sage, S.O., and T.J. Rink. 1987. The kinetics of changes in intracellular calcium concentration in fura-2-loaded human platelets. J Biol Chem. 262:16364-9.

Sambrano, G.R., E.J. Weiss, Y.W. Zheng, W. Huang, and S.R. Coughlin. 2001. Role of thrombin signalling in platelets in haemostasis and thrombosis. Nature. 413:74-8.

Sarbassov, D.D., S.M. Ali, D.H. Kim, D.A. Guertin, R.R. Latek, H. ErdjumentBromage, P. Tempst, and D.M. Sabatini. 2004. Rictor, a novel binding partner of mTOR, defines a rapamycin-insensitive and raptor-independent pathway that regulates the cytoskeleton. Curr Biol. 14:1296-302.

Schenck, A., L. Goto-Silva, C. Collinet, M. Rhinn, A. Giner, B. Habermann, M. Brand, and M. Zerial. 2008. The endosomal protein Appl1 mediates Akt substrate specificity and cell survival in vertebrate development. Cell. 133:486-97.

Schraw, T.D., P.P. Lemons, W.L. Dean, and S.W. Whiteheart. 2003. A role for Sec1/Munc18 proteins in platelet exocytosis. Biochem J. 374:207-17.

Shattil, S.J., and P.J. Newman. 2004. Integrins: dynamic scaffolds for adhesion and signaling in platelets. Blood. 104:1606-15. 
Shiojima, I., and K. Walsh. 2002. Role of Akt signaling in vascular homeostasis and angiogenesis. Circ Res. 90:1243-50.

Shiojima, I., and K. Walsh. 2006. Regulation of cardiac growth and coronary angiogenesis by the Akt/PKB signaling pathway. Genes Dev. 20:3347-65.

Shiraga, M., S. Miyata, H. Kato, H. Kashiwagi, S. Honda, Y. Kurata, Y. Tomiyama, and Y. Kanakura. 2005. Impaired platelet function in a patient with P2Y12 deficiency caused by a mutation in the translation initiation codon. J Thromb Haemost. 3:2315-23.

Signarvic, R.S., A. Cierniewska, T.J. Stalker, K.P. Fong, M.S. Chatterjee, P.R. Hess, P. Ma, S.L. Diamond, R.R. Neubig, and L.F. Brass. 2010. RGS/Gi2alpha interactions modulate platelet accumulation and thrombus formation at sites of vascular injury. Blood. 116:6092-100.

Simon, D.I., Z. Chen, H. Xu, C.Q. Li, J. Dong, L.V. Mclntire, C.M. Ballantyne, L. Zhang, M.I. Furman, M.C. Berndt, and J.A. Lopez. 2000. Platelet glycoprotein ibalpha is a counterreceptor for the leukocyte integrin Mac-1 (CD11b/CD18). J Exp Med. 192:193-204.

Song, G., G. Ouyang, and S. Bao. 2005. The activation of Akt/PKB signaling pathway and cell survival. J Cell Mol Med. 9:59-71.

Soriani, A., B. Moran, M. de Virgilio, T. Kawakami, A. Altman, C. Lowell, K. Eto, and S.J. Shattil. 2006. A role for PKCtheta in outside-in alpha(Ilb)beta3 signaling. J Thromb Haemost. 4:648-55.

Staal, S.P. 1987. Molecular cloning of the akt oncogene and its human homologues AKT1 and AKT2: amplification of AKT1 in a primary human gastric adenocarcinoma. Proc Natl Acad Sci U S A. 84:5034-7.

Stambolic, V., A. Suzuki, J.L. de la Pompa, G.M. Brothers, C. Mirtsos, T. Sasaki, J. Ruland, J.M. Penninger, D.P. Siderovski, and T.W. Mak. 1998. Negative regulation of PKB/Akt-dependent cell survival by the tumor suppressor PTEN. Cell. 95:29-39.

Steele, B.M., M.T. Harper, I.C. Macaulay, C.N. Morrell, A. Perez-Tamayo, M. Foy, R. Habas, A.W. Poole, D.J. Fitzgerald, and P.B. Maguire. 2009. Canonical Wnt signaling negatively regulates platelet function. Proc Natl Acad Sci U S A. 106:19836-41.

Stefanini, L., R.C. Roden, and W. Bergmeier. 2009. CalDAG-GEFI is at the nexus of calcium-dependent platelet activation. Blood. 114:2506-14. 
Stephens, L.R., A. Eguinoa, H. Erdjument-Bromage, M. Lui, F. Cooke, J. Coadwell, A.S. Smrcka, M. Thelen, K. Cadwallader, P. Tempst, and P.T. Hawkins. 1997. The G beta gamma sensitivity of a PI3K is dependent upon a tightly associated adaptor, p101. Cell. 89:105-14.

Stojanovic, A., J.A. Marjanovic, V.M. Brovkovych, X. Peng, N. Hay, R.A. Skidgel, and X. Du. 2006. A Phosphoinositide 3-Kinase-AKT-Nitric Oxide-cGMP Signaling Pathway in Stimulating Platelet Secretion and Aggregation. $J$ Biol Chem. 281:16333-9.

Thimmaiah, K.N., J.B. Easton, G.S. Germain, C.L. Morton, S. Kamath, J.K. Buolamwini, and P.J. Houghton. 2005. Identification of N10-substituted phenoxazines as potent and specific inhibitors of Akt signaling. $J$ Biol Chem. 280:31924-35.

Thomas, D.W., R.B. Mannon, P.J. Mannon, A. Latour, J.A. Oliver, M. Hoffman, O. Smithies, B.H. Koller, and T.M. Coffman. 1998. Coagulation defects and altered hemodynamic responses in mice lacking receptors for thromboxane A2. J Clin Invest. 102:1994-2001.

Tolmachova, T., M. Abrink, C.E. Futter, K.S. Authi, and M.C. Seabra. 2007. Rab27b regulates number and secretion of platelet dense granules. Proc Natl Acad Sci U S A. 104:5872-7.

Tschopp, O., Z.Z. Yang, D. Brodbeck, B.A. Dummler, M. Hemmings-Mieszczak, T. Watanabe, T. Michaelis, J. Frahm, and B.A. Hemmings. 2005. Essential role of protein kinase B gamma (PKB gamma/Akt3) in postnatal brain development but not in glucose homeostasis. Development. 132:2943-54.

Ulmer, A.J., and H.D. Flad. 1979. Discontinuous density gradient separation of human mononuclear leucocytes using Percoll as gradient medium. $J$ Immunol Methods. 30:1-10.

Vu, T.K., D.T. Hung, V.I. Wheaton, and S.R. Coughlin. 1991. Molecular cloning of a functional thrombin receptor reveals a novel proteolytic mechanism of receptor activation. Cell. 64:1057-68.

Wagner, D.D., J.B. Olmsted, and V.J. Marder. 1982. Immunolocalization of von Willebrand protein in Weibel-Palade bodies of human endothelial cells. $J$ Cell Biol. 95:355-60. 
Walker, K.S., M. Deak, A. Paterson, K. Hudson, P. Cohen, and D.R. Alessi. 1998. Activation of protein kinase $B$ beta and gamma isoforms by insulin in vivo and by 3-phosphoinositide-dependent protein kinase-1 in vitro: comparison with protein kinase B alpha. Biochem J. 331 ( Pt 1):299-308.

Wang, D., J. Feng, R. Wen, J.C. Marine, M.Y. Sangster, E. Parganas, A. Hoffmeyer, C.W. Jackson, J.L. Cleveland, P.J. Murray, and J.N. Ihle. 2000. Phospholipase Cgamma2 is essential in the functions of $B$ cell and several Fc receptors. Immunity. 13:25-35.

Ware, J. 1998. Molecular analyses of the platelet glycoprotein Ib-IX-V receptor. Thromb Haemost. 79:466-78.

Watanabe, N., L. Bodin, M. Pandey, M. Krause, S. Coughlin, V.A. Boussiotis, M.H. Ginsberg, and S.J. Shattil. 2008. Mechanisms and consequences of agonist-induced talin recruitment to platelet integrin alphallbbeta3. J Cell Biol. 181:1211-22.

White, J.G., and W.J. Conard. 1973. The fine structure of freeze-fractured blood platelets. Am J Pathol. 70:45-56.

Wonerow, P., A.C. Pearce, D.J. Vaux, and S.P. Watson. 2003. A critical role for phospholipase Cgamma2 in alphallbbeta3-mediated platelet spreading. $J$ Biol Chem. 278:37520-9.

Woulfe, D., H. Jiang, A. Morgans, R. Monks, M. Birnbaum, and L.F. Brass. 2004. Defects in secretion, aggregation, and thrombus formation in platelets from mice lacking Akt2. J Clin Invest. 113:441-50.

Woulfe, D.S. 2010. Akt signaling in platelets and thrombosis. Expert Rev Hematol. 3:81-91.

Wu, Y., N. Asazuma, K. Satoh, Y. Yatomi, T. Takafuta, M.C. Berndt, and Y. Ozaki. 2003. Interaction between von Willebrand factor and glycoprotein Ib activates Src kinase in human platelets: role of phosphoinositide 3-kinase. Blood. 101:3469-76.

Xi, X., R.J. Bodnar, Z. Li, S.C. Lam, and X. Du. 2003. Critical roles for the COOHterminal NITY and RGT sequences of the integrin beta3 cytoplasmic domain in inside-out and outside-in signaling. J Cell Biol. 162:329-39.

Xi, X., P. Flevaris, A. Stojanovic, A. Chishti, D.R. Phillips, S.C. Lam, and X. Du. 2006. Tyrosine phosphorylation of the integrin beta 3 subunit regulates beta 3 cleavage by calpain. $J$ Biol Chem. 281:29426-30. 
Xiang, B., G. Zhang, J. Liu, A.J. Morris, S.S. Smyth, T.K. Gartner, and Z. Li. 2010. A G(i) -independent mechanism mediating Akt phosphorylation in platelets. J Thromb Haemost. 8:2032-41.

Yanaga, F., A. Poole, J. Asselin, R. Blake, G.L. Schieven, E.A. Clark, C.L. Law, and S.P. Watson. 1995. Syk interacts with tyrosine-phosphorylated proteins in human platelets activated by collagen and cross-linking of the Fc gamma-IIA receptor. Biochem J. 311 ( Pt 2):471-8.

Ye, F., and B.G. Petrich. 2011. Kindlin: helper, co-activator, or booster of talin in integrin activation? Curr Opin Hematol. 18:356-60.

Yin, H., J. Liu, Z. Li, M.C. Berndt, C.A. Lowell, and X. Du. 2008a. Src family tyrosine kinase Lyn mediates VWF/GPIb-IX-induced platelet activation via the cGMP signaling pathway. Blood. 112:1139-46.

Yin, H., A. Stojanovic, N. Hay, and X. Du. 2008b. The role of Akt in the signaling pathway of the glycoprotein $\mathrm{Ib}-\mathrm{IX}$ induced platelet activation. Blood. 111:658-65.

Yousuf, O., and D.L. Bhatt. 2011. The evolution of antiplatelet therapy in cardiovascular disease. Nat Rev Cardiol. 8:547-59.

Yusuf, S., F. Zhao, S.R. Mehta, S. Chrolavicius, G. Tognoni, and K.K. Fox. 2001. Effects of clopidogrel in addition to aspirin in patients with acute coronary syndromes without ST-segment elevation. N Engl J Med. 345:494-502.

Zhang, G., B. Xiang, A. Dong, R.C. Skoda, A. Daugherty, S.S. Smyth, X. Du, and Z. Li. 2011a. Biphasic roles for soluble guanylyl cyclase (sGC) in platelet activation. Blood. 118:3670-9.

Zhang, G., B. Xiang, S. Ye, M. Chrzanowska-Wodnicka, A.J. Morris, T.K. Gartner, S.W. Whiteheart, G.C. White, 2nd, S.S. Smyth, and Z. Li. 2011b. Distinct roles for Rap1b protein in platelet secretion and integrin alphallbbeta3 outside-in signaling. J Biol Chem. 286:39466-77.

Zhang, J., H. Banfic, F. Straforini, L. Tosi, S. Volinia, and S.E. Rittenhouse. 1998. A type II phosphoinositide 3-kinase is stimulated via activated integrin in platelets. A source of phosphatidylinositol 3-phosphate. J Biol Chem. 273:14081-4. 


\section{Rights \& Permissions}

Material published in Blood is covered by copyright. All rights reserved. No part of the publication may be reproduced (see exception below), stored in a retrieval system, translated, or transmitted in any form or by any means now or hereafter known, electronic or mechanical, without permission in writing from the publisher, The American Society of Hematology (ASH).

The copyright owner consents that copies of articles may be made for personal or internal use, or for the personal or internal use of specific clients, for those registered with the Copyright Clearance Center Inc. This consent is given on the condition that the copier pay the stated per-copy fees through the Copyright Clearance Center, Inc., for copying beyond that permitted by Sections 107 and 108 of the US Copyright Law (Fair Use). This consent does not extend to other kinds of copying, such as copying for general distribution, for advertising or for promotional purposes, for creating new collective works, or for resale. For those kinds of purposes, permission must be sought from the publisher using the following guidelines. If you have any questions regarding our rights and permissions policies, or if you have a special request not covered by these guidelines, please contact Blood Permissions.

Republication Requests

- Authors reusing their own material

- All others wishing to use material

Photocopy Requests

Translation Rights

Regulatory Approval/Patent and Trademark Applications

Reprints

- Author reprints

- Commercial reprints

ASH Annual Meeting abstracts

Blood Embargo Policy

Copyright Clearance Center

\section{Republication Requests}

\section{Authors reusing their own material}

Authors have permission to do the following after their article has been published in Blood, either in print or online as a First Edition Paper.

- Reprint the article in print collections of the author's own writing.

- Present the work orally in its entirety.

- Use the article in theses and/or dissertation.

- Reproduce the article for use in courses the author is teaching. If the author is employed by an academic institution, that institution may also reproduce the article for course teaching.

- Distribute photocopies of the article to colleagues, but only for noncommercial purposes.

- Reuse figures and tables created by the author in future works.

- Post a copy of the article on the author's personal website, departmental website, and/or the university intranet. A hyperlink to the article on the Blood website must be included.

The author must include the following citation when citing material that appeared in the print edition of Blood:

"This research was originally published in Blood. Author(s). Title. Blood. Year; Vol:pp-pp. (c) the American Society of Hematology."

Material from a First Edition Paper can only be reused if the article has not yet been published in its final form in the print version of

Blood. When using material from a First Edition Paper, it should be cited as follows (shown here with sample date and DOI): 


\section{(0) Wolters Kluwer Health}

Lippincott Williams \& Wilkins

Requesting permission to reuse content from an LWW publication.
Title:

ADP-Stimulated Activation of Akt During Integrin Outside-In Signaling Promotes Platelet Spreading by Inhibiting Glycogen Synthase Kinase-3 $\beta$

Author: Kelly A. O'Brien, T. Kent Gartner, Nissim Hay, Xiaoping Du

Publication: ATVB

Publisher: Wolters Kluwer Health

Date: Jul 19, 2012

Copyright (c) 2012, Wolters Kluwer Health

\section{Order Completed}

Thank you very much for your order.

This is a License Agreement between kelly a obrien ("You") and Wolters Kluwer Health ("Wolters Kluwer Health"). The license consists of your order details, the terms and conditions provided by Wolters Kluwer Health, and the payment terms and conditions.

\section{Get the printable license.}

\begin{tabular}{|c|c|}
\hline License Number & 2957180 \\
\hline License date & Jul 27,20 \\
\hline $\begin{array}{l}\text { Licensed content } \\
\text { publisher }\end{array}$ & Wolters \\
\hline $\begin{array}{l}\text { Licensed content } \\
\text { publication }\end{array}$ & ATVB \\
\hline Licensed content title & $\begin{array}{l}\text { ADP-Sti } \\
\text { Spreadi }\end{array}$ \\
\hline Licensed content author & Kelly A. \\
\hline Licensed content date & Jul 19 \\
\hline Type of Use & Dissert \\
\hline Requestor type & Individ \\
\hline $\begin{array}{l}\text { Title of your thesis / } \\
\text { dissertation }\end{array}$ & The rol \\
\hline $\begin{array}{l}\text { Expected completion } \\
\text { date }\end{array}$ & Jul 2012 \\
\hline Estimated size(pages) & 125 \\
\hline Total & 0.00 \\
\hline
\end{tabular}

\section{ORDER MORE... CLOSE WINDOW}

Copyright (c) 2012 Copyright Clearance Center, Inc. All Rights Reserved. Privacy statement. Comments? We would like to hear from you. E-mail us at customercare@copyright.com 


\section{UC UNIVERSITY OF ILLINOIS

March 23, 2011

Xiaoping Du

Pharmacology

M/C 868

Dear Dr. Du:
Office of Animal Care and

Institutional Biosafety Committees (MC 672)

Office of the Vice Chancellor for Research

206 Administrative Office Building

1737 West Polk Street

Chicago, Illinois 60612-7227

The protocol indicated below was reviewed at a convened ACC meeting in accordance with the Animal Care Policies of the University of Illinois at Chicago on 3/15/2011. The protocol was not initiated until final clarifications were reviewed and approved on $\mathbf{3} / \mathbf{1 7} / \mathbf{2 0 1 1}$. The protocol is approved for a period of $\mathbf{3}$ years with annual continuation.

Title of Application: Signaling Mechanisms of Platelet Activation

ACC Number: 11-029

Initial Approval Period: 3/17/2011 to 3/15/2012

Current Funding: Portions of this protocol are supported by the funding sources indicated in the table below.

Number of funding sources: 5

\begin{tabular}{|c|c|c|c|c|}
\hline Funding Agency & \multicolumn{3}{|l|}{ Funding Title } & $\begin{array}{l}\text { Portion of } \\
\text { Proposal } \\
\text { Matched }\end{array}$ \\
\hline $\mathrm{NIH}$ & \multicolumn{3}{|c|}{ Signaling Mechanism of Platelet Glycoprotein Ib-Ix } & Matched \\
\hline Funding Number & Current Status & UIC PAF NO. & $\begin{array}{l}\text { Performance } \\
\text { Site }\end{array}$ & Funding PI \\
\hline RO1 HL062350-10 & Funded & 2010-00091 & UIC & Xiaoping Du \\
\hline Funding Agency & \multicolumn{3}{|l|}{ Funding Title } & $\begin{array}{l}\text { Portion of } \\
\text { Proposal } \\
\text { Matched }\end{array}$ \\
\hline $\mathrm{NIH}$ & \multicolumn{3}{|c|}{$\begin{array}{l}\text { The Role of Calpain and beta3 Cytoplasmic Domain in } \\
\text { Platelet Integrin Signaling }\end{array}$} & Matched \\
\hline Funding Number & Current Status & UIC PAF NO. & $\begin{array}{l}\text { Performance } \\
\text { Site }\end{array}$ & Funding PI \\
\hline RO1 HL080264 & Funded & $2006-05386$ & UIC & Xiaoping $D u$ \\
\hline Funding Agency & \multicolumn{3}{|l|}{ Funding Title } & $\begin{array}{l}\text { Portion of } \\
\text { Proposal } \\
\text { Matched }\end{array}$ \\
\hline $\mathrm{NIH}$ & \multicolumn{3}{|c|}{$\begin{array}{l}\text { The Roles Of Platelet Adhesion and cGMP Signaling in } \\
\text { Sickle Cell Disease }\end{array}$} & Matched \\
\hline Funding Number & Current Status & UIC PAF NO. & $\begin{array}{l}\text { Performance } \\
\text { Site }\end{array}$ & Funding PI \\
\hline
\end{tabular}




\begin{tabular}{|c|c|c|c|c|}
\hline N/A & Pending & 2011-03949 & $U I C$ & Xiaoping Du \\
\hline Funding Agency & \multicolumn{3}{|l|}{ Funding Title } & $\begin{array}{l}\text { Portion of } \\
\text { Proposal } \\
\text { Matched }\end{array}$ \\
\hline $\mathrm{NIH}$ & \multicolumn{3}{|c|}{$\begin{array}{l}\text { Outside-in signaling mechanisms of platelet integrin } \\
\text { alpha-llb-beta3 }\end{array}$} & Matched \\
\hline Funding Number & Current Status & UIC PAF NO. & $\begin{array}{l}\text { Performance } \\
\text { Site }\end{array}$ & Funding PI \\
\hline HL-080264 & Pending & $2011-02188$ & UIC & Xiaoping Du \\
\hline Funding Agency & \multicolumn{3}{|l|}{ Funding Title } & $\begin{array}{l}\text { Portion of } \\
\text { Proposal } \\
\text { Matched } \\
\end{array}$ \\
\hline $\mathrm{NIH}$ & \multicolumn{3}{|c|}{$\begin{array}{l}\text { Crosstalk between integrins and Galpha13 in cell } \\
\text { migration }\end{array}$} & Matched \\
\hline Funding Number & Current Status & UIC PAF NO. & $\begin{array}{l}\text { Performance } \\
\text { Site }\end{array}$ & Funding PI \\
\hline GM-097464 & Pending & $2010-06808$ & $U I C$ & Xiaoping Du \\
\hline
\end{tabular}

This institution has Animal Welfare Assurance Number A3460.01 on file with the Office of Laboratory Animal Welfare (OLAW), NIH. This letter may only be provided as proof of IACUC approval for those specific funding sources listed above in which all portions of the funding proposal are matched to this ACC protocol.

In addition, all investigators are responsible for ensuring compliance with all federal and institutional policies and regulations related to use of animals under this protocol and the funding sources listed on this protocol. Please use OLAW's “What Investigators Need to Know about the Use of Animals” (http://grants.nih.gov/grants/olaw/InvestigatorsNeed2Know.pdf) as a reference guide. Thank you for complying with the Animal Care Policies and Procedures of UIC.

Sincerely yours,

$$
\text { Richaid T. Aqualiall }
$$

Richard D. Minshall, PhD

Chair, Animal Care Committee

$\mathrm{RDM} / \mathrm{ss}$

cc: BRL, ACC File, Aleksandra Stojanovic, PAF \# 2010-00091, PAF \# 2006-05386, PAF \#

2011-03949, PAF \# 2011-03949, PAF \# 2011-02188, PAF \# 2010-06808 


\section{KELLY A. O'BRIEN}

\section{EDUCATION}

Ph.D. in Pharmacology

September 2006-present

University of Illinois at Chicago, College of Medicine, Department of

Pharmacology

Advisor: Xiaoping Du

B.Sc. in Biological Sciences

June 2005

DePaul University, Chicago, IL

RESEARCH EXPERIENCE

Graduate Research Assistant (Doctoral Research) September 2006-present

University of Illinois at Chicago, College of Medicine, Department of

Pharmacology

Advisor: Xiaoping Du

Research Specialist

April 2005-

September 2006

University of Illinois at Chicago, College of Medicine, Department of

Pharmacology

Advisor: Athar Chishti

\section{CONFERENCE PARTICIPATION}

Oral Presentations

"The role of Akt3 in platelet activation"; $12^{\text {th }}$ Biennial Midwest Platelet

Conference, Lexington, KY, October 2008.

"An important role for Akt3 in platelet activation and thrombosis"; American Heart Association Scientific Sessions, Chicago, IL, November 2010.

\section{Posters}

"The role of Akt3 in platelet activation"; American Society of Hematology Annual Meeting, San Francisco, CA, December 2008.

"An important role for Akt3 in platelet activation and thrombosis" Gordon Research Conference on Thrombosis and Hemostasis, Waterville Valley, $\mathrm{NH}$, July 2010 
"An important role for Akt3 in platelet activation and thrombosis"; American Heart Association, Early Career Networking Reception, Chicago, IL, December 2010.

"An important role for Akt3 in platelet activation and thrombosis"; NIH National Graduate Student Research Conference, Bethesda, MD, October 2011.

"The role of Akt3 in mediating outside-in signaling of the platelet integrin allbb3"; American Society of Hematology Annual Meeting, San Diego, CA, December 2011.

\section{PUBLICATIONS}

Li Z, Delaney MK, O'Brien KA, Du X. Signaling during platelet adhesion and activation. Arterioscler Thromb Vasc Biol. 2010 Dec; 30(12):2341-9.

O'Brien KA, Stojanovic-Terpo A, Hay N, Du X. An important role for Akt3 in platelet activation and thrombosis. Blood. 2011 Oct 13; 118(15):4215-23.

O'Brien KA, Gartner TK, Hay N, Du X. ADP-stimulated activation of Akt during integrin outside-in signaling promotes platelet spreading by inhibiting glycogen synthase kinase-3 $\beta$. Arterioscler Thromb Vasc Biol 2012 Jul 19. In press.

\section{RESEARCH GRANTS}

NIH Lung and Vascular Biology Pre-doctoral Training Grant

\section{AWARDS}

2011 NIH National Graduate Student Research Conference Award 2010 AHA ATVB Travel Award for Young Investigators 2008 Midwest Platelet Conference Young Investigator Award 2008 UIC Graduate College Presenter Award

\section{PROFESSIONAL MEMBERSHIPS}

American Heart Association Member, Arteriosclerosis, Thrombosis, \& Vascular Biology Council 
Faculty of 1000 Associate Faculty Member, Immunopharmacology and Hematologic Pharmacology Section 